\title{
Evidence for two sympatric sirenian species (Mammalia, Tethytheria) in the early Oligocene of Central Europe
}

\author{
Manja Voss and Oliver Hampe \\ Museum für Naturkunde Berlin - Leibniz Institute for Evolution and Biodiversity Science, Invalidenstrasse 43, 10115 Berlin, Germany \\ 〈manja.voss@mfn-berlin.de〉, 〈oliver.hampe@mfn-berlin.de $\rangle$
}

\begin{abstract}
The early Oligocene (Rupelian) sirenian Halitherium schinzii Kaup, 1838, which represents the type species of the genus Halitherium Kaup, 1838, is revised herein based on a morphological re-evaluation of skeletal material originally assigned to this taxon. This study provides new and comprehensive information on the cranial and postcranial anatomy and allows the distinction of two sympatric species. Following a recent approach on the invalidity and subsequent rejection of $H$. schinzii Kaup, 1838, Kaupitherium gruelli new genus new species is established on the basis of a nearly complete holotype. The second taxon resembles $K$. gruelli $\mathrm{n}$. sp. in a number of skeletal features, such as reduced nasals and absence of the canines, but can be clearly distinguished mainly by the post-canine dental formula and the supraoccipital morphology. The diagnostic skullcap of a species formerly synonymized under " $H$. schinzii" is re-validated as the holotype of K. bronni (Krauss, 1858). On the basis of paleoecological implications, a hypothesis is established to explain the overlapping stratigraphic and biogeographic occurrences (i.e., sympatry of both taxa). A diagnosis and up-to-date synonymy complement the taxonomical information. The revision of " $H$. schinzil" provides new data on the past sirenian diversity and forms the basis for a taxonomic and systematic re-evaluation of species originally grouped in the genus "Halitherium."
\end{abstract}

\section{Introduction}

Sirenia, or sea cows, represent a unique group of marine mammals that adapted to strictly herbivorous life-styles, specialized on marine angiosperms (i.e., seagrass) (Domning, 1981, 2001a; Phillips and Meñez, 1988; De Iongh et al., 1996) or a variety of freshwater macrophytes (Domning, 1980, 1982). They have a long and rich fossil record reflecting their evolutionary adaptation to a life in water, which can be reconstructed over some $50 \mathrm{Ma}$ back into the early Eocene (Domning, 2001a). Fossil members are well known from Africa, North America, and Europe indicating a maximum diversity during the Oligocene and Miocene, often characterized by the occurrence of sympatric taxa (Domning, 2001b). In the early Oligocene (33-29 Myr) of Central and Western Europe, especially Germany and Belgium, the presence of a single species, Halitherium schinzii, has long been postulated (e.g., Lepsius, 1882; Fischer and Krumbiegel, 1982; Heizmann, 1992). Several attempts to reconsider this single-species hypothesis on the basis of potentially interspecific variation have not been successful, as indicated by the postulation of new species such as H. kaupi Krauss, 1858, Manatherium delheidi Hartlaub, 1886, and H. schinzii lareolensis Pilleri, 1987, all of which are considered synonymous with $H$. schinzii (Domning, 1996). Hence, up to now Sickenberg's (1934) indication that the genus Halitherium and its type species $H$. schinzii require revision remained unconsidered (see Domning, 1996). Recently, Voss $(2010,2012)$ took up the issue of significant morphological differences, which are observable among putative specimens of $H$. schinzii, and rekindled the debate on the splitting of species currently lumped under this taxon.

The present study is the result of a re-examination of sirenian skeletal material from the early Oligocene of Central Europe, focusing on a revision of $H$. schinzii. This re-evaluation proved particularly necessary after the recognition of $H$. schinzii as a nomen dubium (Voss, 2014) because its holotype is non-diagnostic. Thereafter, this generic and species name is not applicable to any currently proposed sirenian species, including all other congeneric taxa. By following the principle of priority (ICZN, 1999, Art. 23.3.5), the taxonomic potential of all nominal junior synonyms was tested and each proofed as an inappropriate replacement for "Halitherium" due to their poor material basis, uncertain taxonomic assignment, and juvenile status, or a combination of these factors. Voss (2014) also outlined that the particulars of the qualifying conditions for the designation of a neotype specified in article 75.3 (ICZN, 1999) do not apply. Most importantly, designation of a neotype is not possible because two sympatric, but different sirenian species are hypothesized, which hampers an unambiguous choice of a potential neotype. This hypothesis is shown here to be corroborated by a suite of morphological characters. Considering taxonomic stability in terms of "taxonomic identity" (ICZN, 1999, Art. 75.5), the name " $H$. schinzii" is rejected in favor of a new generic name, which is established in the present study. The new genus includes the re-validated species " $H$." bronni 
Table 1. Summary of species formerly lumped under Halitherium and considered valid (Voss, 2013; *indicates discussions that will appear in separate papers).

\begin{tabular}{|c|c|}
\hline Species & Status \\
\hline Halitherium schinzii Kaup, 1838 & $\begin{array}{l}\text { Type species of the genus Halitherium, but species name is a nomen dubium (Voss, 2014). Species is taxonomically and } \\
\text { morphologically revised in the present work by establishing a new dugongid genus that comprises Kaupitherium gruelli } \\
\text { n. gen. n. sp. and the new combination K. bronni. }\end{array}$ \\
\hline H. taulannense $\mathrm{Sa}$ & *Well known from several specimens, but referred to a new genus belonging to the Dugongidae. \\
\hline H. bellunense De Zigno, 1875 & $\begin{array}{l}\text { Poorly preserved by its holotype and only known specimen, a juvenile. However, it is diagnostic to a certain extent and } \\
\text { confirmed to belong to the Dugonginae (Voss et al., in press). }\end{array}$ \\
\hline H. alleni Simpson, 1932 & $\begin{array}{l}\text { Poorly known from some skull caps. Status and affinities uncertain, according to Domning (1996), but revealed to have a } \\
\text { position at the basis of the newly established sister grouping between K. gruelli } \mathrm{n} \text {. sp. and K. bronni in Voss (2013). } \\
\text { *It is being re-described and taxonomically revised. }\end{array}$ \\
\hline H. antillense Matthew, 1916 & $\begin{array}{l}\text { Status and affinities uncertain according to Domning (1996), which was confirmed by Voss (2013). *Holotype and only known } \\
\text { specimen is a non-diagnostic mandibular fragment; species name is a nomen dubium. }\end{array}$ \\
\hline
\end{tabular}

(Krauss, 1858) and a further, but new species. Table 1 summarizes the present status of all species originally referred to the genus "Halitherium" (see also Domning, 1996), which are now in need of revision. A phylogenetic approach on the basis of the new morphological results as shown in Voss (2013) is in progress, but beyond the scope of the present paper.

\section{Paleobiogeography}

Geological setting of the type area.-Both sirenian species described herein are well known from early Oligocene (Rupelian) deposits at various localities in the type area, the Mainz Basin (Fig. 1). It represents a large, 1,850 km² "hanging" fault ridge (Rothausen and Sonne, 1984) in the overlap area between the Ortho-Graben and the Para-Graben in the intersection of the Upper Rhine Rift and the Permocarboniferous Saar-Nahe Basin. Fully marine conditions prevailed in the Mainz Basin during the second or late Rupelian transgression event (Berger et al., 2005a, b; Pirkenseer et al., 2010). The North Sea extended to the Lower Rhine and today's German low mountain range (Meulenkamp and Sissingh, 2003), and northern Belgium was part of the southern North Sea Basin (e.g., De Man et al., 2004; Van Simaeys et al., 2004; Vandenberghe et al., 2004). The almost N-S-trending Rhine Graben began to subside during the middle Eocene (Lutetian; Sissingh, 1998). Due to the generally assumed rift-controlled tectonic subsidence and regional relative sea-level rise (Rousse et al., 2012), the Rhine Graben has two marine connections: to the North Sea Basin and to the Paratethyan Molasse Basin (Sissingh, 1998; Rögl, 1999; Spiegel et al., 2007). A faunal interchange is supported by the syngnathiform razorfish Aeoliscus heinrichi, which is typical for the Paratethys (Sissingh, 1998), and the basking shark Cetorhinus parvus that emmigrated from the North Sea (Grimm et al., 2002). A marine-brackish connection existed to the Paris Basin (Meulenkamp and Sissingh, 2003; Fig. 1). In the Rhine Graben, the main current system was originally directed southwards (Martini and Müller, 1971); a northwards direction is indicated from the middle late Rupelian onwards (Martini, 1982; Spiegel et al., 2007).

The sirenian material from the Mainz Basin is stored in various scientific collections, but often lacking sufficient data on its discovery including a precise stratigraphy. For example, the label of NHMUK PV M9415 indicates "Halitherium,
Bodenheim, Germany, Oligocene". By contrast, the available information for the new holotype BSPG 1956 I 540 is more precise according to Barthel (1962, p. 65), who stated that it was found in "middle" Oligocene marine sands or "Meeressanden" (today: Rupelian, lower Oligocene; Grimm et al., 2000) of a gravel pit in Eckelsheim near Alzey (Mainz Basin). Nevertheless, it is commonly accepted that fossil sea cows are only known from sandy and clayey sediments that were deposited during the second Rupelian transgression (e.g., Bahlo and Tobien, 1982; Rothausen and Sonne, 1984; Pirkenseer et al., 2010). The most recent stratigraphic framework of the Mainz Basin was established by Grimm et al. (2000), Grimm and Grimm (2003), and Grimm (2005), and therefore it is mainly referred to these works in the following unless otherwise stated. These authors introduced the Alzey Formation for the marine coastal sands and the Bodenheim Formation for the clayey offshore sediments. Both formations represent the early Oligocene lower section of the Selztal Group.

The Alzey Formation, originally named "Lower Marine Sand" (Rothausen and Sonne, 1984; Sissingh, 1998), is composed of coarse-grained sands and gravels of yellow, white, or gray color, which locally appear reddish and greenish. Occasionally, also shell layers, carbonate, and silt are observable. Based on biostratigraphy, this coastal facies can be assigned to two standard calcareous nannoplankton zones: the middle to higher part of NP23 and the lower part of NP24 (Sissingh, 1998). Further, two foraminiferal zones can be distinguished: the Planorbulina Zone at the base and the Miliolid Zone at the top (Grimm, 1998, 2002). Radioisotope data obtained from ${ }^{87} \mathrm{Sr} /{ }^{86} \mathrm{Sr}$ values of a single shell from the lower Miliolid Zone reveal a date of $30.1 \pm 0.1 \mathrm{Myr}$. The Alzey Formation is very fossiliferous and yields sometimes nearly complete sirenian skeletons (Bahlo and Tobien, 1982), which are light-colored in accordance with the color of the neighboring sea sands.

The basin facies of the Bodenheim Formation corresponds to and laterally interfingers with the Alzey Formation (e.g., Grimm, 1998), and was formerly called "Rupel Clay" (Rothausen and Sonne, 1984; Sissingh, 1998). This formation is subdivided into the Wallau Member at the base, the interjacent Hochberg Member, and the Rosenberg Member at the top. It is the Hochberg Member, where fossil sirenians are found (Rothausen and Sonne, 1984) that differ from those of the Alzey Formation in having a dark-color. This member largely 


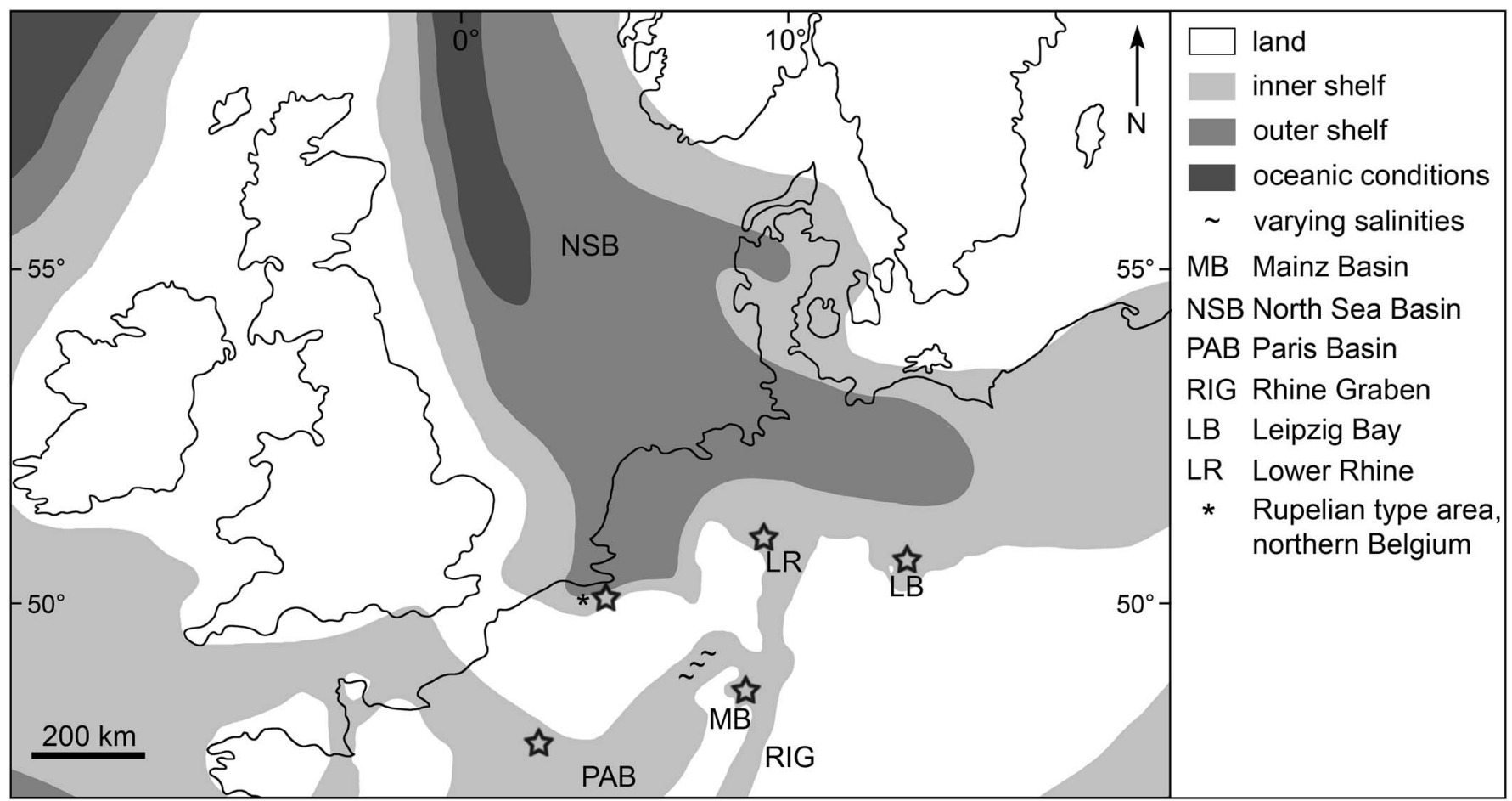

Figure 1. Geographic setting of sirenian sites and paleogeography during the early Oligocene of Central Europe (modified after Meulenkamp and Sissingh, 2003; Gürs and Janssen, 2004). Open asterisks indicate estimated find localities of the sympatric species Kaupitherium gruelli n. gen. n. sp. and K. bronni.

corresponds to the "Fish Shale" or "Middle Rupel Clay" (Rothausen and Sonne, 1984; Grimm, 2002) and is characterized by finely stratified to laminated, bituminous clays and marls, which transgress locally on the coastal deposits. The Hochberg Member was deposited in water depths of up to $150 \mathrm{~m}$ and represents the most prominent unit of the Bodenheim Formation, with a maximum thickness of $80 \mathrm{~m}$. The Alzey and Bodenheim formations were deposited in a subtropical to Mediterranean climate, which is indicated by plant remains such as palm trees near Flörsheim and cones of conifers near Eckelsheim (Schaarschmidt, 1982).

Sites in Central Europe outside the type area.-According to Grimm (1994, 1998, 2002), seven foraminifera zones can be distinguished from bottom to top within the Hochberg Member of the Mainz Basin. These biostratigraphic data allow an excellent correlation between the sediments of the UpperRhine-Graben and the Rupelian stratotype in northern Belgium (Grimm and Steurbaut, 2001; Fig. 1). The Rupelian Stage of Northwest Belgium is mainly composed of clays cropping out along the river Rupel, which are lithostratigraphically referred to as the Boom Clay Formation (De Man et al., 2004; Van Simaeys et al., 2004). Numerous sirenian finds have been reported from these strata and were extensively described by Sickenberg (1934). The Boom Clay Formation also can be correlated biostratigraphically with the sirenian-bearing Ratingen Member in the Lower Rhine area (Vandenberghe et al., 2004; Voss, 2008; Fig. 1). Other conservation lagerstätten yielding with certainty at least one of the two species described herein are the lower Oligocene brackish-marine phosphorite nodule horizon of the Böhlen Formation of the
Bay of Leipzig, East Germany (Fischer and Krumbiegel, 1982; Böhme, 2001), and the Rupelian marine sands of the Paris Basin (Bizzarini, 1995; Bizzarini and Reggiani, 2010; Fig. 1).

\section{Materials and methods}

Material examined.-Skeletal and dental material previously assigned to the species "Halitherium schinzii" and accessible in museums and universities all over Europe, North America, and Australia was personally examined following a thorough morphological approach. Isolated elements including teeth were considered if appropriate. The available material pertains not only to already described specimens, but also to new and as yet undescribed individuals, as well as to those that have not been investigated since Lepsius (1882) and Sickenberg (1934). The description of Kaupitherium gruelli focuses on the holotype and the partial skeleton NHMUK PV M9415. Besides the holotype, K. bronni is described on the basis of the well-preserved partial skeleton MB.Ma. 52009, including a nearly complete skull, and specimens MCZ 8829 and MHNM PW 1984/37-1.

Methodology.-Macroscopic descriptions consider the cranial and postcranial osteology, providing the basis for the distinction of the two morphospecies. Measurements were carried out with either a digital caliper of standard size $(\max .150 \mathrm{~mm})$ or a large caliper (up to $200 \mathrm{~cm}$ ). All measurements are in millimeters, unless otherwise stated, and are listed in Supplementary Data sets 2 and 4. Images were taken with a digital 
camera in all relevant views, mostly using the macro-function under normal light or a special photo-desk with camera-stand and lights. Line drawings of important skeletal elements or complete skulls complement the descriptions. Casts of the skull, lower jaw, and cervical series of MB.Ma. 52009 were produced to allow direct comparative investigations. With respect to hitherto unknown individuals, the preparation of cranium FIS M8385 was implemented by the Museum für Naturkunde Berlin to improve the acquisition of morphological data; a nearly complete skeleton (HLMD-WT 420) was prepared in the Hessisches Landesmuseum Darmstadt.

Repositories and institutional abbreviations.-ALMD = Aquazoo Löbbecke-Museum, Düsseldorf, Germany; BSPG = Bayerische Staatssammlung für Paläontologie und Geologie, München, Germany; FIS = Forschungsinstitut und Naturmuseum Senckenberg, Frankfurt a. M., Germany; FMD = Fossilienmuseum Dotternhausen, Germany; GPMH = Geologisch-Paläontologisches Museum der Universität Heidelberg, Germany; HLMD = Hessisches Landesmuseum, Darmstadt, Germany; IRSNB = Institut Royal des Sciences Naturelles de Belgique, Bruxelles, Belgium; JCU = James Cook University, Townsville, Queensland, Australia; LS RLP = Landessammlung Rheinland-Pfalz, Mainz, Germany; $\mathbf{M A z}=$ Museum Alzey, Germany; $\mathbf{M B}=$ Museum für Naturkunde Berlin, Germany; MCZ = Museum of Comparative Zoology, Harvard University, Cambridge, MA, USA; MNHM = Mainzer Naturhistorisches Museum, Germany; $\mathbf{M N H N}=$ Muséum National d'Histoire Naturelle (et Grande Galerie de l'Évolution), Paris, France; MSNVE = Museo di Storia Naturale di Venezia, Italy; MWNH = Museum Wiesbaden, Naturhistorische Landessammlung, Germany; NHMUK = Natural History Museum, London, UK; $\mathbf{N L}=$ Naturkundemuseum Leipzig, Germany; $\mathbf{N M D U}=$ Naturwissenschaftliches Museum Duisburg, Germany; NMV = National Museum Victoria, Melbourne, Australia; NRM $=$ Naturhistoriska Riksmuseet, Stockholm, Sweden; PMN = Paläontologisches Museum Nierstein, Germany; $\mathbf{Q B}=$ Quadrat Bottrop, Museum für Ur-und Ortsgeschichte, Germany; SMNS = Staatliches Museum für Naturkunde Stuttgart, Germany.

\section{Systematic paleontology}

Anatomical abbreviations. $-\mathbf{a}=$ acromion; $\mathbf{a c}=$ anterior cingulum; acc = accessory cuspules; act = acetabulum; amef = accessory mental foramen; $\mathbf{a m r}=$ ascending mandibular ramus; an = auditory (VIII) nerve; ang = angle; as = alisphenoid; asc = alisphenoid canal; bf = bony falx cerebri; bigr = bicipital groove; bl = break line; $\mathbf{b o}=$ basioccipital; bs = basisphenoid; $\mathbf{C} / \mathbf{c}=$ upper/lower canine or alveolus; C1-7 = cervical vertebra 1-7; Ca1-26 = caudal vertebra 1-26; cap = caput; capi = capitulum; cnf = coronoid foramen; cnfos = coronoid fossa; $\mathbf{c n p}=$ coronoid process; col = collum; colsc = collum scapulae; corp $=$ coracoid process; decr = deltoid crest; depecr = deltopectoral crest; der = distal epiphysis of radius; detu = deltoid tuberosity; $\mathbf{d e u}=$ distal epiphysis of ulna; $\mathbf{d e x}=$ distal extremity; $\mathbf{d h}=$ diaphysis of humerus; DP1-5/dp1-5 = upper/lower deciduous premolar or alveolus $1-5 ; \mathbf{d r}=$ diaphysis of radius; $\mathbf{d u}=$ diaphysis of ulna; $\mathbf{e}=$ ethmoid; $\mathbf{e a m}=$ external auditory meatus; $\quad$ elf = endolymphatic foramen; $\quad$ eo = exoccipital; exocr $=$ external occipital crest $;$ exopr $=$ external occipital protuberance; $\mathbf{f}=$ frontal; $\mathbf{f i n c}=$ foramen incisivum; $\mathbf{f l}=$ foramen lacerum; $\mathbf{f m}=$ foramen magnum; $\mathbf{f n}=$ facial (VII) nerve; fo = fenestra ovalis; fob = foramen obturatum; fov = foramen ovale; fproc $=$ frontal process; fpsut $=$ frontoparietal suture; $\mathbf{f s}=$ fracture surface; gcav = glenoid cavity; gt = greater tubercle; hgf = hypoglossal foramen; $\mathbf{h m r}=$ horizontal mandibular ramus; hy = hypocone; $\mathbf{I} \mathbf{1}=$ first upper incisor; $\mathbf{i l}=$ ilium; indsq $=$ indentation of squamosal; iof $=$ infraorbital foramen; iop = internal occipital protuberance; iosp $=$ interosseus space; isch $=$ ischium; ispf $=$ infraspinous fossa $; \mathbf{j}=$ jugal; $\mathbf{j z p}=$ zygomatic process of jugal; $\mathbf{l}=$ lacrimal; latec $=$ lateral epicondyle; lfor = lacrimal foramen; IP1-5 = left upper premolar 15; $\mathbf{l t}=$ lower tubercle; $\mathbf{m}=$ malleus; $\mathbf{M 1 - 3 / m 1 - 3}=$ upper/lower molar or alveolus $1-3 ; \quad$ ma $=$ mandibular angle; $\quad$ mas $=$ masticating surface; $\mathbf{m c}=$ mandibular condyle; $\mathbf{m c a u d}=$ margo caudalis $;$ mcl $=$ metaconule $;$ mcran $=$ margo cranialis; $\mathbf{m d f}=$ mandibular foramen; $\mathbf{m d o r}=$ margo dorsalis; $\mathbf{m e}=$ metacone; medec $=$ medial epicondyle $;$ mef $=$ mental foramen; $\mathbf{m f}=$ mastoid foramen; $\mathbf{m f o s}=$ mandibular fossa; $\mathbf{m l}=$ metaloph; $\mathbf{m r f}=$ mesorostral fossa ( $=$ external nares $) ; \mathbf{m s y m}=$ mandibular symphysis; $\mathbf{m x}=$ maxilla; $\mathbf{n}=$ nasal; $\mathbf{n c r}=$ nuchal crest $\quad$ nproc $=$ nasal $\quad$ process $; \quad$ occ $=$ occipital $\quad$ condyle; $\mathbf{o l}=$ olecranon; $\quad$ olf $=$ olecranon fossa $; \quad \mathbf{o s}=$ orbitosphenoid otcr $=$ orbitotemporal crest; $\mathbf{p}=$ parietal; P1-5/p1-5 = upper lower premolar $1-5 ; \mathbf{p a}=$ paracone; $\mathbf{p a l}=$ palatine; parop $=$ paroccipital process; $\mathbf{p b}=$ posterior basin $; \mathbf{p c}=$ posterior cingulum; per $=$ periotic; pet $=$ petrosal; $\mathbf{p f t}=$ processus fonticulus; $\mathbf{p g p}=$ postglenoid process $; \mathbf{p l}=$ protoloph; $\mathbf{p l f}=$ perilymphatic foramen; $\mathbf{p m}=$ premaxilla; $\mathbf{p m s y m}=$ premaxillary symphysis; $\mathbf{p r}=$ protocone; $\mathbf{p r l}=$ protoconule $\quad(=$ paraconule according to Thenius, 1998$)$; prop $=$ preorbital process; $\mathbf{p r t m}=$ promontorium; $\quad \mathbf{p r v}=$ processus $\quad$ retroversus $; \quad \mathbf{p s}=$ presphenoid; $\mathbf{p t}=$ pterygoid $; \quad \mathbf{p t p}=$ pterygoid process $; \quad \mathbf{p t y m p}=$ post tympanic process $; \mathbf{p u b}=$ pubis; $\mathbf{p y r}=$ pyramid $; \mathbf{r}=$ radius $; \mathbf{R} \mathbf{1}-$ $\mathbf{1 9}=$ rib $1-19 ; \quad$ rart $=$ articulation for rib; $\mathbf{s c f}=$ supracondylar fossa; $\mathbf{s c s p}=$ scapular spine; $\mathbf{s f c}=$ suprafacial commissure; $\quad$ sln $=$ semilunar $\quad$ notch; $\quad$ so $=$ supraoccipital $; \quad$ soe $=$ sphenooccipital eminence; $\mathbf{s o p}=$ supraorbital process; $\mathbf{s q}=$ squamosal; sqzp = zygomatic process of squamosal; $\mathbf{s r}=$ sigmoid ridge; $\mathbf{s s p f}=$ supraspinous fossa; suted $=$ suture between epiphysis and diaphysis; $\mathbf{t}=$ tympanic; $\mathbf{T 1 - 1 9}=$ thoracic vertebra $1-19 ; \mathbf{t b}=$ triangular bone; $\mathbf{t c r}=$ temporal crest; $\mathbf{t f}=$ fragment of tympanic; to $=$ tentorium osseum; trsul $=$ transverse sulcus; $\mathbf{t t}=$ tegmen tympani; $\mathbf{t u}=$ tuberosity; $\mathbf{t u b}=$ tuberculum; $\mathbf{t v}=$ transverse valley; $\mathbf{u}=$ ulna; $\mathbf{v}=$ vomer; $\mathbf{v p r t}=$ ventral protuberance; $\mathbf{z o b r}=$ zygomatic-orbital bridge; $?=$ unknown element.

The anatomical terminology used here mainly follows Domning $(1978,1988)$ unless otherwise stated in the description section.

Class Mammalia Linnaeus, 1758

Superorder Afrotheria Stanhope et al., 1998

Mirorder Tethytheria McKenna, 1975

Order Sirenia Illiger, 1811

Family Dugongidae (Gray, 1821) Simpson, 1932 
Remarks.-The taxonomic scheme is modified by the exclusion of the dugongid subfamily Halitheriinae, because this study aims at using a classification comprising only monophyletic taxa. According to Voss (2014), the Halitheriinae Carus, 1868, in which the taxa described herein were originally grouped, proved to be invalid for two reasons: (1) the type genus Halitherium is declared a nomen dubium, and (2) this subfamily is considered paraphyletic in all known studies (Domning 1994; Velez-Juarbe et al., 2012; Springer et al., 2015). In this respect, it should be stressed that the family Dugongidae has also long been considered to be paraphyletic (Domning, 1994; Voss, 2013), but was recently recovered as monophyletic (Springer et al., 2015). Considering other recent works, using smaller datasets (e.g., Velez-Juarbe and Domning 2014, 2015), but supporting the monophyly of the Dugongidae, the new genus proposed herein is considered as a member of this family.

\section{Genus Kaupitherium new genus}

Type species.-Kaupitherium gruelli $\mathrm{n}$. gen. n. sp. (see remarks below).

\section{Other species.—Kaupitherium bronni (Krauss, 1858).}

Diagnosis.-Dugongid genus on the basis of the following combination of synapomorphies: absence of alisphenoid canal, open foramen ovale, loss of permanent fifth premolar, and squamosal reaching temporal crest. Differs from the Dugonginae, the Hydrodamalinae, and other dugongid genera (Eotheroides, Prototherium, Eosiren, Caribosiren, Priscosiren, Metaxytherium, and other species formerly lumped under "Halitherium" [Table 1] by displaying the following unique combination of plesiomorphies: frontal roof flat; supraorbital process of the frontal dorsoventrally flattened with well-developed, prominent posterolateral corner; supraoccipital wider dorsally than ventrally; exoccipitals meet in a suture dorsal to the foramen magnum; posttympanic process with a prominent anteroventral process for attachment of $\mathrm{m}$. sternomastoideus; paroccipital process of exoccipital long, reaching as far ventrally as occipital condyles; accessory mental foramina present; horizontal ramus of mandible slender dorsoventrally; permanent premolars present. Synapomorphies: nasals reduced, but still meet in midline (shared with some Eosiren ssp. and Prototherium intermedium), nasal incisure at posterior end of the mesorostral fossa small, not extending posterior to the supraorbital processes (shared with some Metaxytherium spp., Caribosiren, Dusisiren, and Eosiren imenti); ventral border of the horizontal mandibular ramus moderately concave and sharply downturned anteriorly (shared with some Eotheroides spp., some Prototherium spp., Eosiren libyca, and "Halitherium" taulannense), masticating surface of mandible narrow, scarcely wider than the two rows of alveoli it bears (shared with some Prototherium spp., some Eotheroides spp., Eosiren libyca, and "H." taulannense). In contrast to the contemporary Old World species E. imenti, the I1 alveolus depth is about half the length of the premaxillary symphysis, and the canines and $\mathrm{P} 1 / \mathrm{p} 1$ are absent.

Etymology.-In honor of Prof. Dr. J.J. Kaup in recognition of his contributions to knowledge of the fossil sirenians from the

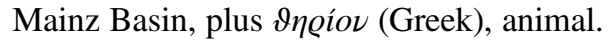

Occurrence.-Known from lower Oligocene deposits of the Mainz Basin, Germany (Alzey and Bodenheim Formation [Hochberg Member]); the Lower Rhine and southern Münsterland, western Germany (upper Ratingen Member); the Bay of Leipzig, eastern Germany (phosphorite nodule horizon of the Böhlen Formation); the Antwerp and East Flanders Provinces, northern Belgium (Boom Clay Formation); and the Paris Basin (Sables de Fontainebleau). Kaupitherium sp. indet is also known from Hungary, Switzerland, and the Gironde Region in France.

Remarks.-As outlined above, "Halitherium schinzii" is based on a non-diagnostic premolar as the holotype, which is why Voss (2014) proved the species name as a nomen dubium. Consequently, the name " $H$. schinzii" is rejected and a new genus, Kaupitherium, is established on the basis of a new type species, $K$. gruelli n. gen. n. sp., which comprises material assigned to the former taxon " $H$. schinzii," but not material of the species K. bronni (Krauss, 1858). Kaupitherium bronni, which was formerly treated as synonymous with " $H$. schinzii," is validated in this study. This species is based on a skullcap (SMNS 1539) that shows, among other characters, a diagnostic supraoccipital morphology. Due to the fact that the holotype of K. gruelli (BSPG 1956 I 540) includes a nearly complete skull, which provides a broad basis to define the new genus, this taxon is chosen as type species of Kaupitherium n. gen.

\section{Kaupitherium gruelli new species} Figures 2-9

1855 Halitherium schinzi (Kaup) (part); sensu Kaup, p. 11, pl. 2, fig. 1.

1858 Halitherium kaupi; Krauss, p. 528.

1862 Halitherium schinzi; Krauss, p. 385, pl. 6, figs. 1-10, pl. 7, figs. 1-7.

1882 Halitherium schinzi (Kaup) (part); sensu Lepsius, p. 1, pl. 5, fig. 52, pl. 10, figs. 96-97.

1912 Halitherium schinzi; Schmidtgen, p. 457, pl. 29, figs. 4-5.

1934 Halitherium schinzi Kaup forma delheidi; Sickenberg, p. 271, text-fig. 2a, pl. 9, fig. 1.

1962 Halitherium schinzi; Barthel, p. 65, pl. 7, figs. 1-3.

1995 Halitherium schinzi; Bizzarini, p. 163, text-fig. 1, pl. 1.

2008 Halitherium schinzii; Voss, p. 259, text-figs. 2-7.

2008 Halitherium sp. indet; Voss, p. 263, text-figs. 9-10.

2010 Halitherium schinzi; Bizzarini and Reggiani, p. 131, text-figs. 1-4.

Holotype.-Partial skeleton of an adult specimen (BSPG 1956 I 540) including the skull, mandible, nearly complete vertebral column, full rib series of the left side, and left innominate from the Alzey Formation at Eckelsheim in the Mainz Basin, Germany.

Occurrence.-Known only from lower Oligocene deposits of the Mainz Basin, Germany (Alzey Formation and Hochberg Member [Bodenheim Formation]); the Lower Rhine, western Germany (upper Ratingen Member); the Antwerp and East Flanders Provinces, North Belgium (Boom Clay Formation); and the Paris Basin (Sables de Fontainebleau). 

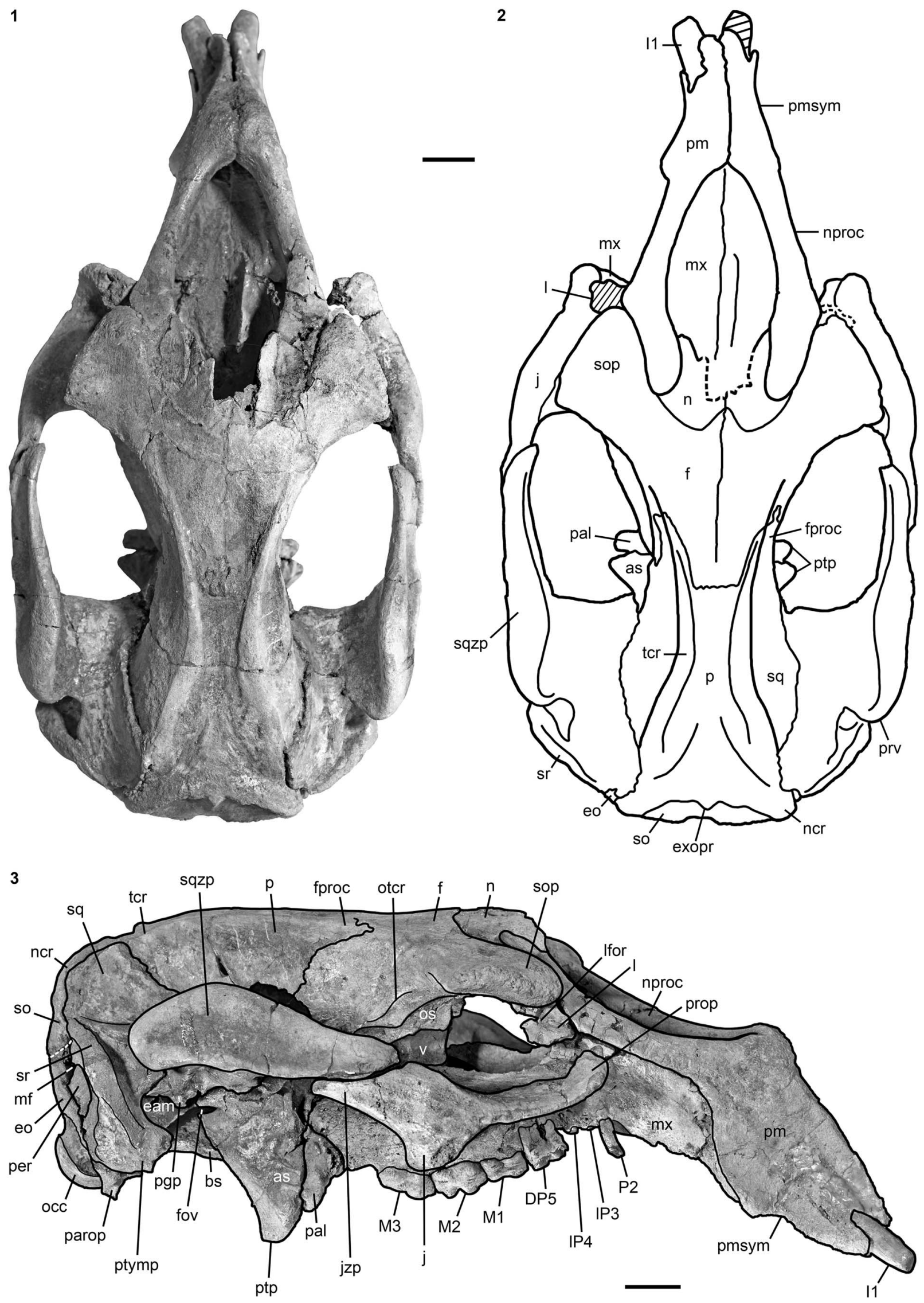

Figure 2. Cranium of Kaupitherium gruelli n. gen. n. sp. (BSPG 1956 I 540, holotype): $(\mathbf{1}, \mathbf{2})$ in dorsal and $(\mathbf{3})$ right lateral views $(\mathbf{1}=$ photograph; $\mathbf{2}=$ outline drawing; shaded areas indicate missing or reconstructed parts; dashed lines indicate broken parts). Anatomical abbreviations indicated in text. Scale bar is $2 \mathrm{~cm}$. 
Description.-Species description is given below.

Premaxilla.-Rostrum is laterally compressed forming a middorsal ridge anterodorsally, with its summit being upraised to form a bulbous boss (Fig. 2.3). Premaxillary symphysis exceeds half the total anteroposterior extension of the premaxilla and is enlarged relative to the condylobasal skull length. It is strongly downturned, forming an angle between $55^{\circ}$ and $60^{\circ}$ with the occlusal plane. Anteroventralmost end of the maxillopremaxillary suture is on the vertical level of (i.e. perpendicular to) the symphyseal summit. Mesorostral fossa is not indented anteriorly, but retracted and enlarged, reaching posterior to the level of the anterior margin of the orbit (Fig. 2.1, 2.2). Nasal process is thin and tapers at its posterior end. Alveoli for the first incisor tusks are preserved; those for $\mathrm{I} 2$ and $\mathrm{I} 3$ are absent (Fig. 3.1, 3.2). A dentiform process as in hydrodamalines is not developed. Masticating surface is lanceolate in shape, reaching its maximum transversal dimension at the level of the posterior end of the foramen incisivum. The latter opens anteriorly without distinct demarcation. Anterior palatal roof in front of the infraorbital foramina is distinctly narrower than the posterior palate.

Nasal.-Internasal area is thin and often broken, but its full extent is observable in the specimens LS RLP PW 2005/5042-LS and PMN SSN12WD14. Nasals are small, with the internasal suture being shorter than half the length of the interfrontal suture (Fig. 2.1, 2.2). They extend anterolaterally almost up to the level of the anteriormost extension of the supraorbital process in adults, extend even farther in juveniles (FMD SRK Eck 124; Fig. 4.3), and then slope backwards to form a shorter median tip. Nasals meet in the midline and are separated by a nasal process from the frontals. A nasal incisure is present at the posterior end of the mesorostral fossa, but it is small, not extending posterior to the supraorbital processes.

Ethmoidal region.-Mesethmoid forms a distinct perpendicular plate of $15 \mathrm{~mm}$ in maximum width, but becomes narrower and is constricted dorsally and ventrally. Becoming narrower also posteriorly, this vertical wall extends below the nasals and along the narial passages to fuse with the presphenoid. Crista galli is triangular in cross section, projecting upward from a broad base and becomming thinner towards the roof of the cranial cavity. The often not well-preserved cribiform plates of the exethmoids are deeply grooved and perforated for the passage of the olfactory nerves. Usually, a large ethmoturbinal, or concha maxima ethmoidalis (Kaiser, 1974), is visible as a thick, vertically flattened plate on each side below the nasals and medial to the frontal. A thin lamina papyracea is sometimes preserved, but broken on the ventromedial side of the supraorbital process in all available specimens. Other ethmoturbinals are either not developed or not preserved.

Vomer.-Exposed on the damaged anterior medial wall of the temporal fossa (Fig. 2.3) and on the ventral side of the holotype, forming the anterodorsal extension of the presphenoidal crest (Fig. 3.1, 3.2). It passes along most of the internal narial passage and contacts the maxilla and palatine before it runs out in a longitudinal groove on the dorsal side of the maxilla. Only the right lateral border of this maxillary groove is visible through the mesorostral fossa in the holotype (Fig. 2.1, 2.2), the vomer itself is not preserved there.

Lacrimal.- Not completely preserved in any available specimen, but its extent can be judged from the imprints on the adjacent jugal and maxilla. This bone is arranged in an oblique dorsoventral axis and fills a space of $\sim 20 \mathrm{~mm}$ in height between the jugal and frontal. Lacrimal contacts premaxilla anterodorsally, which is best preserved in the holotype and can be also traced in FIS M8002 and M2597. Nasolacrimal canal, which extends into the nasal cavity, is clearly discernible in BSPG 1956 I 540 (Fig. 2.3).

Frontal.-Frontal roof is flat and delimited by the temporal crests, which form distinct keels that are as prominent on the frontal as on the parietal (Fig. 2.1, 2.2) and vary between types C, D, and E (Domning, 1988, p. 405). A knoblike boss is not developed posteromedial to the temporal crests. Internasal process can be differently developed, but it is generally short and does not exceed half the length of the internasal suture (Figs. 2.1, 2.2, 4.3). Supraorbital process is dorsoventrally flattened with its dorsal surface gently inclined ventrolaterad (Fig. 2.3). Its lateral margin is smooth and oriented along an anteromedial-posterolateral axis, ending in a prominent posterolateral corner. Orbitotemporal crest is weak. Lamina orbitalis has a thin falciform anterior edge, contributing to the medial wall of the temporal fossa.

Parietal.-Parietal roof is flat between lyriform temporal crests (Fig. 2.1, 2.2). In adults of advanced age (e.g., FIS M8002), these crests can rise high above the parietal roof that, in consequence, becomes slightly concave. Intertemporal constriction is distinct, reaching its maximum at about the center of the skull roof, and producing parietals, which bulge laterally. Frontoparietal suture is V-shaped and the frontal processes do not exceed half of the interfrontal length. Of all studied specimens, the parietal is longer than the frontal and the cranial roof is elongated relative to the width of the supraoccipital; the ratio $l_{\mathrm{FP}} / \mathrm{w}_{\mathrm{SO}}$ varies between 2.07 in BSPG 1956 I 540 and 2.6 in FIS M8002. In endocranial view (Fig. 4.1, 4.2), the parietooccipital suture is detectable as a slight transverse sulcus or at least as deep dorsolateral pits. Posterior margin of the parietal can be either convex as in ALMD-JBH A92 (Voss, 2008, fig. 9B) or double-curved, forming a median tip as in NMDU-Geo 0001 (Voss, 2008, fig. 4B). Tentorium osseum is well developed, and the internal occipital protuberance forms a prominent projection at the intersection of the bony falx and the tentorium. Bony falx cerebri is distinct and gradually flattens out before reaching the frontoparietal suture. Below the internal protuberance, a roughly triangular bone is present. Endocranial surface shows wide grooves and traces of vessels.

Supraoccipital.- Intercalated between the parietals, following the angle of the lambdoid suture (Fig. 2.1, 2.2). Parietal and supraoccipital form an angle that varies between $120^{\circ}$ (e.g., BSPG 1956 I 540 [Fig. 2.3], ALMD-JBH A92) and 140 (e.g, FIS M2597, MNHM PW 1991/66-LS). It is wider than high (Figs. 3.3, 4.4-4.7), with a width-to-height ratio that exceeds 1.5. Nuchal crest is pronounced and broadly convex, extending downwards to about half the height of the supraoccipital. Greatest width of the bone is at this level, and is greater than its width more ventrally at the supraoccipital-exoccipital sutures. External occipital protuberance is caudally prominent in all specimens, even in the juvenile FMD SRK Eck 124 (Fig. 4.3, 4.4). It either remains approximately at the level of the parietal roof (e.g., NHMUK PV M9415 [Fig. 4.5], NMDU-Geo 0001 [Fig. 4.7], BSPG 1956 I 540 [Fig. 3.3]) or rises slightly above it (e.g., IRSNB unnumbered [Fig. 4.6], HLMD-WT Az 174 and 177, MCZ 8830). External occipital crest exceeds half 

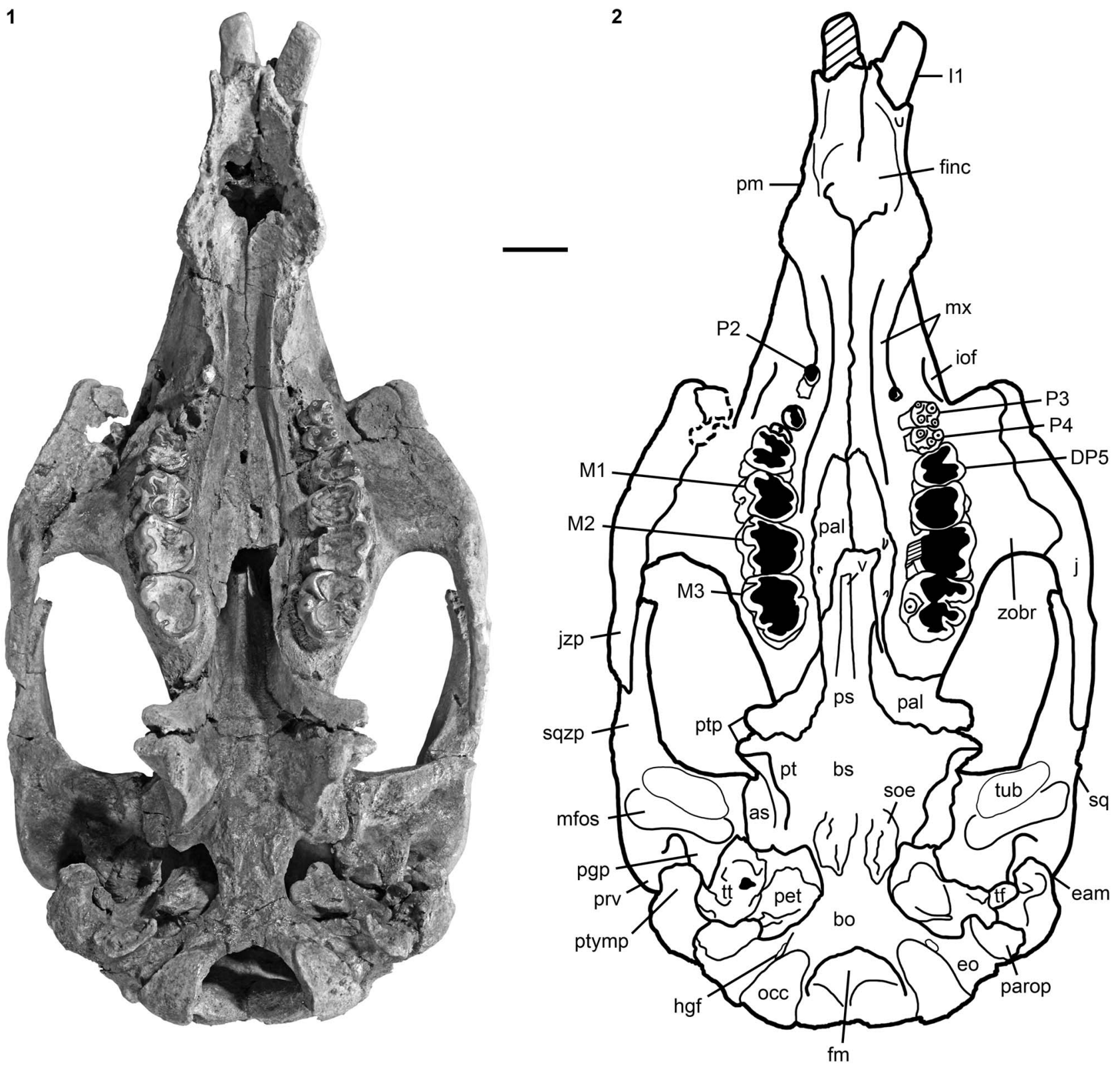

3

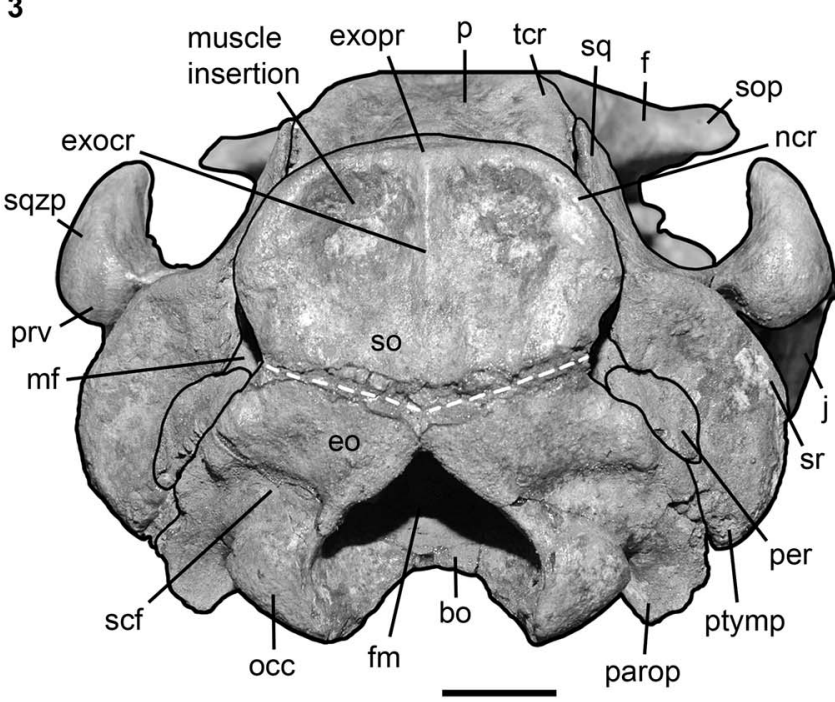

4

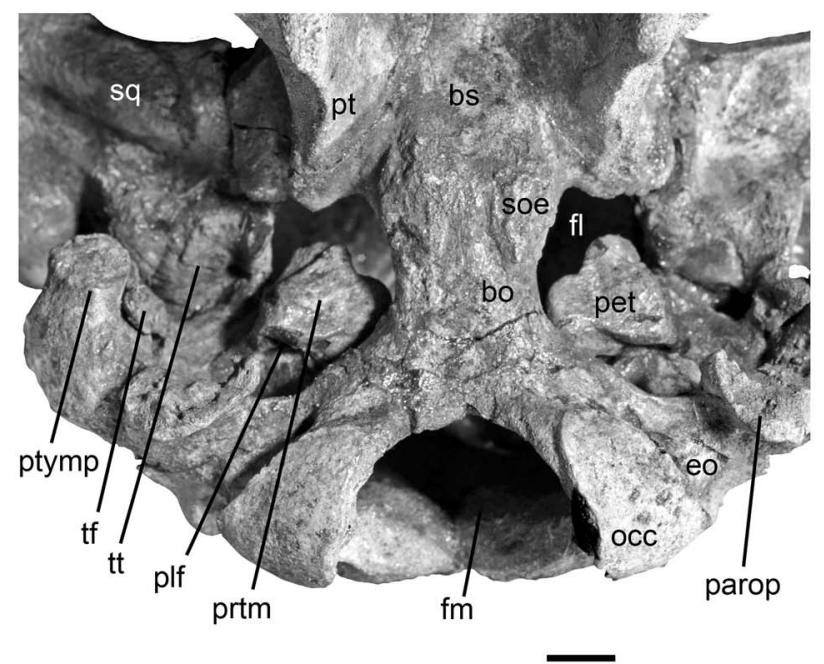


the height of the supraoccipital and sometimes even reaches its ventral margin (ALMD-JBH A92; see also Voss, 2008, fig. 9). In some specimens (FIS M2715 and IRSNB unnumbered [Fig. 4.6]), a nutrient foramen penetrates the upper part of this crest. Two shorter ridges (i.e., the medial edges of the semispinalis capitis muscle insertions) accompany the external occipital crest. They are usually distinctly developed, but behind the level of the median crest, giving a crown-shaped appearance to the external occipital protuberance. This feature is observable to a less distinct degree in BSPG 1956 I 540 (Fig. 3.3) and FMD SRK Eck 124 (Fig. 4.4). Insertion areas for the semispinalis muscles are rugose and irregularly shaped depressions, which are defined ventrally by more or less prominent ridges that meet the nuchal crest laterally, giving the depressions a roughly triangular form. Internal lamina show paired bulges that can either be ovoid (Voss, 2008, figs. 4B, 9B) or terete. A more or less pronounced furrow is present medially (FIS M2597; Fig. 4.1, 4.2), which accompanies a ridge extending up to the parietooccipital suture in NMDU-Geo 0001(Voss, 2008, fig. 4B) instead of a triangular bone as described above. Other specimens (ALMD-JBH A92; Voss, 2008, fig. 9B) have a nutrient foramen at the base of this furrow. Sutural surfaces for the exoccipitals have an irregular relief and intersect medially at an angle that varies between $140^{\circ}$ (BSPG 1956 I 540 [Fig. 3.3], NMDU-Geo 0001 [Fig. 4.7], ALMD-JBH A92) and $150^{\circ}$ (IRSNB unnumbered; Fig. 4.6).

Exoccipital.-Meet in a suture of $10 \mathrm{~mm}$ dorsal to the foramen magnum (Fig. 3.3). Dorsolateral borders are rounded, more or less smooth and not flange-like. Paroccipital processes are long, reaching as far ventrally as the occipital condyles. Foramen magnum has a triangular outline with its dorsal peak surpassing the level of the occipital condyles. Supracondylar fossae are deep and extend across the entire widths of the condyles. A hypoglossal (condyloid) foramen completely surrounded by bone is present (Fig. 3.1, 3.2).

Basioccipital.-Firmly fused with the basisphenoid in adults, so that the suture between the two elements is obliterated (Fig. 3.1, 3.2, 3.4). Sphenooccipital eminences for the longus capitis muscles form bilateral rugosities that are convex and separated by a slight furrow.

Presphenoid, basisphenoid, orbitosphenoid.-Well preserved in the holotype (Fig. 3.1, 3.2), with the basi- and presphenoid firmly fused and in obliterated contact with the orbito- and alisphenoid, and pterygoid. Basi- and presphenoid have a flat ventral surface with a slight anterodorsad slope. Presphenoid forms a median crest that projects out cranially to join the vomer. Orbitosphenoid is not completely preserved, but partially exposed on the right lateral side of the skull (Fig. 2.3). It contributes to the anterior medial wall of the temporal fossa. Alisphenoid wing-shaped pterygoid processes originate ventrolateral to the basisphenoid; their posterolateral sides are each formed by the alisphenoid (Fig. 2.3). Outer surface is flat to slightly uneven. An alisphenoid canal is no longer discernible and the foramen ovale forms a distinct incisure. This is excellently visible laterally and also ventrally in the holotype (Figs. 2.3, 3.4), where the foramen ovale opens into the foramen lacerum.

Pterygoid.-Pterygoid processes are posteromedially formed by the pterygoid (Fig. 3.1, 3.2). Pterygoid fossa extends above the level of the roof of the internal nares. Distal end builds up ventromedially a hook-shaped hamular process.

Palatine.-Anterior parts are dorsoventrally flattened and anteroposteriorly elongated, extending beyond the posterior edge of the zygomatic-orbital bridge of the maxilla up to the anterior margin of DP5 in subadults (FIS M2597; Fig. 4.1, 4.2) or even to the level of P4 in adults (BSPG 1956 I 540; Fig. 3.1, 3.2). Posterior border has an incisure that does not surpass the level of M2 even though it is broken posteriorly in some specimens. Small and paired foramina can occupy a position more or less medial to M3 (BSPG 1956 I 540; Fig. 3.1, 3.2) or to M1 (FIS M2597; Fig. 4.1, 4.2). In BSPG 1956 I 540, a larger foramen is also present medial to the left M2. Posterior parts contribute to the anteromedial margins of the pterygoid processes as well as to the posterior wall between the internal nares and the temporal fossa. Sutures with the surrounding bones are still visible.

Maxilla.-Infraorbital foramen is small, does not exceed $200 \mathrm{~mm}^{2}$ and is oval in cross section, distinctly higher than wide (Fig. 3.1, 3.2). Infraorbital canal is not obstructed. Zygomatic-orbital bridge is elongated anteroposteriorly and has a concave, smooth surface. Its ventral side is nearly level with the palate or slightly above the alveolar margin, ranging between $10 \mathrm{~mm}$ and $15 \mathrm{~mm}$ in adults and subadults. Anterior margin of zygomatic-orbital bridge is very thin, $2 \mathrm{~mm}$ on average, while the posterior margin is thickened, between $10 \mathrm{~mm}$ and $20 \mathrm{~mm}$. Tooth arcades are lyriform, broadly convex between the molars, tapering at the level of the premolars and widening again towards the foramen incisivum. Palate is thin at the level of the penultimate cheek tooth. Posterior opening of the maxillopremaxillary canal can be detected through the orbit.

Squamosal.-Extends to the temporal crests and forms conspicuous indentations in the posterior corners of the parietal, causing the separation of the temporal and nuchal crests (Figs. 2, 4.3). Delimits the mastoid foramen anteriorly together with the exoccipital posteriorly and the supraoccipital dorsally. Sigmoid ridge is prominent and relatively straight, extending to the level of the ventral margin of the supraoccipital and onto the rostrad-projecting ventral tip of the posttympanic process. The latter is roughened and serves as attachment for the sternomastoid muscle. External auditory meatus is short mediolaterally and about as wide anteroposteriorly as high. Zygomatic process is strongly developed, triangular in lateral view with a rounded posterior and a tapering anterior end, often with a slightly dorsad-rising tip. Its outline is straight to concave posterodorsally and nearly straight anterodorsally and ventrally. Lateral surface is generally smooth, with a horizontal concavity in the anterior half. Medial side of the zygomatic process is flat

Figure 3. Cranium of Kaupitherium gruelli n. gen. n. sp. (BSPG 1956 I 540, holotype): $(\mathbf{1}, \mathbf{2})$ in ventral and $(\mathbf{3})$ caudal views $(\mathbf{1}=$ photograph; 2 = outline drawing; shaded areas indicate missing or reconstructed parts; black dashed lines refer to broken parts; white dashed line marks the supposed supraoccipitalexoccipital suture); (4) close-up of basicranium in posteroventral view exhibiting the ear region. Anatomical abbreviations indicated in text. Scale bars are $2 \mathrm{~cm}$ (1-3), or $1 \mathrm{~cm}(4)$. 
1

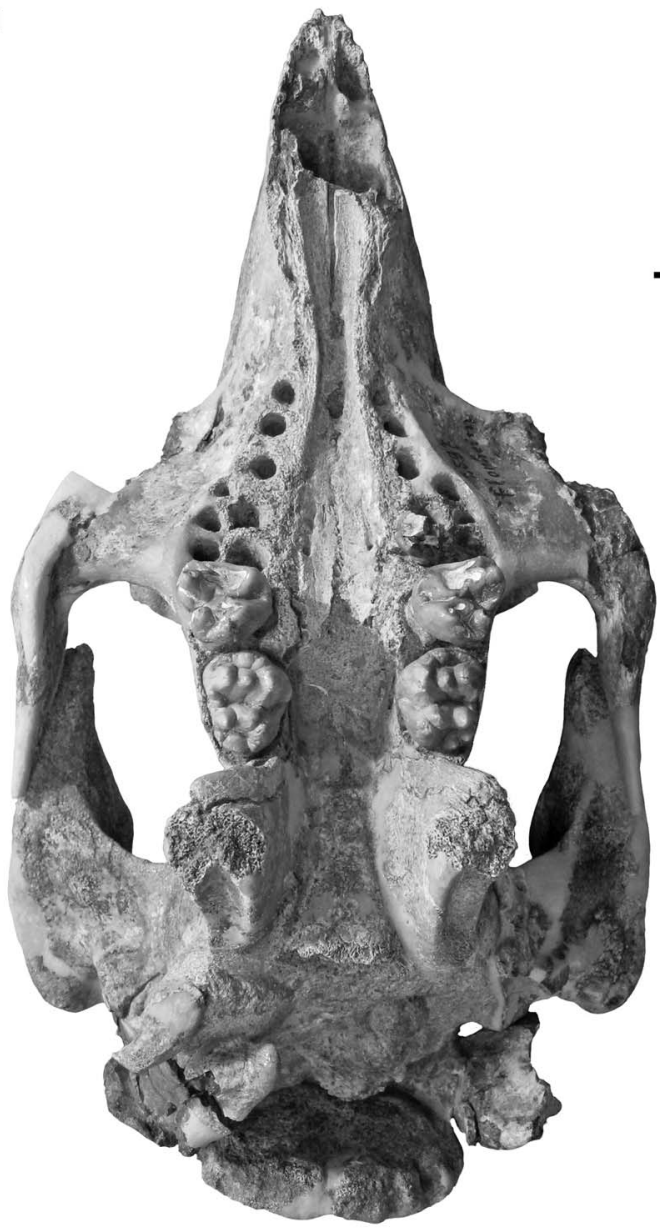

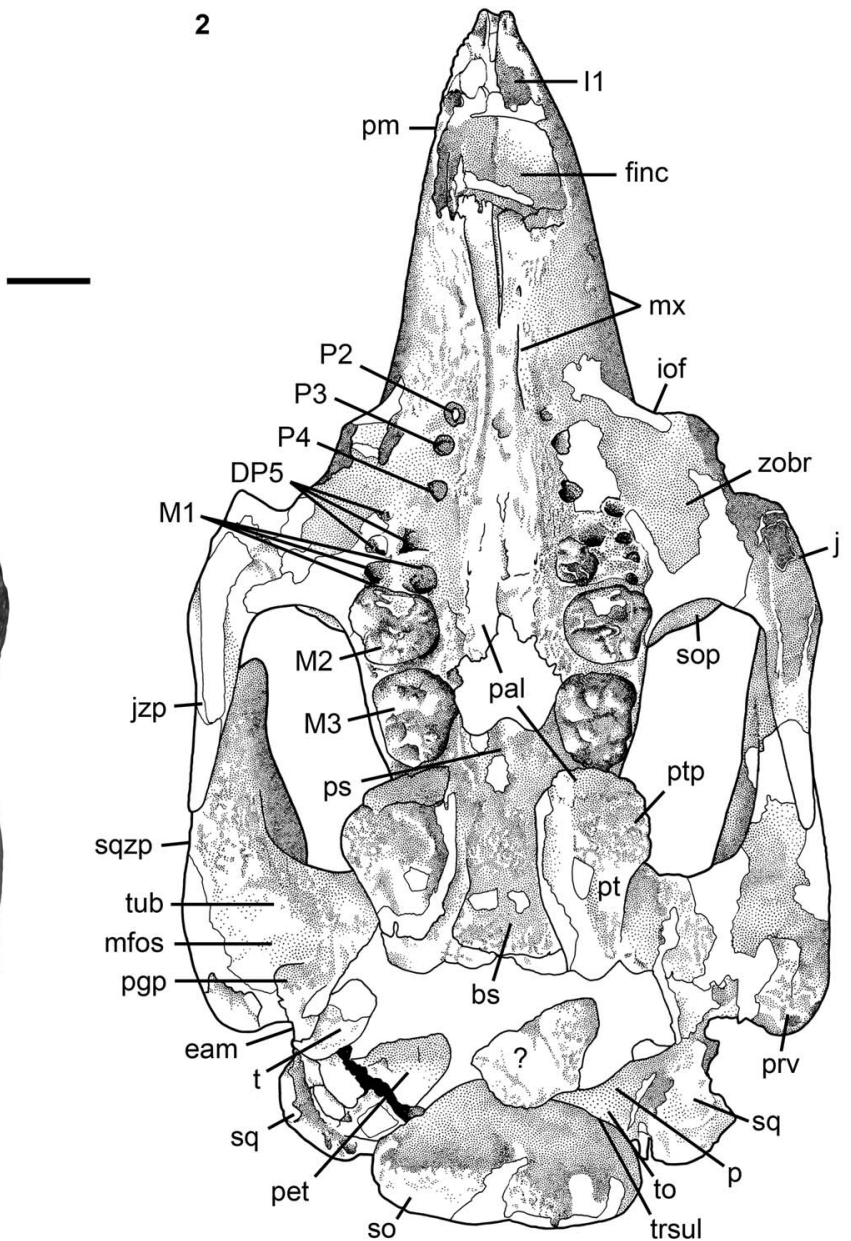

3

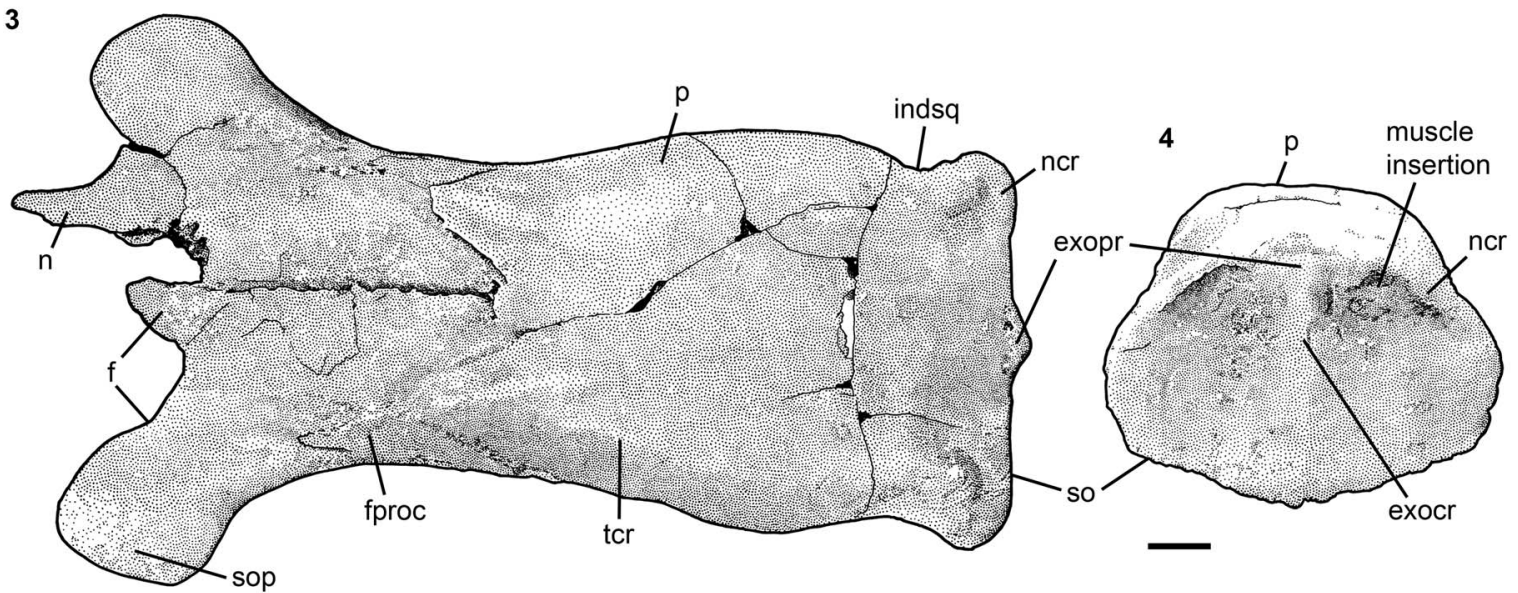

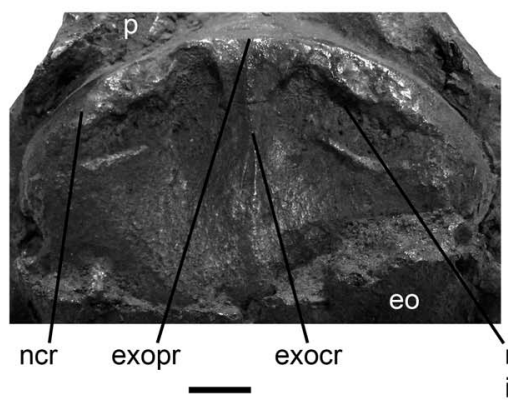

6

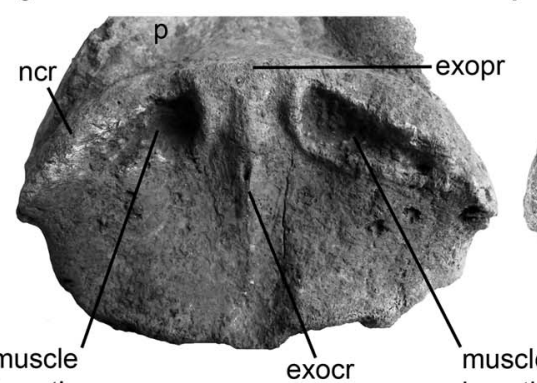

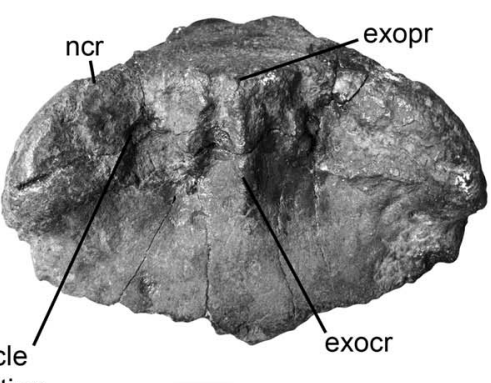


1

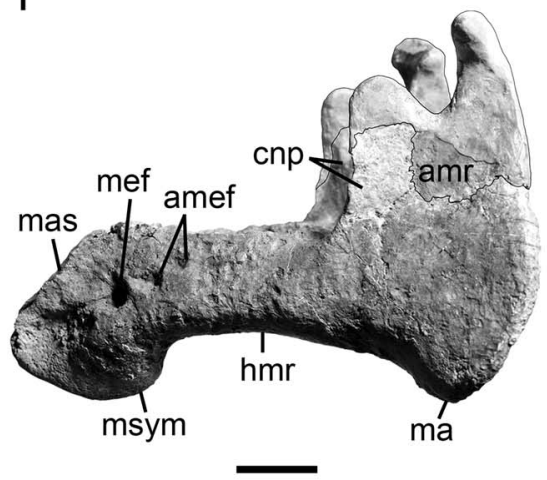

2

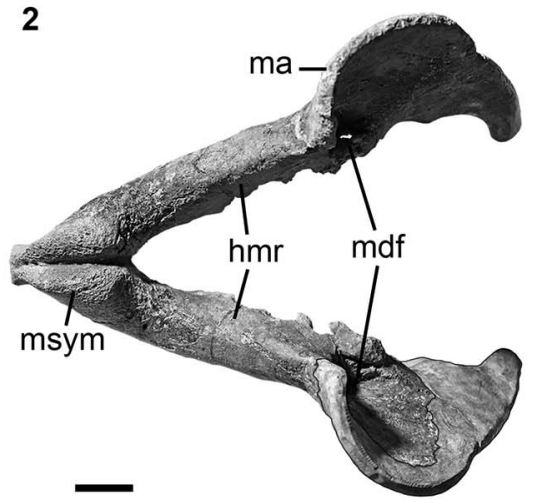

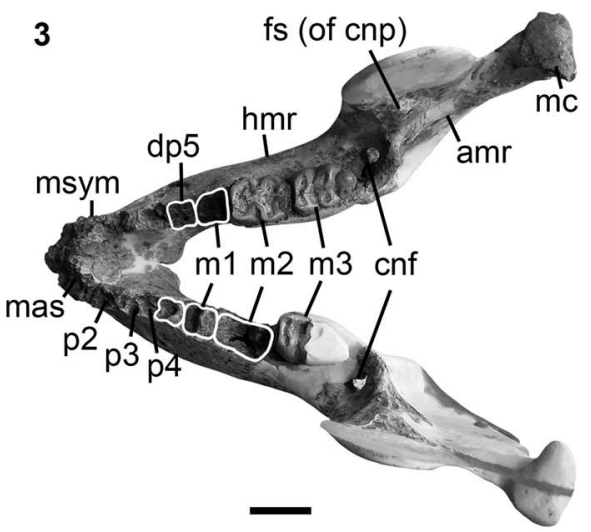

4

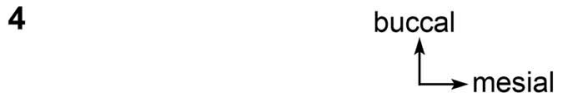

5

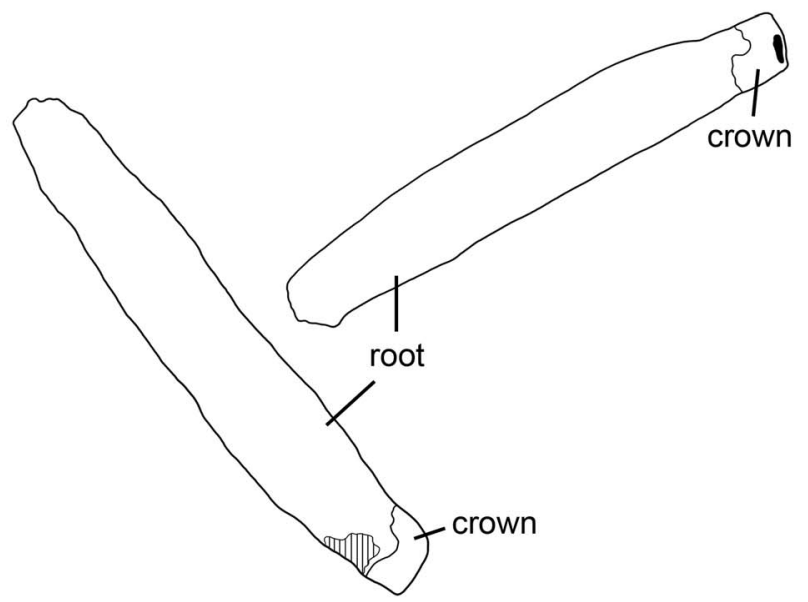

Figure 5. Mandibles (1-3) and dentition (4, 5) of Kaupitherium gruelli n. gen. n. sp.: (1, 2) BSPG 1956 I 540 (holotype) in (1) left lateral and (2) ventral views; (3) MB.Ma. 52010 in occlusal view (white and outlined areas indicate missing or reconstructed parts); (4) right M3-M2 (from left to right) of FIS M2597 in occlusal views; (5) outline drawings of tusks (I1) of PMN SSN12EC55 (shaded area indicates broken part; exact scale and anatomical provenance are undetermined because the skeleton is on display). Anatomical abbreviations indicated in text. Scale bars are $3 \mathrm{~cm}(\mathbf{1 - 3})$, or $1 \mathrm{~cm}(\mathbf{4})$.

to concave and defined dorsally by a sigmoidally curved dorsal edge. Zygomatic root shows a distinct notch posteriorly. Processus retroversus is moderately inflected (Fig. 3.1-3.3). Mandibular fossa is deep, tuberculum is broad and prominent, both being transversely directed. Postglenoid process forms a prominent knob, defining the mandibular fossa posteriorly.

Jugal.-Preorbital process is thin and does not reach the premaxilla (Fig. 2.3). Ventral rim of the orbit is not overhanging. Ventral extremity lies approximately under the posterior edge of the orbit. A postorbital process is present dorsally, but distant from the supraorbital process. Unless broken as in BSPG 1956 I 540, the zygomatic process of the jugal extends posteriorly on the ventral side of the zygomatic process of the squamosal to the anterior margin of the tuberculum. Its length exceeds the diameter of the orbit.

Ear region.-NHMUK PV M9415, MNHM PW 1991/66-LS, MB.Ma. 52010, and BSPG 1956 I 540 (Fig. 3.4) preserve the periotic completely or in parts, comprising the mastoid, petrosal, and tegmen tympani. Periotic is set in a closely fitting cavity of the squamosal, not fused with the alisphenoid or any other skull bone. It is often broken, lacking the petrosal, and then reveals the characteristic density of sirenian bones. Mastoid is fused anteriorly with the petrosal and tegmen tympani; its transition to the latter is smooth and continuous. Processus fonticulus forms an oval and roughened protuberance that fits into the mastoid foramen (Figs. 2.3, 3.3). Tegmen tympani is convex, kidney-shaped, and adjacent to the lateral side of the cranium, forming the roof of the tympanic chamber. Anteromedially, it tapers into a blunt end. Tegmen tympani and the mastoid are of similar size. Petrosal extends far into the foramen lacerum (Fig. 3.4), is nearly circular in cross section and bears a smooth-surfaced, knoblike promontorium on its ventral side. Promontorial ridge extends posterolaterad up to the level of the squamosoexoccipital suture. Oval window (fenestra ovalis or fenestra vestibuli) opens anterolaterally and is (contrary to what its name suggests) rounded. A large, oval perilymphatic foramen opens posteromedial to the promontorium. Medial to the posterior attachment surface of the tympanic, a distinct, 
1

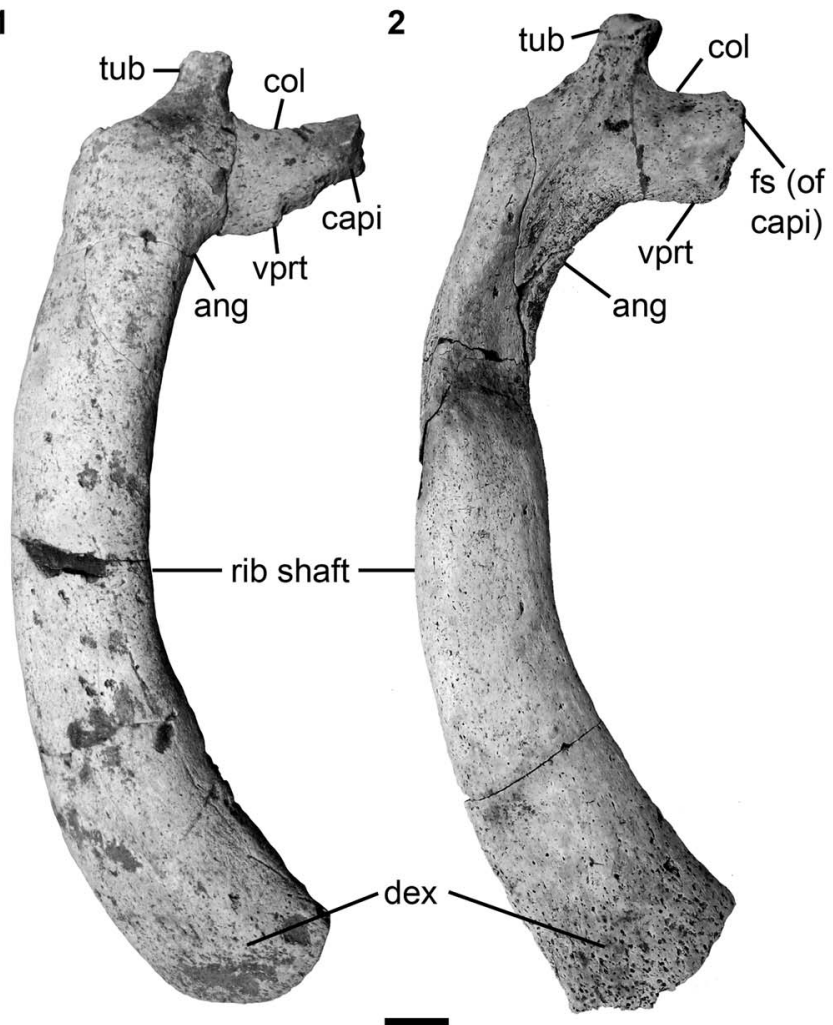

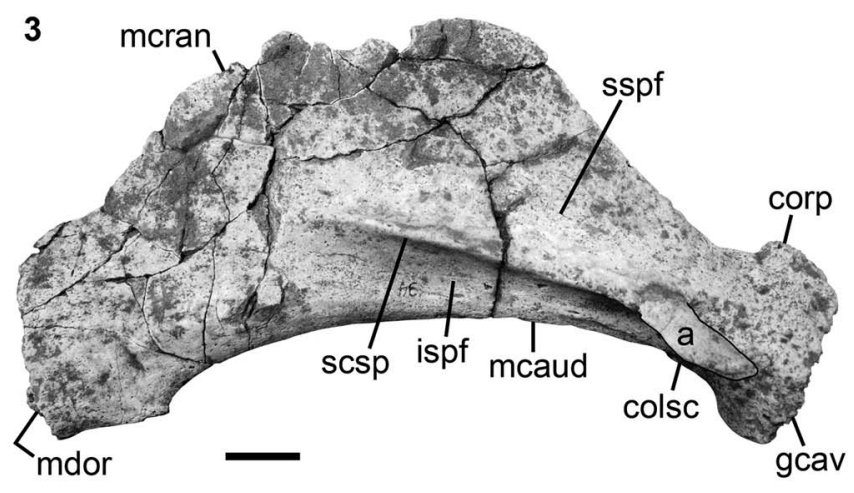

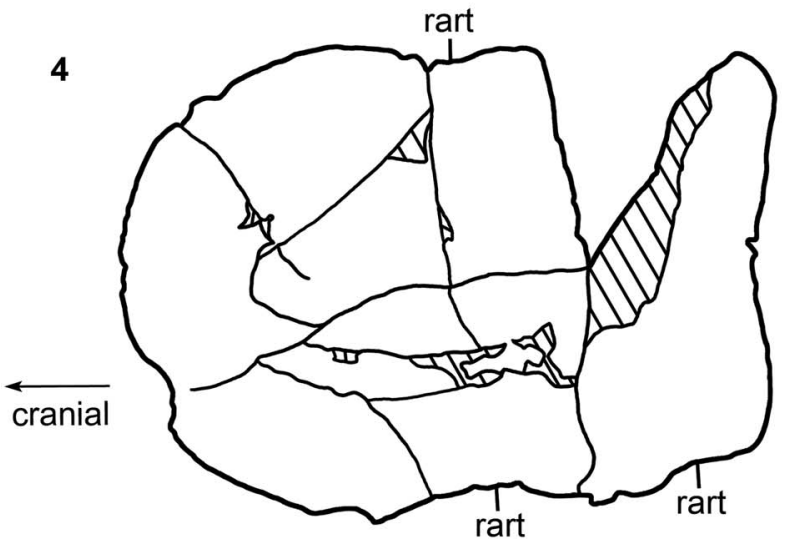

Figure 6. Postcranial elements of Kaupitherium gruelli n. gen. n. sp.: (1-3) represent MNHM PW 1991/66-LS; (1) right R1 in anterior view; (2) left R1 in posterior view; (3) right scapula in lateral view; (4) outline drawing of manubrium (LS RLP PW 2005/5042-LS) in ventral view (shaded areas indicate broken parts; exact scale was not determinable because the skeleton is on display). Anatomical abbreviations indicated in text. Scale bars are $1 \mathrm{~cm}(\mathbf{1}, \mathbf{2})$ or $2 \mathrm{~cm}(\mathbf{3})$.

mediolaterally elongated concavity for the origin of the musculus stapedius is present. Endocranially, the endolymphatic foramen forms a narrow and slit-like opening. Tympanic is asymmetrical, bulbous, and smooth-surfaced, with a blunt medioventrally directed tip. Its anterior branch is shorter than the posterior one and attached to the tegmen tympani. Posterior branch expands into a rounded and flat plate, facing the anteromedial side of the posttympanic process, and is preserved in the holotype (Fig. 3.4). Lumen of the tympanic arch is spanned by the malleus, which is present in situ in HLMD-WT 420 on the left side as the only preserved auditory ossicle. It is a massive and stout element, with a sharp vertical ridge on its lateral side.

Hyoid apparatus.- - Not known from any available specimen assignable to Kaupitherium gruelli n. gen. n. sp.

Mandible.-Symphysis is distinctly higher than long. Principal mental foramen, accompanied dorsoposteriorly by several accessory mental foramina (Fig. 5.1). Horizontal mandibular ramus is slender, moderately concave ventrally and sharply downturned anteriorly and not tangent to the angle posteriorly. Below the condyle, the posterior outline is broadly convex, lacking a processus angularis superior. Although broken or replaced by plaster in most specimens, the coronoid process of the ascending ramus has a slight anterior slope. Condyles occupy a position below the level of the coronoid processes, which is erroneously reconstructed in the holotype (Fig. 5.1). In ventral view, the mandibular symphysis is broad and bulging laterally (Fig. 5.2). Mandibular foramen is undivided and exposes the dental capsule of $\mathrm{m} 3$ posteroventrally. Condyles are elliptical, with the medial and lateral edges having the same anteroposterior length (Fig. 5.3).
Coronoid foramen is enlarged, with $7 \mathrm{~mm}$ in average diameter. Masticating surface is narrow, scarcely wider than the two rows of tooth alveoli it bears, without a furrow in the median plane.

Dentition.-Complete cheek tooth series including DP5/dp5 is preserved in the upper and/or lower jaws of NHMUK PV M9415, MNHM PW 1949/157, and BSPG 1956 I 540 (Fig. 3.1, 3.2), the latter preserving also the antemolar dentition. Besides a pair of tusks, the dental formula included three permanent premolars, a persistent deciduous fifth premolar and three molars (I1/i0, $\mathrm{C} 0 / \mathrm{c} 0, \mathrm{P} 2 / \mathrm{p} 2-4, \mathrm{DP} 5 / \mathrm{dp} 5, \mathrm{M} 1-3 / \mathrm{m} 1-3)$.

Incisor tusks (I1) are preserved in BSPG 1956 I 540 (Figs. 2, 3.1, 3.2), LS RLP PW 2005/5042-LS, and PMN SSN12EC55 (Fig. 5.5). They extend about half the length of the premaxillary symphysis, are slightly curved along their longitudinal axis, and protruded $2.0 \mathrm{~cm}$ from the premaxillae. Crown is distinct from the root and composed of enamel on all sides, being suboval or subelliptical in cross section. Its ventral tip is often slightly worn.

P2-P4 are single-rooted (Figs. 3.1, 3.2, 4.1, 4.2). In BSPG 1956 I $540, \mathrm{P} 2$ is heavily worn, which causes a pencil-shaped appearance of it, indicating that this tooth occluded with its lower counterpart. P3 and P4 are moderately worn, but still reveal a high central cusp that is surrounded mesially, lingually, and distally by accessory cuspules, whose number apparently increases distad within the tooth arcade. Crowns of the left P3-4 are nearly unworn and preserved in situ in PMN SSN12WD14. This specimen is on display in the position in which it was found in the rock, and therefore the teeth were not fully accessible, but only visible from their smooth and convex labial side. DP5 crown is heavily worn in all available specimens (Fig. 3.1, 3.2), but it can be clearly identified as a 
1

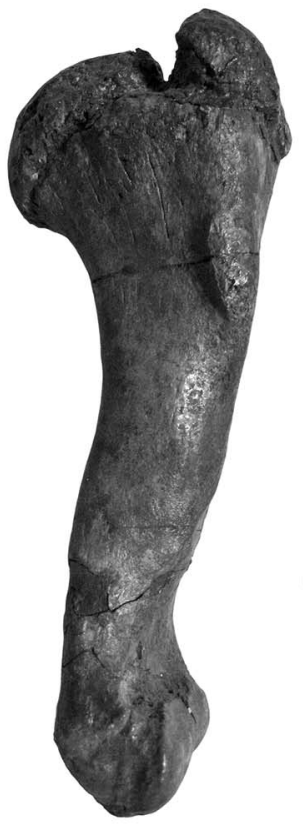

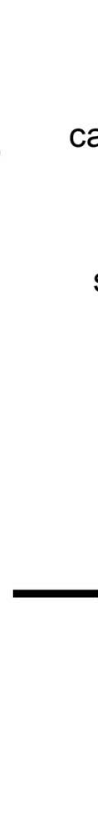

2

(1) 3
5

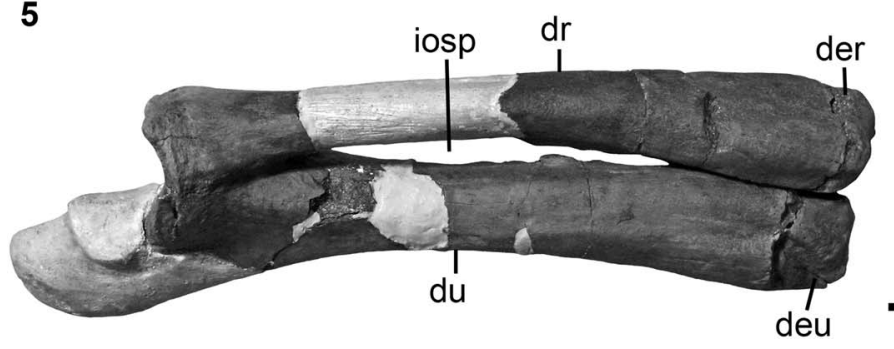

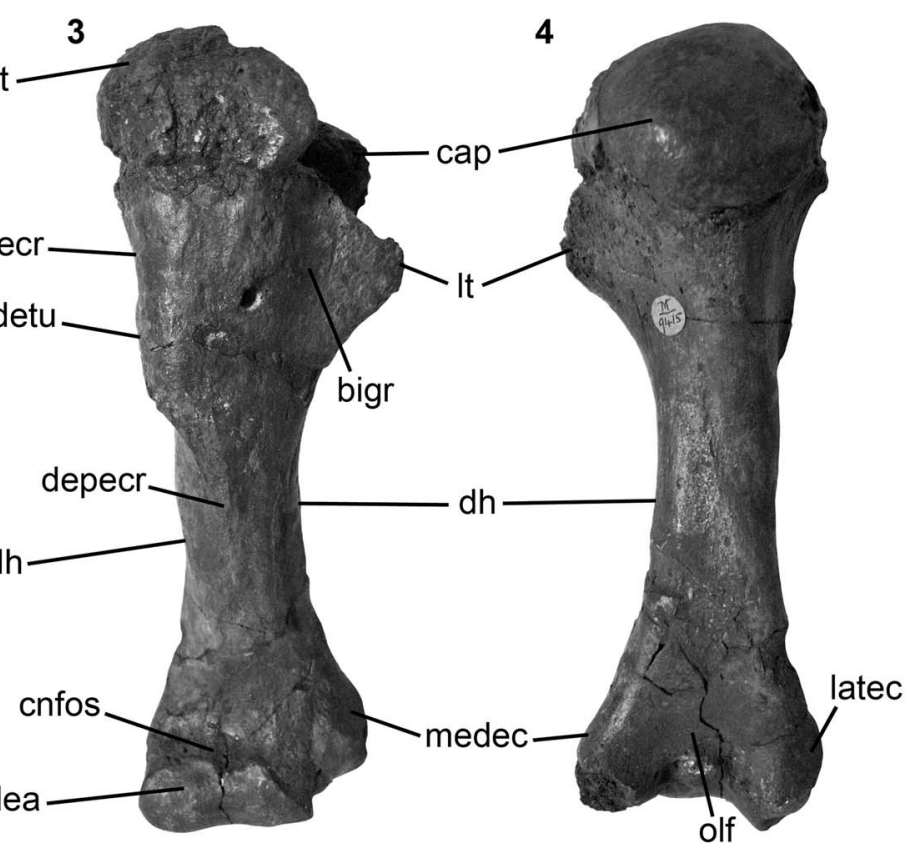

6

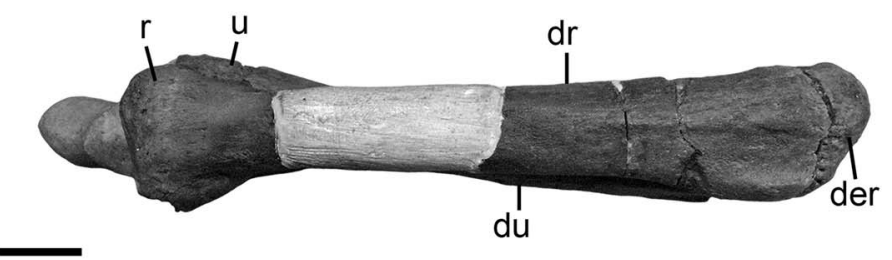

Figure 7. Stylopodium and zeugopodium of Kaupitherium gruelli $\mathrm{n}$. gen. n. sp.: (1-4) right humerus of NHMUK PV M9415 in (1, 2) lateral (1 = photograph; $\mathbf{2}=$ drawing), (3) anterior, and (4) posterior views; $(\mathbf{5 , 6})$ right radius and ulna of HLMD-WT 420 in (5) lateral and (6) anterior views (white areas indicate either missing or reconstructed parts). Anatomical abbreviations indicated in text. Scale bars are $2 \mathrm{~cm}$.

three-rooted molariform tooth, indicating that no replacement occured at this locus. DP5 is heart-shaped in outline, but smaller than M1. Proto- and metaloph and an anterior cingulum are usually observable.

Upper molars show the highest degree of tooth wear on M1 and the lowest degree on M3. Only in very old individuals like BSPG 1956 I 540 are the occlusal surfaces of M1-3 uniformly flattened and concave (Fig. 3.1, 3.2). Size of the molars is not reduced relative to the skull, but increases in the distal direction within the tooth arcade, M3 being the largest molar. Molars are morphologically similar with roughly heart-shaped crowns, whose lingual sides are pointed. Roots always consist of a mesiolabial, distolabial and lingual part. Enamel is smooth and 2 mm thick. M1 is heavily worn in all specimens, but both M2s of FIS M2597 (Fig. 5.4) and NHMUK PV M9415 still reveal the cusp pattern. Protoloph forms a transverse row of paracone, protoconule, and protocone. Metaloph shows the metacone and hypocone at the same level, with the metaconule shifted towards the protoloph, obstructing the transverse valley. Transverse valley, separating both lophs, is deep and $\mathrm{V}$-shaped where it opens at the lingual and labial sides. Sometimes, its lingual and/or labial terminations bear an accessory cuspule, as on the left M2 of FIS M2597 (Fig. 4.1, 4.2). Pre- and postcingula form strong ridges that are attached lingually to the proto- and metaloph. They decrease in height and open to the labial (or buccal) side. Postcingulum is usually bicuspate. Anterior and posterior basins are about equal in size and do not exceed the maximum length of the transverse valley. On M2, the protoloph is slightly larger than the metaloph, a condition that is developed to a marked degree on M3, which has a rather elongated form. FIS M2597 (Fig. 5.4) and NHMUK PV M9415 preserve nearly unworn M3s, which are not yet fully erupted, indicating the subadult age of both individuals. M3 morphology does not strikingly differ from that of M2. Distolabial to the paracone, one or two accessory cuspules can close the transverse valley. Precingulum is cuspate, attached to the paracone, and open lingually. Anterior basin is narrow and deep. Metaconule, obstructing the transverse valley, is not a small cusp between the usually larger metacone and hypocone, but it is about as large as the adjacent cusps. Its apex slopes lingually towards the hypocone. A distinct furrow separates the hypocone and metaconule. Hypocone is somewhat set back and not on the same level with the metacone, causing a convex arrangement of the metaloph. Posterior basin is larger than the anterior one and generally enclosed by two to three cingular cusps. Postcingulum is attached to the hypocone and opens labially.

Lower dentition is best known from mandibles of NHMUK PV M9415 and MB.Ma. 52010 (Fig. 5.3). Masticating surface of the mandibular symphysis is marked by four closely spaced and shallowly concave pairs of alveoli filled with spongy bone tissue. These 


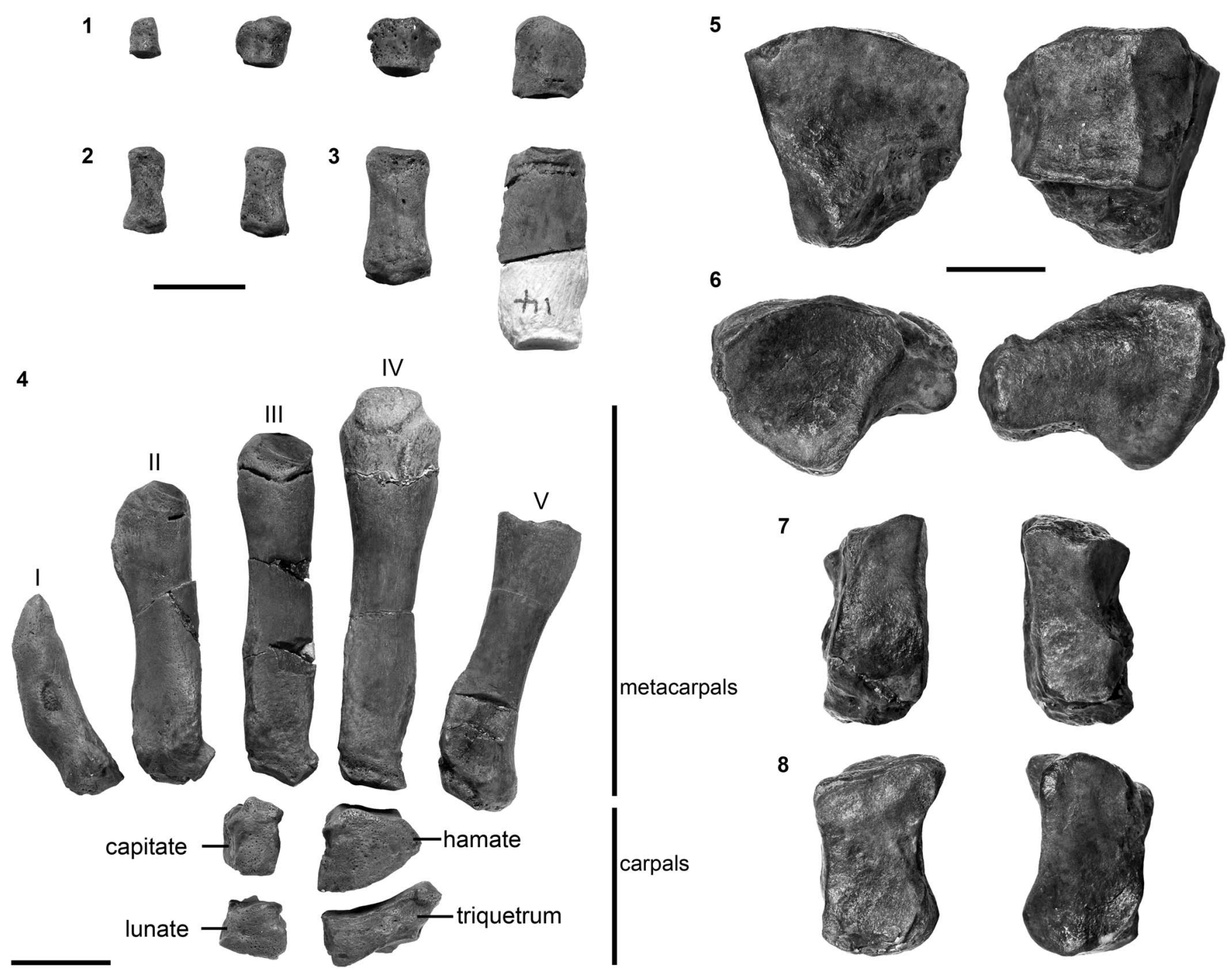

Figure 8. Autopodium of Kaupitherium gruelli n. gen. n. sp. (HLMD-WT 420): (1) distal phalanges II-V; (2) middle phalanges II-III; (3) proximal phalanges IV-V; (4) metacarpals I-V and preserved carpals (each in lateral view from left to right; white areas indicate either missing or reconstructed parts); (5) hamate; (6) triquetrum; (7) capitate; (8) lunate (each in proximal and distal views from left to right). Scale bars are $2 \mathrm{~cm}(\mathbf{1 - 4})$ or $1 \mathrm{~cm}(5-8)$.

1

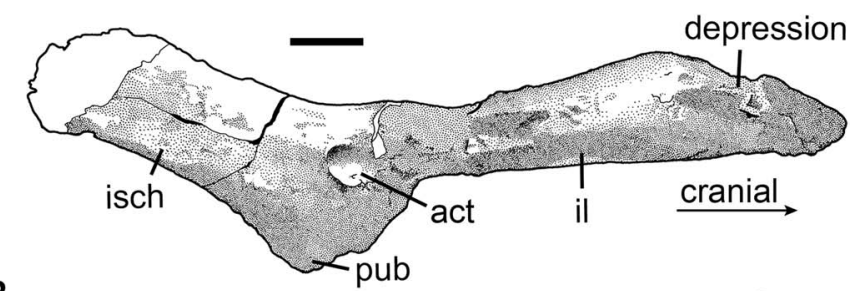

2

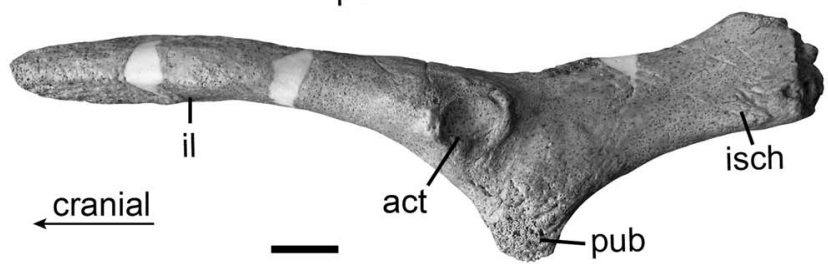

3

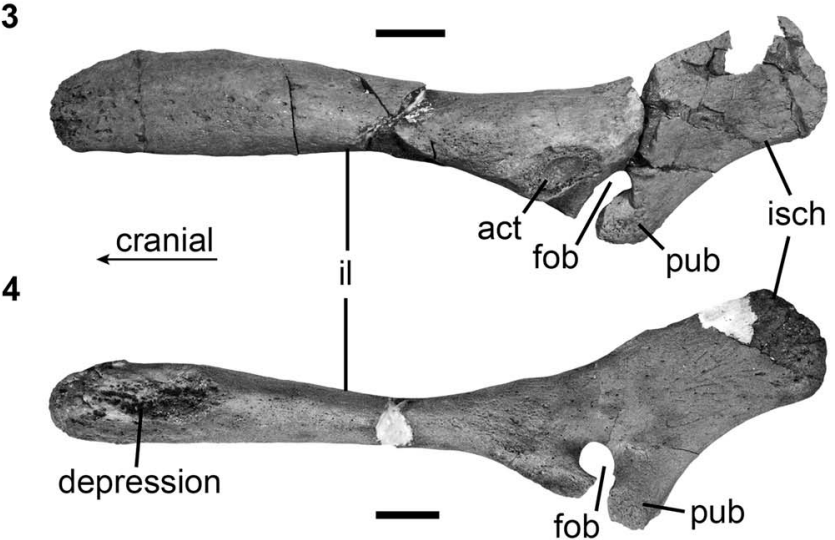

Figure 9. Innominates of Kaupitherium gruelli n. sp.: (1) drawing of NHMUK PV M9415 in right lateral and (2) photograph of MB.Ma. 52010 in left lateral views; $(\mathbf{3}, \mathbf{4})$ HLMD-WT 420 in $(\mathbf{3})$ left lateral and $(\mathbf{4})$ right medial views (white areas indicate either missing or reconstructed parts). Scale bars are $2 \mathrm{~cm}$.

depressions presumably represent the former positions of three incisors and one canine on each side, which are no longer developed in this taxon.
Presence of p2-4 is indicated by their single alveoli, which are broken out in some specimens and, therefore, not always clearly determinable. Although collections like the HLMD and the MNHM 
house numerous isolated premolars, such teeth associated with any of the investigated specimens are not known to date.

NHMUK PV M9415 preserves dp5-m3 on both sides, with dp5-m2 worn. Molars and the molariform dp5 are two-rooted with mesiodistally elongated crowns, which slightly increase in size distad within the tooth arcade. Crowns show an equally sized protolophid and hypolophid, separated by a deep transverse valley, and are higher lingually than labially. Metaconid and an accessory cuspule, connected mesiolingually to the hypoconid and obstructing the transverse valley, can be still detected on $\mathrm{m} 2$. A slight precingulum is visible at least on $\mathrm{m} 1-\mathrm{m} 2$. Hypoconulid lophule is bicuspate and encloses a distinct talonid basin. Lower $\mathrm{m} 3$ is not yet fully erupted in NHMUK PV M9415 and in a moderate state of wear in MB.Ma. 52010 (Fig. 5.3). Protolophid is slightly larger than the hypolophid. Proto- and metaconid and hypo- and entoconid are subequal in size. Anterior cingulum is indistinct anterolabially. Hypoconulid has one large cusp in NHMUK PV M9415; in MB.Ma. 52010 (Fig. 5.3), an additional and smaller cusp is present lingually. Talonid basin is variable in width. Otherwise, $\mathrm{m} 3$ resembles the preceding molars.

Vertebral column.-Fourteen vertebrae from the thoracic, lumbar, and caudal segments were already described and illustrated for NMDU-Geo 0001 (Voss, 2008), now assigned to Kaupitherium gruelli $\mathrm{n}$. gen. n. sp. Therefore, the following description is kept generalized and complemented by data obtained from (nearly) complete skeletons like NHMUK PV M9415 and BSPG 1956 I 540.

NHMUK PV M9415 most likely preserves a complete series of 55 vertebrae: seven cervicals, 19 thoracics, three lumbars, and 26 caudals. Atlas broken and attached to the occipital region. Remaining column comprises two series of articulated vertebrae separated between T17 and T18. Vertebrae are compressed and partially broken up to the level of T8.

Atlas, completely preserved in BSPG 1956 I 540, has kidneyshaped and concave cranial and caudal articular facets. Transverse processes are aliform and slope posterodorsad, bearing the foramen transversarium at their base. Articular surface for the odontoid process of the axis extends caudad and forms an oval concavity. Upper arch is broadly convex with a slight median keel and a posterior indentation for the neural spine of the axis. Axis has a prominent odontoid process, which bears a flattened and rounded facet ventrally and a roughened rostral tip. Transverse processes are hook-shaped and the foramen transversarium is oval. Anterior articular facets are suboval, higher than wide, and flat to slightly convex. Neural spine is rounded and massive, with a median keel anteriorly that terminates into a pointed rostral tip for the atlas. Spine has a median cleft posteriorly. Postzygapophyses are flattended ventrally, facing ventrolaterad. In BSPG 1956 I 540, the axis and C3 are fused in their dorsal half, so that both vertebrae are visibly separated only in lateral view. This ankylosis is a peculiar characteristic of this specimen and a deviation from the normal condition in this species, which normally comprises seven clearly distinguishable cervical vertebrae. C3-7 have anteroposteriorly flattened centra, slender and dorsally keeled neural arches, and large vertebral foramina. Transverse processes are short and hookshaped, often with small and irregular protuberances ventrally. Foramen transversarium is opened in C7 lacking a dorsolateral bony bar. Pre- and postzygapophyses lie at the same level.
Articular facets are directed dorsomediad in the first and ventrolaterad in the latter.

Thoracics have knob-like transverse processes with a ventrolateral facet for the tuberculum of the corresponding rib. Neural arch surrounds a keyhole-shaped vertebral foramen in the majority of thoracics. On T1-3, it is distinctly larger, resembling those of the preceding cervicals. Neural spines are keeled anteriorly and concave posteriorly, sometimes with a thin median crest, and have roughened summits, forming a more or less triangular tuberosity. Those of T1-3 are narrower craniocaudally than in the following thoracics, strongly elongated dorsoventrally, and pointed. A distinct caudad inclination of the neural spines starts from T6. Caudad slope slightly decreases from T15 onwards, where the neural spines also reach their maximum craniocaudal extension. Prezygapophyses are dorsally flat and horizontally directed. Mammillary processes are short, but distinct. Postzygapophyses are backward-pointed and flat ventrally.

Except for the mammillary processes, the neural arches of the lumbars do not differ from the posterior thoracics. Neural canals are suboval, wider than high. Neural spines are keeled anteriorly and posteriorly. Third lumbar is interpreted as sacral vertebra, because its transverse processes are roughened ventrally and have a thickened, blunt distal end for the attachment of the pelvic ligaments.

Anterior caudals are slightly heart-shaped, the more posterior ones are either elliptical or hexagonal. Starting with $\mathrm{Ca} 9$, the transverse processes no longer originate from about the middle of the centrum, but from its upper third. Transverse processes of Ca1-4 are similar to the lumbars in transversal length and horizontal extension. From $\mathrm{Ca} 5$ onwards, they progressively sweep back, extending up to or passing the level of the caudal epiphysis, become nearly parallel to the midline between $\mathrm{Ca} 9$ and $\mathrm{Ca} 13$, straighten again at $\mathrm{Ca} 14$ and are perpendicular to the horizontal body axis from $\mathrm{Ca} 16$ to $\mathrm{Ca} 23$. Transverse processes are slight lateral extensions on $\mathrm{Ca} 24-26$. Neural spines are moderately high, with a mid-cranial keel and a slight cleft posteriorly in the more anterior caudals. Otherwise, the spine descends straight downward or forms a mid-caudal keel. Distinct inclination of the neural spine begins with $\mathrm{Ca} 4$ and increases continuously caudad. Ca20-26 lack a neural arch and a real vertebral canal. Ca1-2 still bear short and pointed postzygapophyses that are absent on the remaining ones.

Chevrons.-Complete series not preserved in any specimen. Four isolated halves, which may have been articulated, but not fused with their counterparts, and one pair are known from HLMD-WT 420. They are roughly Y-shaped or U-shaped. Ventral edges are broader than the dorsal ones, and both are thickened and rugose.

Ribs.-Do not significantly differ from NMDU-Geo 0001 (Voss, 2008). Complete series is preserved in BSPG 1956 I 540 and NHMUK PV M9415, including 19 left ribs and most of their right complements. Overall shape either can be slender, with wide intercostal spaces (NHMUK PV M9415) or thick and nearly touching along their shafts (BSPG 1956 I 540, NMDUGeo 0001). Cranial- and caudalmost elements differ from the otherwise uniform morphology. R1 (Fig. 6.1, 6.2) articulates with $\mathrm{C} 7$ and $\mathrm{T} 1$ and bears a protuberance below the capitulum for the origin of the musculus longus capitis. Distal end is 
extended mediolaterally, in some specimens (BSPG 1956 I 540) to a remarkable degree, and has a rugose concavity for cartilage attachment to the sternum. R2-R3 are medium-sized, truncated and concave distally, and probably were also connected to the sternum. From R4 onwards, the ribs are convex and smooth distally and most likely had no sternal connection. Capitulum and tuberculum are distant from each other on R1-6, reflecting the significant length of the collum (i.e., the neck of the rib). R16 also show a distinct angle that is kept in R4-6 through the total length so that their shafts are strongly bent inward. Capitulum and tuberculum come progressively closer on R7-18. Their angle is less distinctly developed and the shaft is mediolaterally compressed about midlength. Ribs are elliptical in cross section and reach their maximum craniocaudal width and mediolateral thickness in their distal third. R19 is the shortest of all ribs, with its capitulum and tuberculum virtually fused.

Sternum.-Only the manubrium is known and preserved in LS RLP PW 2005/5042-LS (Fig. 6.4) and FMD SRK Eck 124. It is elongated anteroposteriorly and flattened to slightly concave dorsally. Ventral side is slightly convex and sometimes has a knoblike convexity anterocentrally, but a real median sternal keel is not developed. Lepsius (1882, pl. 6, fig. 63) figured a manubrium (HLMD-WT Az12) that was found in the same deposits as Kaupitherium gruelli n. gen. n. sp. and shows ventrally a distinct median keel. However, this find is isolated and looks distorted, or probably is asymmetrical, as sirenian sterna sometimes are, and therefore is not further considered here. In the juvenile FMD SRK Eck 124, the cranial half is somewhat narrower than the caudal one, ending in a bluntly rounded and straight anterior margin. Manubrium of LS RLP PW 2005/ 5042-LS keeps a more or less constant mediolateral width along its length and has a smoothly convex cranial end (Fig. 6.4). In either case, an anterior tongue-shaped process as outlined by Furusawa (2004) is not developed. Articulation facets for R1 are large and rugose laterocentrally in LS RLP PW 2005/5042-LS, where the bone reaches its greatest width. Posterolaterally, the articulation (demifacet) for R2 is preserved on the right side. Caudal margin is straight to concave and thickened for the cartilaginous attachment to the supposed corpus, indicating that the sternum of $K$. gruelli $\mathrm{n}$. sp. is definitively composed of more than one element. Most likely, it resembles that of $K$. bronni, comprising also a compact corpus and an elongated xiphisternum.

Scapula.-Slender and sickle-shaped with a smooth lateral surface divided by a short and straight scapular spine (Fig. 6.3). A proximal rugosity (tuber spinae) is not developed and the spine is slightly caudad-inflected, running diffusely out about half the length of the blade. Spine is either low and smoothly rounded (NHMUK PV M9415), or it is more elevated above the outer surface and somewhat sharpened (MNHM PW 1991/ 66-LS; Fig. 6.3). Acromion is missing in most specimens and broken in MNHM PW 1991/66-LS, but still attached to the spine, extending up to the level of the neck (i.e., the collum scapulae), and ending in a smoothly convex tip. Supraspinous fossa is smoothly concave and wider than the infraspinous fossa. Coracoid process is blunt and moderately sized, inflected mediad, and not separated from the anterior apex of the articular glenoid. Glenoid cavity is large, moderately concave, and oval. Costal surface is flat to smoothly concave.
Humerus.-Compact element with distinctly developed epiphyses and preserved in NHMUK PV M9415 (Fig. 7.1-7.4), HLMD-WT 420, and MNHM PW 1991/66-LS. Greater tubercle is elevated above the caput and continues distad into the deltoid crest (Fig. 7.1, 7.2). Deltoid crest overhangs laterally (Fig. 7.3), forming a marked deltoid tuberosity, and tapers into a narrow deltopectoral crest at about half the length of the shaft. Caput is rounded and flanked distomedially by the lesser tubercle. Articulation facet for the radius and ulna is bisymmetrical and nearly perpendicular relative to the proximodistal axis. Coronoid and olecranon fossae are distinct and deep (Fig. 7.3, 7.4).

Radius and ulna.-Right elements of HLMD-WT 420 are incompletely preserved (Fig. 7.5, 7.6). Both are fused proximally and distally. Radial and ulnar distal epiphyses are separated from the diaphyses by visible sutures. Epiphyses are trapezoidal and bear the articular facets for the adjacent carpals. Shallow grooves for extensor digiti quinti and extensor carpi radialis tendons are present on the laterodistal end of the ulna and anterolaterally on the distal end of the radius, respectively, as well as on the adjacent epiphyses. Diaphysis of the ulna does not extend as far distally as that of the radius, but the ulnar epiphysis is longer than that of the radius, so that both bones terminate at the same level. Anteroposterior thickness of the ulnar diaphysis exceeds that of the radius, but the transversal length of both is similar below the level of the proximal ends.

Manus.-Rarely preserved and only known from HLMDWT 420. Neumann (1936) described the incomplete autopodium of two lower Oligocene specimens from Flörsheim (western Germany). While his "skeleton II" (Neumann, 1936, p. 258) was no longer available for personal investigations in the FIS due to its presumed loss in WWII, his "skeleton I" was in part accessible in Mainz (MNHM PW 1910/1). Identification of the latter as belonging to $K$. gruelli $\mathrm{n}$. sp. is not certain due to distortion and damage by fire, however, it gives a benchmark for the following description. Kaiser's (1974) terminology is applied here in order to avoid confusion in the use of different terms for the same parts. HLMD-WT 420 preserves 17 elements from the right side, comprising four carpals, five metacarpals, and eight phalanges (Fig. 8). Carpals are arranged in a proximal and a distal row, each consisting of originally three single elements, of which the fused trapezium-trapezoid, scaphoid, and pisiform are missing as well as four phalanges.

Triquetrum (Fig. 8.6) is discoid and articulates with the ulna proximally, hamate and metacarpal $\mathrm{V}$ distally, pisiform posteriorly (on the ulnar side) and lunate anteriorly (on the radial side). Ulnar facet is triangular and saddle-shaped and smaller than the one for the hamate, which is nearly flat and subtriangular. The latter is continuous with the facet for metacarpal V, which is narrow and suboval and overlaps on the lateral side. Stripshaped area of 7-9 $\mathrm{mm}$ is present laterally. Ulnar side bears an irregularly shaped concavity for the pisiform. Anterodistally, a narrow, mediolaterad-extending ridge articulates with the lunate.

Lunate (Fig. 8.8) resembles a cuboid. Proximal facet for the radius is nearly flat and delimited by roughly parallel-extending edges. Attachment for the capitate is kidney-shaped, with a smooth s-shaped flexure, slightly convex laterally and concave medially. Ulnar side is trapezoid and bears distally a narrow and elongated facet for the triquetrum, which is continuous with that 
for the capitate. A less-distinct facet for the scaphoid is present proximally on the radial side and is continuous with that for the radius. Medial or volar side is smoothly convex, whereas, the lateral side has a smooth, but uneven surface.

Hamate (Fig. 8.5) is wedge-shaped and essentially articulates with the triquetrum proximally, capitate anteriorly, and metacarpals III, IV, and V distally. Proximal facet is the largest of all, roughly triangular and slightly concave; a very small articulation for the lunate is present anteromedially. On the distal side, three continuous facets meet each other at angles between $130^{\circ}$ and $135^{\circ}$, all being slightly concave. Articulation for metacarpal IV is the largest and roughly rectangular. Facet for metacarpal III is mediolaterally elongated and that for metacarpal V is trapezoid and the smallest of all facets. Radial side bears proximally a mediolaterally elongated and irregularly shaped facet for the capitate; a second, distal, facet forms a slight ridge for metacarpal III. Medial and lateral sides are convex, with the first being knob-like and uneven and the latter smooth-surfaced.

Capitate (Fig. 8.7) is overall trapezoid and articulates with the lunate proximally, metacarpal III distally, trapezium-trapezoid and metacarpal II anteriorly, and hamate posteriorly. Proximal facet is nearly flat. Distal articulation is slightly concave, having a weak ridge for the hamate posteriorly. Radial surface is tripartite, with a $4 \mathrm{~mm}$ wide band for the trapezium-trapezoid extending along the proximal margin, and distally, a larger lateral and smaller medial semicircular facet for metacarpal II, which are continuous with that for metacarpal III. Ulnar side bears a proximal and distal facet for the hamate. Lateral side is flat to slightly convex, the medial side is knob-like and uneven.

Metacarpals (Fig. 8.4) are elongated with simple facets for the phalanges distally, except for metacarpal I, which terminates in a blunt conical tip and appears to have not been attached to a phalanx. It measures $39 \mathrm{~mm}$ in total length, is curved in the ulnar direction forming a distinct ridge anteriorly, and is triangular in cross section. Diaphysis and proximal epiphysis are fused, with the suture still visible on the volar side. Metacarpal II is $56 \mathrm{~mm}$ long, smooth-surfaced, but moderately rugose on its proximal end. Lateral side is less concave than the medial side. Radial side shows a longitudinal ridge that rises distally into a blunt tuberosity. Ulnar side forms a gentle, distad-extending keel at about half the length of the diaphysis. Proximal end is triangular in cross section and articulates with metacarpals I and III, the trapezium-trapezoid, and capitate. Metacarpal III measures $65 \mathrm{~mm}$ in length and differs only slightly from metacarpal II in that it is rectangular to trapezoid in cross section proximally, and elliptical centrally and distally. Two proximal and continuous articulation surfaces meet at an angle of $\sim 120^{\circ}$; they are nearly rectangular and flat. Distal epiphysis is connected with the diaphysis by a clearly visible suture. Metacarpal IV is $58 \mathrm{~mm}$ in preserved length lacking the distal epiphysis, which is reconstructed in Figure 8.4 and was most likely shorter than it appears, considering the epiphyseal length in metacarpals II and III. It resembles metacarpal III as supposedly does the size, considering the distal epiphysis to be included. Metacarpal V also lacks its distal epiphysis and is $55 \mathrm{~mm}$ long. It is mediolaterally flattened, suboval in cross section, and bears posteroproximally an extension for the pisiform.
Eight of originally 12 phalanges are preserved (Fig. 8.1-8.3). Digits II-V each preserves the distal phalanx forming a small, plate-like bone. Digit II has a $19 \mathrm{~mm}$ long middle phalanx with a nearly flat lateral and a concave medial side. Facets for the adjacent proximal and distal phalanges are small and subcircular. Distal phalanx is the smallest of all, measuring $9 \mathrm{~mm}$ in length. Proximal articulation surface is oval. It is somewhat shorter anteriorly than posteriorly, producing an oblique distal margin. Phalanges of digit III only differ in size from those of digit II, with the middle phalanx $20 \mathrm{~mm}$ long and the distal one about as long as wide, measuring $11 \mathrm{~mm}$ in maximum dimensions. Proximal phalanx of digit IV is $29 \mathrm{~mm}$ long, but otherwise resembles the latter. Distal phalanx is wider than long $(15 \mathrm{~mm} \times 11 \mathrm{~mm})$ and terminates in a more or less straight margin. Digit $\mathrm{V}$ preserves a $29 \mathrm{~mm}$ long distal part of the proximal phalanx, indicating that it is the largest of all the phalanges. This is in accord with Neumann (1936, p. 273), who gave a maximum length of $41 \mathrm{~mm}$ for it. Bone is semicircular in cross section and mediolaterally flattened. Laterally, the distal epiphyseal suture is visible. Facet for the distal phalanx is flat and semicircular. Distal phalanx is slightly longer than wide $(17 \mathrm{~mm} \times 15 \mathrm{~mm})$ and longer anteriorly than posteriorly, causing an inclination of the distal margin. Both phalanges of digit V have flat volar and slightly convex lateral sides.

Innominate.-Known from NHMUK PV M9415 (Fig. 9.1), BSPG 1956 I 540, MB.Ma. 52010 (Fig. 9.2), PMN SSN12EC55, and HLMD-WT 420 (Fig. 9.3, 9.4). The latter are also illustrated in Schmidtgen (1912, pl. 29, figs. 4, 5). This sample reflects a uniform morphology lacking distinct intraspecific variation. Ilium, ischium, and pubis are firmly fused in adults, but loosely connected with each other in juveniles, as can be inferred from an isolated ilium in FMD SRK Eck 124. Ilium is elongated, slender, and rounded in cross section. Proximal end is slightly swollen with a $20-30 \mathrm{~mm}$ long depression dorsomedially that serves as attachment of the ligaments for the sacral vertebra. Pubis is short and triangular, with a moderately rugose ventral tip. Acetabulum is round and distinctly concave. Ischium is transversally flattened, plate-like, and the widest element due to its oblique dorsoventral expansion. Distal end is somewhat thickened with a rugose area. Pubis is inflected mediad while the ischium inclines laterad. Foramen obturatum is generally not developed, but present ventroposterior to the acetabulum in HLMD-WT 420 (Fig. 9.3, 9.4), indicating individual variation and an observation reminiscent of Metxytherium krahuletzi (Domning and Pervesler, 2001, pl. 19, fig.1). Anteroventral margin of both foramina is broken out, but its maximum dimensions amount to about $5 \mathrm{~mm} \times 7 \mathrm{~mm}$.

Femur.-A number of isolated femora are known from different collections (e.g., HLMD, MNHM, IRSNB), but none of these is associated with skeletal remains enabling a clear taxonomic assignment to $K$. gruelli n. sp. Femora are slender with rounded proximal epiphyses and tapered distal ends lacking any articulation for the zeugopodium. This is in accordance with the pelvic morphology and the acetabulum size allowing the indirect determination of a vestigial femur.

Etymology.- - In honor of Dieter Grüll, who discovered several of the specimens of this new species and other relevant sirenian finds from the Mainz Basin. 
Materials.-For detailed listing of the referred specimens and their preserved skeletal parts see Supplementary data set 1; Supplementary data set 2 provides measurements.

Remarks.-Kaupitherium gruelli n. gen. n. sp. differs from $K$. bronni (Krauss, 1858) in that the infraorbital foramen is oval, distinctly higher than wide; frontal processes of parietal are short, do not exceed half the length of frontal roof; cranial roof is elongated relative to the transversal extent of the supraoccipital; lacrimal contacts premaxilla; external occipital protuberance and external occipital crest are prominent; and P2/p2 are present.

As depicted by Voss (2014), "Halitherium" kaupi Krauss, 1858 is neither used as the oldest available junior synonym to replace the invalid taxon name " $H$. schinzil" nor is its type specimen considered as a potential neotype. The holotype of " $H$." kaupi is merely composed of an incomplete and poorly preserved skull cap and, most importantly, belongs to a juvenile that shows mainly undiagnostic features. Therefore, it is difficult to unambiguously distinguish this specimen from other sirenian taxa and hence it is not considered as a suitable holotype defining the new species proposed here. However, because only two sympatric species are hypothesized herein for this particular stratigraphic and geographic range, this juvenile specimen is referred to K. gruelli n. sp. Although most features would be consistent with both sympatric species, the main reason for this assignment is the similar supraoccipital morphology differing clearly from that of $K$. bronni.

\section{Kaupitherium bronni (Krauss, 1858)}

Figures 10-16

1853-1858 Halitherium schinzi; Bronn, p. 1130, pl. 48, fig. 9. 1856

1858 Halitherium bronni Krauss, p. 530, pl. 20, figs. 1-4.

1934 Halitherium schinzi Kaup forma delheidi; Sickenberg, p. 271, text-fig. 2 b.

1982 Halitherium schinzi; Fischer and Krumbiegel, p. 73, photo 1.

2012 Halitherium sp.; Voss, p. 207, text-figs. 2-10.

Holotype.-SMNS 1539, a natural endocranial cast and associated skull roof comprising the frontal, parietal, and supraoccipital, both nasals broken in the median plane, and remnants of the ethmoid and vomer from the Alzey Formation of the Selztal-Group (lower Oligocene) from Flonheim (Mainz Basin, western Germany).

Occurrence.-Known only from lower Oligocene deposits of the Mainz Basin, Germany (Alzey Formation and Hochberg Member of the Bodenheim Formation); the southern Münsterland, western Germany (upper Ratingen Member); the Bay of Leipzig, eastern Germany (phosphorite nodule horizon of the Böhlen Formation); and the Antwerp and East Flanders provinces, northern Belgium (Boom Clay Formation).

Description.-The following description emphasizes differences from $K$. gruelli $\mathrm{n}$. sp. and mainly complements the knowledge on the morphology of $K$. bronni, where still not available in the description of a specimen now assigned to that species provided by Voss (2012).
Premaxilla.-Nasal processes are thin and taper at their posterior ends, with lengthy overlap of the frontals and nasals, but, in contrast to $K$. gruelli n. sp., do not contact the lacrimal (Figs. 10.1, 10.2, 11.2). Symphysis is strongly downturned forming an angle with the horizontal plane of $\sim 57^{\circ}$.

Nasal.-Krauss (1858, pl. 20) depicted the nasals of the holotype in a more complete condition than they are preserved at present. While both elements are now separated in the midline (Fig. 11.3, 11.4), they are shown to have met in the midline posteriorly in Krauss (1858). This is in accord with the condition visible in MB.Ma. 52009 (Fig. 10.1, 10.2), indicating an internasal suture that extends less than half the length of the interfrontal suture.

Ethmoidal region.-Ethmoidal region is comparable to the conditions in $K$. gruelli n. sp. and quite well preserved in the holotype specimen (SMNS 1539; Fig. 11.4). Mesethmoid forms a prominent perpendicular plate that measures $10 \mathrm{~mm}$ to $15 \mathrm{~mm}$ in width, becoming narrower dorsally, ventrally, and posteriorly. Cribiform plates of the exethmoids are clearly visible on the holotype and deeply recessed from the cranial cavity, forming oval depressions for the olfactory bulbs. Ethmoturbinal is large and flanks the frontal medially below the nasal. A thin lamina papyracea is preserved on the lateral side of the ethmoturbinal and also on the ventromedial side of the supraorbital process of the frontal.

Vomer.-Clearly visible on the ventral side of the holotype (Fig. 11.4), though incompletely preserved. It forms a V-shaped bone as in other sirenians and is firmly fused with the ethmoid dorsally. Contact with the presphenoid can be judged from specimen MB.Ma. 52009, where the vomer is visible through the orbit (Fig. 11.2) due to damage of the lateral frontal wall. Dorsal longitudinal groove of the maxilla that housed the anterior extension of the vomer is competely preserved in MB.Ma. 52009 and clearly visible through the mesorostral fossa (Fig. 10.1, 10.2).

Lacrimal.-Both elements preserved in MB.Ma. 52009, with a maximum anteroposterior length of $33 \mathrm{~mm}$ and a lacrimal foramen of $3.7 \mathrm{~mm}$ in maximum diameter (Fig. 11.2). It is not in contact with the premaxilla because the maxilla is interposed, reaching up to the anterior tip of the supraorbital process of the frontal. This condition is best visible on the left side in specimen MB.Ma. 52009 (Fig. 10.1, 10.2), where the lacrimal is completely preserved including a distinct nasolacrimal canal.

Frontal.-Internasal process is small and slightly projects between the nasals posteriorly (Fig. 10.1, 10.2). Temporal crests vary as in $K$. gruelli $\mathrm{n}$. sp. between types C, D, and E (Domning, 1988 , p. 405). Intertemporal constriction is also variable, but strong (i.e., the cranial roof is distinctly narrower than the cranial cavity) and reaches its maximum at about the center of the skull roof (i.e., on the parietal portion).

Parietal.-Parietal roof usually flat between the prominent and lyriform temporal crests (Fig. 11.3, 11.6); in specimens of advanced age, such as MB.Ma. 52009 (Fig. 10.1, 10.2) and SMNS 47736, the parietal roof tends to be concave between high temporal crests. In contrast to K. gruelli n. sp., the frontal processes of the parietal are long and exceed half the length of the interfrontal suture. Overall proportions of the cranial roof indicate a slight brachycephaly according to the ratio $1_{\mathrm{FP}} / \mathrm{w}_{\mathrm{SO}}$, which is 1.93 in the holotype and MB.Ma. 52009. Internally 
1

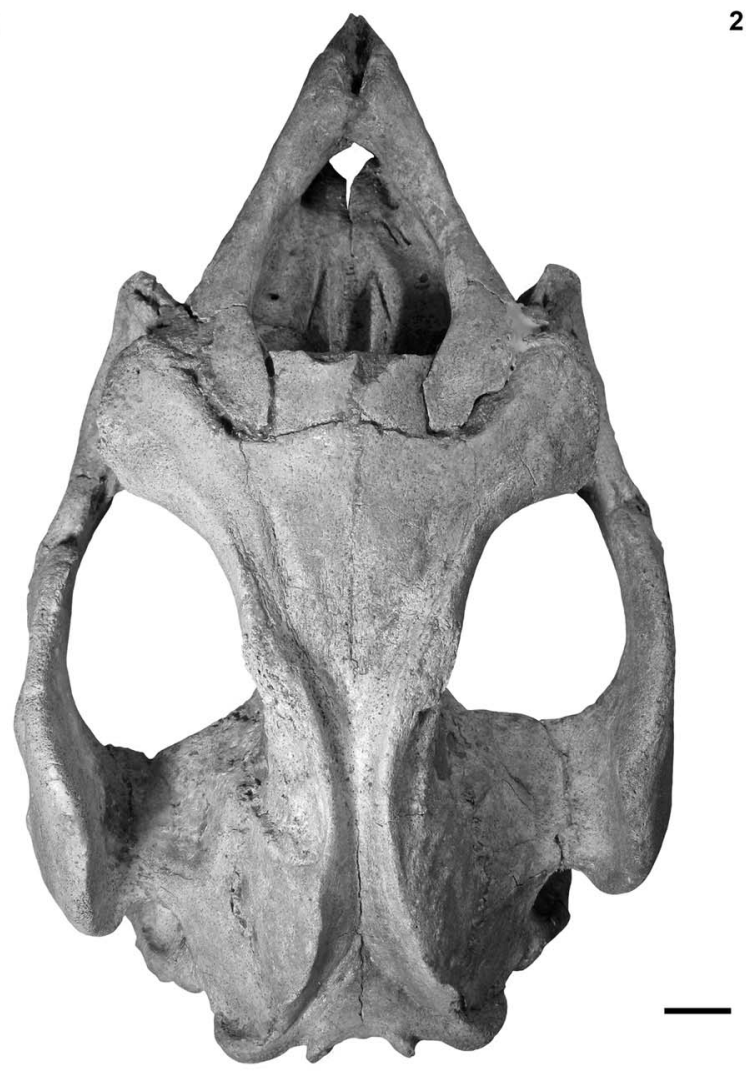

3

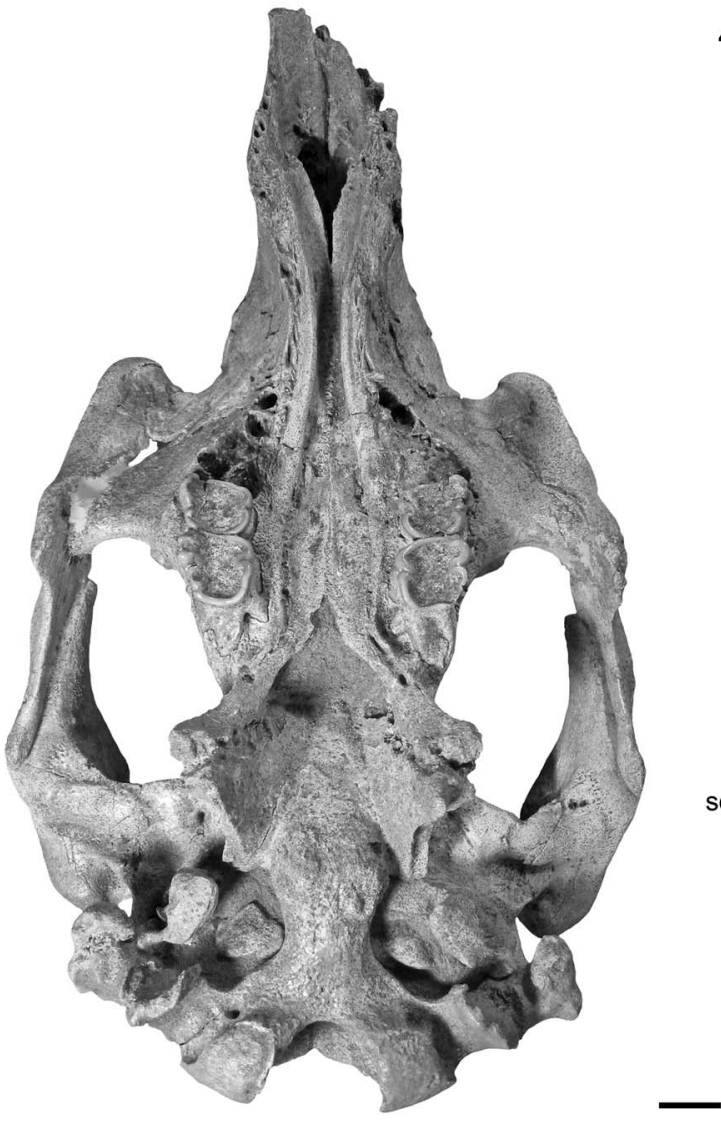

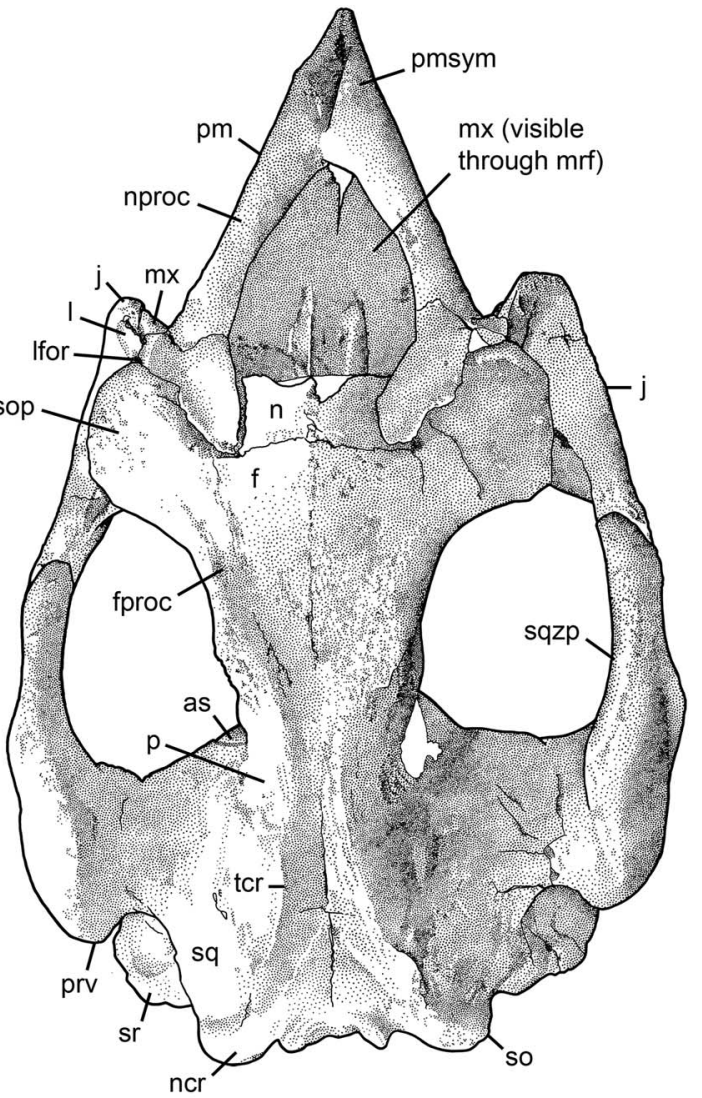

4

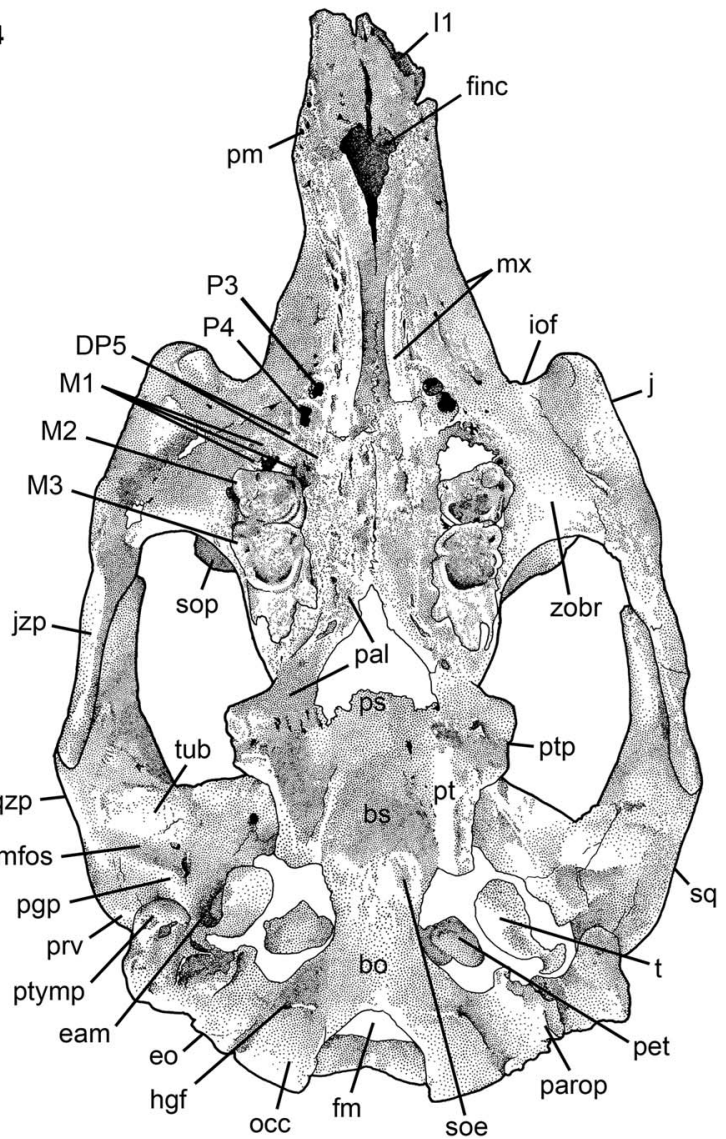

Figure 10. Cranium of Kaupitherium bronni (MB.Ma. 52009): $(\mathbf{1}, \mathbf{2})$ dorsal and $(\mathbf{3}, \mathbf{4})$ ventral views $(\mathbf{1}$ and $\mathbf{3}=$ photograph; $\mathbf{2}$ and $\mathbf{4}=$ drawing; white areas indicate either missing or reconstructed parts, or matrix). Scale bar is $2 \mathrm{~cm}$. 
1

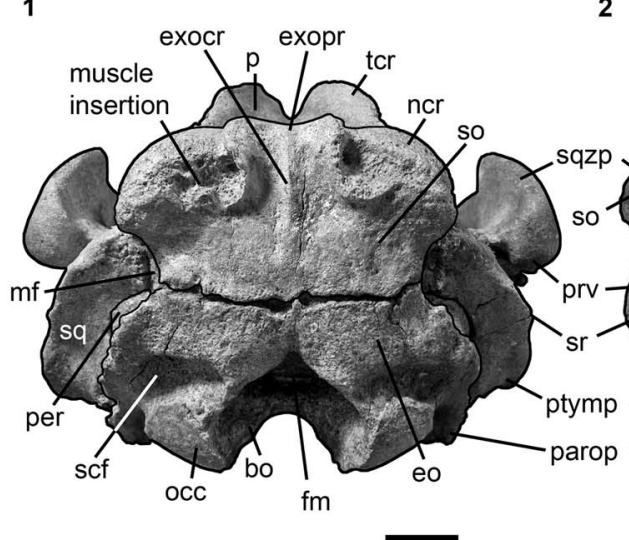

2

3
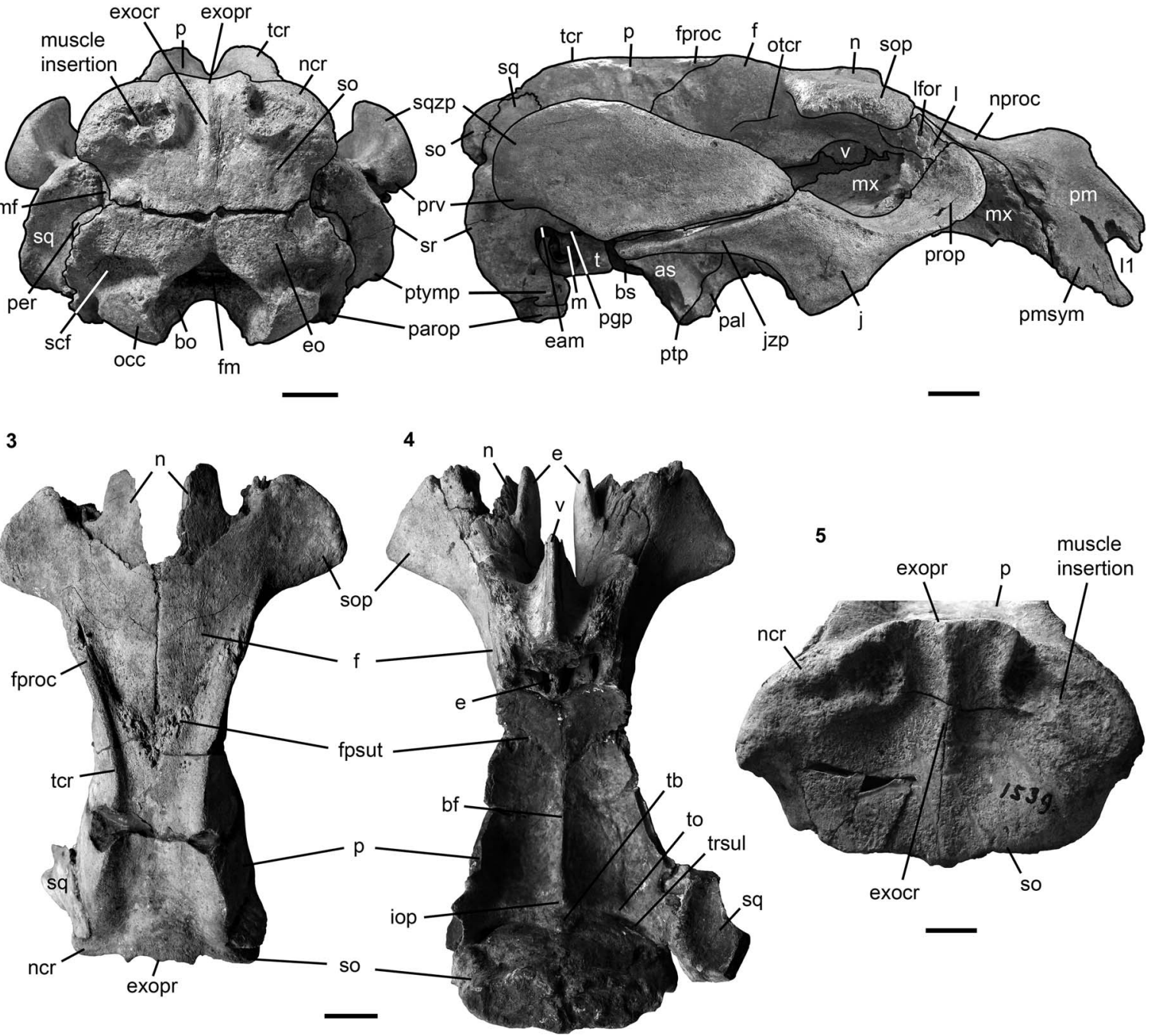

6

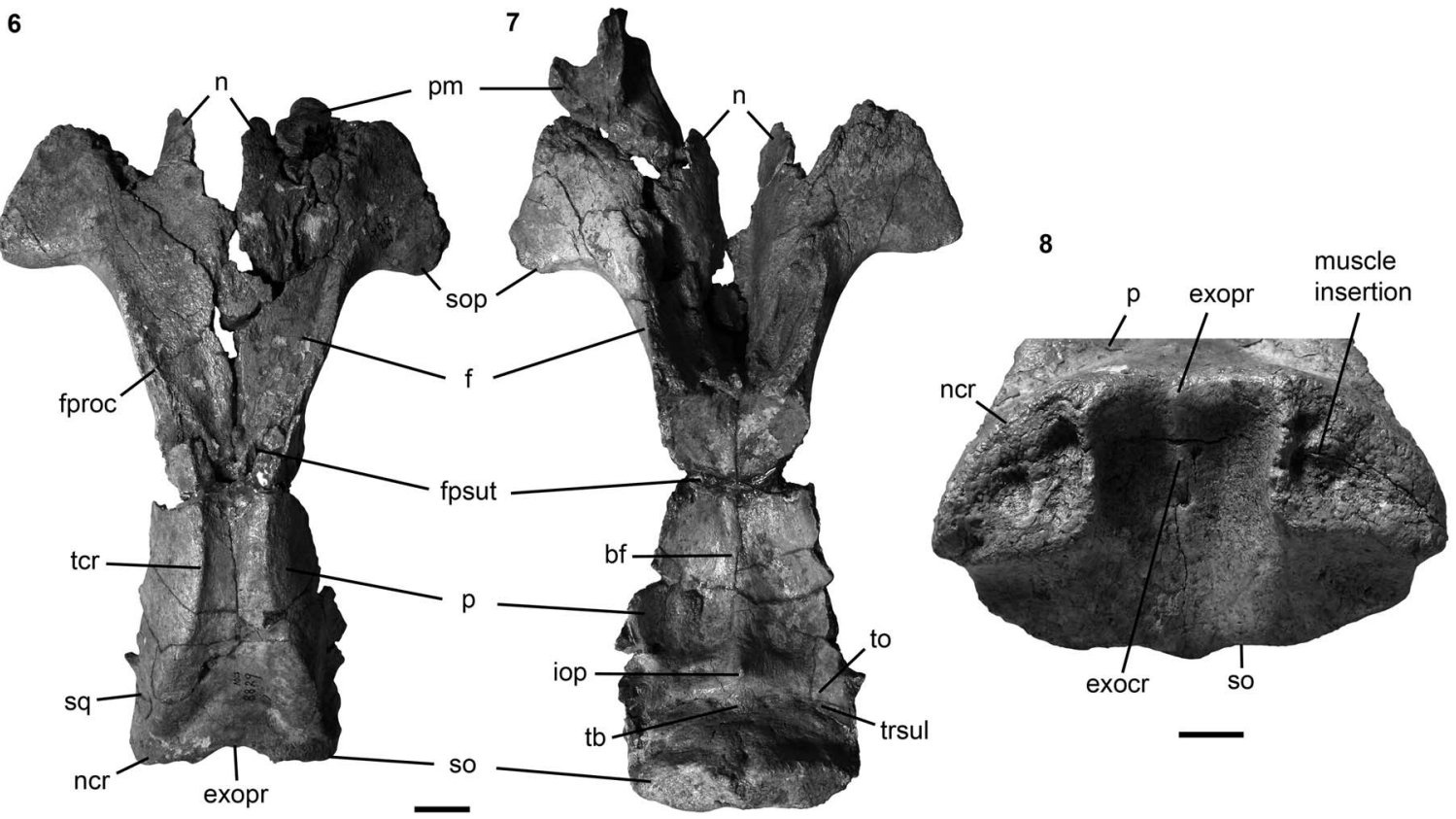

Figure 11. Crania of Kaupitherium bronni: (1, 2) MB.Ma. 52009 in (1) caudal and (2) right lateral views; (3-5) holotype SMNS 1539 in (3) dorsal, (4) ventral and (5) caudal views; (6-8) MCZ 8829 in (6) dorsal, (7) ventral and (8) caudal views. Anatomical abbreviations indicated in text. Scale bars are $2 \mathrm{~cm}(\mathbf{1 - 4 , 6 , 7 )}$ or $1 \mathrm{~cm}(\mathbf{5 , 8})$. 
(Fig. 11.4, 11.7), the tentorium is prominent, with a triangular bone element always present in the median plane, but a median ridge crossing the transverse sulcus as in $K$. gruelli n. sp. has not been observed in the investigated sample.

Occipital region.- Supraoccipital bears a convex nuchal crest that terminates in thickened dorsolateral ends. Nuchal crest has a distinct notch medially, but without the supraoccipital projecting onto the cranial roof (Figs. 10.1, 10.2, 11.1, 11.3, $11.5,11.6,11.8)$. External occipital protuberance is weakly developed, never rises above the level of the parietal roof, and is not differentiated from the external occipital crest. The latter forms a median ridge that can be either distinct (SMNS 1539; Fig. 11.5) or low (e.g., MCZ 8829; Fig. 11.8), and diffusely flattens out about halfway down the external lamina. Both the external protuberance and crest are distinctly indented (e.g., MCZ 8829 [Fig. 11.6, 11.8], IRSNB 8289), though to a lesser extent in the type specimen (SMNS 1539; Fig. 11.3, 11.5) due to the rostrad notching of the nuchal crest and usually do not exceed the level of the medial edges of the muscle insertions. Comparable to the observations in some representatives of $K$. gruelli $\mathrm{n}$. sp., a nutrient foramen is visible at about mid-length of the external occipital crest in MCZ 8829 (Fig. 11.8) and QB 4/12.721 (Voss, 2012, fig. 3). Ventral margin of the supraoccipital is slightly pointed medially, forming an angle of $\sim 140^{\circ}$ between the sutural surfaces for the exoccipitals (SMNS 1539 [Fig. 11.5], MB.Ma. 52009 [Fig. 11.1], and MCZ 8829 [Fig. 11.8]). Endocranially (Fig. 11.4, 11.7), the parietooccipital suture is indicated as a deep transverse sulcus. Relief below the sulcus is relatively flat, with a narrow furrow in the median plane and terete bulges dorsolateral to it. Exoccipital and basioccipital like those of $K$. gruelli n. sp.

Presphenoid, basisphenoid, orbitosphenoid, alisphenoid, pterygoid, palatine.-Do not appear to differ from $K$. gruelli n. sp. Pre- and orbitosphenoid are not completely preserved in any specimen. Otherwise, the sphenoidal, pterygoid, and palatine regions are well displayed in MB.Ma. 52009 (Figs. 11.2, 10.3, 10.4). Similar to $K$. gruelli $\mathrm{n}$. sp., a small foramen is present medial to the right M3 of MB.Ma. 52009 (Fig. 10.3, 10.4).

Maxilla.-Zygomatic-orbital bridge of the maxilla (Fig. 10.3, 10.4) is anteroposteriorly long and nearly on the level of the palate. Its posterior end is thickened in comparison to the very thin anterior margin. Infraorbital foramen is small as in $K$ gruelli n. sp., but contrasts in having a round shape.

Squamosal.-Similar to K. gruelli n. sp., but strikingly particular, the sigmoid ridge rises prominently and nearly vertically up to the ventral margin of the supraoccipital as it can be seen in MB.Ma. 52009 (Fig. 11.2) and FMD SRK Eck-Rat 43. Zygomatic process shows a straight to concave posterodorsal end, which is best visible in dorsal and caudal views of MB.Ma. 52009 (Fig. 10).

Jugal.-Does not differ from that in K. gruelli n. sp.

Ear region.--Is best preserved in MCZ 8829 (Fig. 12) and MB.Ma. 52011, both comprising the whole periotic, whereby MB.Ma. 52011 additionally shows the tympanic and auditory ossicles. Periotic does not differ morphologically from $K$. gruelli n. sp. In endocranial view (Fig. 12.2), the pars canalicularis of the petrosal bears an inflated and rounded pyramid, which corresponds to the cerebral part (Robineau, 1969) that continues with the endocranial surface of the tegmen tympani.
The remaining cerebellar part is plane and rather square. Two foramina open near the anteromedial edge of the cerebellar surface, providing passage for the facial (VII) and auditory (VIII) nerves, and lie in an oval and concave area corresponding to the internal auditory meatus. The most anteromedially facial foramen is delimited by a distinct suprafacial commissure. Towards the mastoid region, in the posterolateral wall of the pyramid, a narrow and slit-like endolymphatic foramen is situated.

An isolated right tympanic with the anterior and posterior branches broken is preserved in MB.Ma. 52011, whereas MB.Ma. 52009 preserves both tympanics in situ, showing the anterior branch to be distinctly shorter than the posterior one (Fig. 10.3, 10.4). Its posterior attachment is still connected to the anteromedial side of the posttympanic process. Whole extent of the attachment surface is visible, revealing a large, oval plate that faces the mastoid posterodorsally and the top of the external auditory meatus of the squamosal anterodorsally. Imprints of the smaller and rounded anterior attachment are visible on the anteroventral side of the tegmen tympani. A ridge and groove along the proximolateral edge of the anterior branch most likely served as attachment area for the tympanic membrane.

Malleus is also preserved in situ in MB.Ma. 52009, filling the lumen of the right tympanic arch (Fig. 11.2). Laterally, a sharp vertical ridge is visible that rises from the otherwise smooth surface. Right malleus from MB.Ma. 52011 is isolated and a stout element. Its posterior end bears a convex orbicular apophysis. Processus muscularis is enlarged and massive, forming a rounded protuberance. Tip of the process appears to be separated from the anterior branch of the tympanic only by a few millimeters in MB.Ma. 52009, indicating a short musculus tensor tympani. Sharp vertical ridge on the lateral side of the malleus originates from the dorsal end of the manubrium and extends ventrad. Its anterior and posterior surfaces are flat, and the dorsal and ventral margins converge, producing a heart-shaped outline of this ridge. External edge of the manubrium is slightly convex. Articulation surface with the incus comprises two facets, a larger anterior and a smaller posterior facet, both being roughened and raised above the body of the malleus. In MB.Ma. 52011, the right incus and stapes are preserved in situ. Incus is only visible in ventromedial view, protecting the crus breve from sight, but revealing the concave articular facets for the malleus. Surface of the incudal body bears anteroventrally two slight concavities. Crus longus is short and stout. Its medial end is formed by the processus lenticularis that sharply curves inward just a few millimeters behind the corpus incudis and articulates

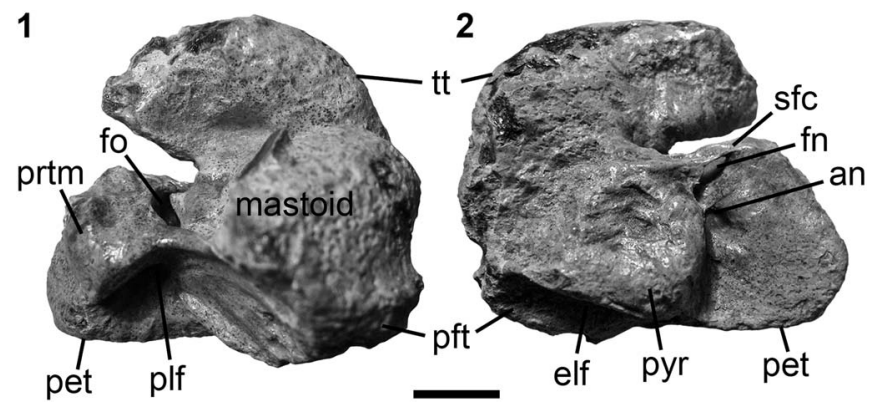

Figure 12. Left periotic of Kaupitherium bronni (MCZ 8829): (1) ventral and (2) dorsal view. Anatomical abbreviations indicated in text. Scale bar is $1 \mathrm{~cm}$. 
with the head of the stapes. Visible length of the stapes measures about $8 \mathrm{~mm}$. Stapedial foramen is well developed just lateral to the basal end, which is attached to the oval window.

Hyoid apparatus.-Not known from any available specimen assignable to $K$. bronni.

Mandible.-Mandibular morphology (Fig. 13) resembles that in $K$. gruelli n. sp.

Dentition.-Although heavily worn, FIS M8385 preserves the complete upper cheek tooth series, which appears not to differ morphologically from $K$. gruelli $n$. sp. Dental formula in the upper jaw was most likely I1, C0, P3-4, DP5, M1-3. I1 is best preserved in MCZ 8829 (Fig. 14.2), is $\sim 10 \mathrm{~cm}$ long, and extends approximately half the length of the premaxillary symphysis (Fig. 11.2). It resembles that in $K$. gruelli $\mathrm{n}$. sp. and, judging from the crown length, it protruded most likely $\sim 20 \mathrm{~mm}$ from the premaxillae.

Subadult MWNH-TER-1 (Fig. 14.3, 14.4) still has a vestigial alveolus, supposedly that of DP3, mesiolingual to both P3. That reflects the opposite of Luckett's (1993) observation that successional teeth develop only lingual to their deciduous predecessors in a wide range of therians. Sirenia that are not included in Luckett's (1993) ontogenetic assessment of dental development might represent an exception, at least in the developmental pattern of the maxillary dentition. A further, vestigial alveolus is clearly visible $\sim 10 \mathrm{~mm}$ anterior to the left P3; an indistinctly preserved one is on the right side. Both are interpreted here to represent the locus for DP2, which unlike $K$. gruelli $\mathrm{n}$. sp., is no longer replaced in this species.

MB.Ma. 52009 (Fig. 10.3, 10.4) shows the alveoli for DP5 in the state of resorption, which is best visible on the right side and in accordance to its advanced age. While the distolabial and lingual alveoli are clearly identifiable, the mesiolabial alveolus is barely present. Roots of M3 are also particular in MB.Ma. 52009, which are strongly developed with the distolabial root jutting out far from the maxilla. Upper molars (Fig. 14.1) are usually worn to such an extent that no detailed description of their cusp pattern is possible, but their preserved morphology resembles that in $K$. gruelli n. sp.

Most complete mandibles, providing information on the tooth morphology and the lower dental formula (i0, c0, p3-4, dp5, m1-3), belong to MNHM PW 1984/37-1, SMNS 47736 (Fig. 13), MAz GP 1000, and FMD SRK Eck-Rat 43. In regard to preservation, the teeth are heavily worn and their presence is mainly indicated by their alveoli. As in $K$. gruelli n. sp., the mandibular symphysis bears a spongy and roughened masticating surface with irregularly formed and shallowly concave alveoli that seem to represent the former loci of three pairs of vestigial incisors and one pair of vestigial canines. Alveoli of p3 and p4 are clearly determinable in most cases. Numerous isolated and single-rooted premolars from the lower Oligocene of Germany are housed in the collections of HLMD and MNHM, but no premolar is known to have been associated with the individuals and partial skeletons assigned to K. bronni. SMNS 47736 (Fig. 13.3, 13.4) shows a further alveolus on the right side at the beginning of the masticating that is small and has no left counterpart and is interpreted here as being vestigial. Specimen MAz GP 1000 preserves dp5 to m3 from both tooth arcades, which do not appear to differ morphologically from $K$. gruelli n. sp. Usually, the bipartite alveoli of dp5 are discernible (MNHM PW 1984/37-1, MB.Ma. 52009), but some specimens show the alveoli of this unreplaced premolar in the state of resorption (FMD SRK Eck-Rat 43, SMNS 47736). In SMNS 47736 (Fig. 13.3, 13.4), the special case of irregular resorption can be observed, because the two dp5 roots are still preserved on the right side, whereas the corresponding alveoli on the left side are already coalesced. Only the remains of the lingual bony interseptum and, deep inside the alveolus, also the interseptum from the labial side indicate that this alveolus was once divided. Indistinct remains of a precingulum are discernible at least on $\mathrm{m} 2$ and $\mathrm{m} 3$ of SMNS 47736, as well as a postcingulum enclosing a moderately wide talonid basin on $\mathrm{m} 2$ and forming a distinct hypoconulid lophule on $\mathrm{m} 3$.

Vertebral column.-A partial vertebral column is already known from QB-4/12.721 (Voss, 2012), which is now assigned to $K$. bronni, and therefore the reader is referred to the description of it. No significant morphological differences are discernible between $K$. gruelli n. sp. and $K$. bronni, and the following data complement the knowledge of K. bronni.

A putative nearly complete column is known from SMNS 47736, comprising seven individual cervicals, 20 thoracics, three lumbars, and 17 caudals. However, some postcranial elements were replaced from a second specimen and it is not certain which ones exactly (R. Ziegler, personal communication, 2013). Thus, it cannot be ascertained if the number of vertebrae, especially from the thoracic and lumbar segments, was correctly determined.

Complete cervical columns of MB.Ma. 52009 and MAz GP 1000 show the special feature of a fused axis and C3, as was already described for $K$. gruelli $\mathrm{n}$. sp., supporting the observation that this fusion occurs occasionally throughout the Sirenia (e.g., Petit, 1928; Domning, 1978, p. 86).

In contrast to 20 thoracic vertebrae assessed for SMNS 47736, specimen MAZ GP 1000 reveals only 16 thoracics. Even if 19 thoracics are taken to be generally present, as is seen in K. gruelli n. $\mathrm{sp}$. , this indicates intraspecific morphological variation comparable to the observations in extant Trichechus species (Domning and Hayek, 1986).

Number of lumbar vertebrae varies, too. In specimen MAZ GP 1000 , four lumbars with the caudalmost one serving as sacral vertebra are identified, which seems to differ from $K$. gruelli $\mathrm{n}$. sp. and SMNS 47736, but is in accordance with the observations in QB-4/12.721 (Voss, 2012).

Caudals 1-3 still have long and nearly horizontally directed transverse processes resembling those of the lumbar region. The lack of markedly roughened distal ends on their transverse processes and the presence of articulation facets for chevrons on the ventral side of the centrum distinguish those caudals from the preceding lumbars and sacral. From Ca4 onwards, the caudad inclination of the transverse processes begins. Considering the total number of 26 caudal vertebrae in $K$. gruelli n. sp., the caudal series in $K$. bronni is not completely known.

Chevrons.-A number of isolated chevron bones are known from MB.Ma. 52009; they do not differ from K. gruelli n. sp. (HLMD-WT 420).

Ribs.-Do not differ morphologically from those described for K. gruelli n. sp. and reference is made to Voss (2012), who already described and illustrated the ribs of QB-4/12.721. Ribs either are compact and voluminous with a great anteroposterior width (MB.Ma. 52009), or they are overall slender (QB-4/12.721). First rib (Fig. 15) has a ventral protuberance and a remarkable width of its distal extremity in all investigated specimens. 
1

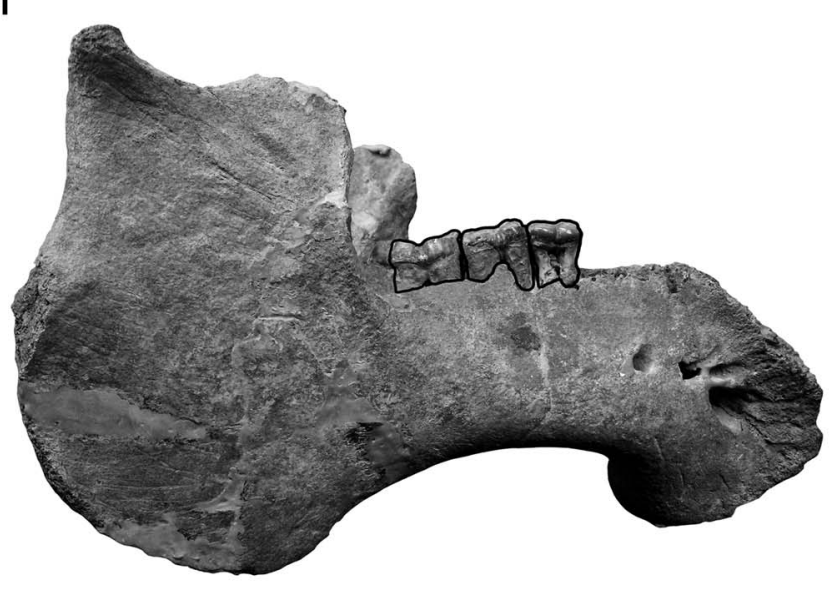

2

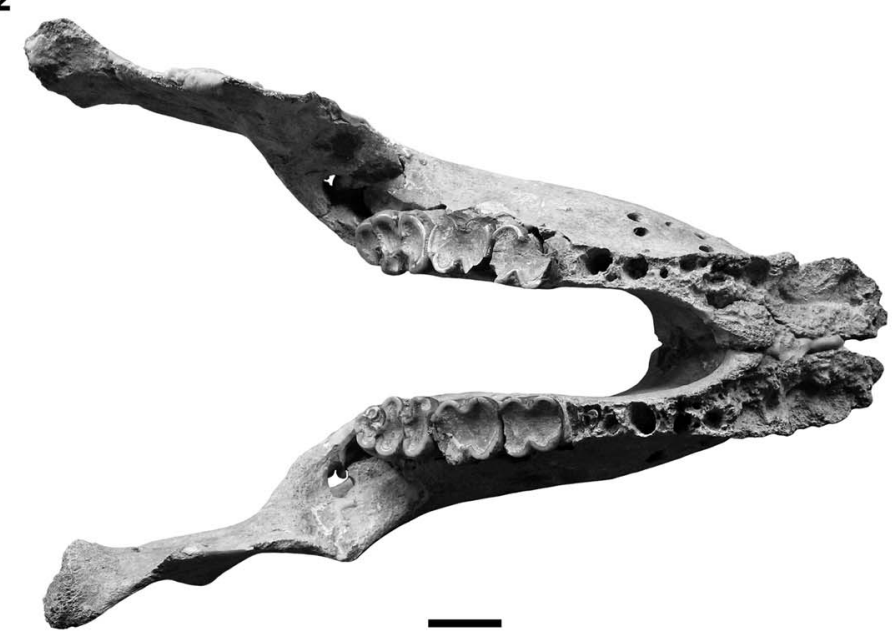

3

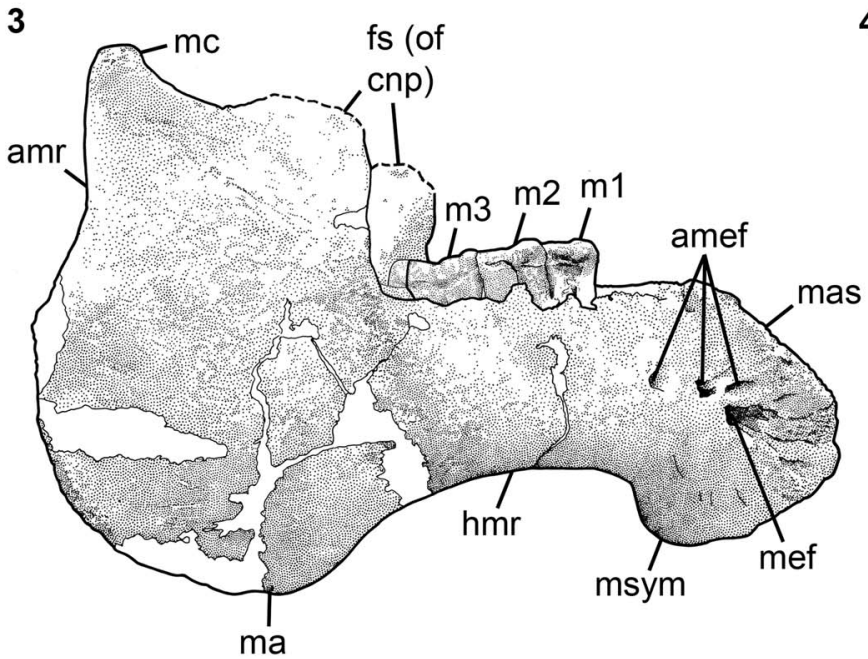

4

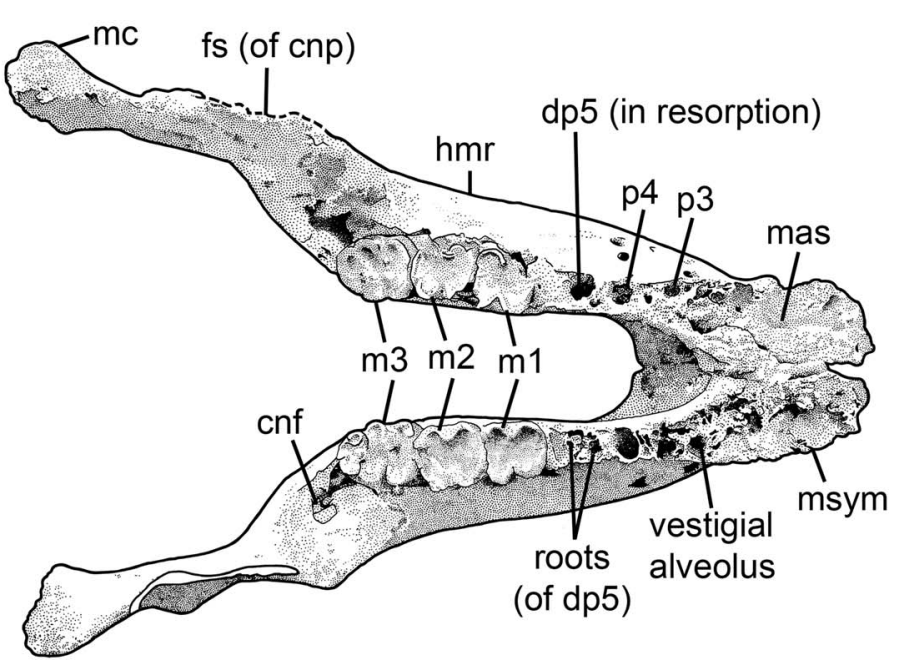

Figure 13. Mandible of Kaupitherium bronni (SMNS 47736): (1, 2) photograph and corresponding drawing in right lateral view; (3, 4) occlusal view (white areas indicate either missing or reconstructed parts). Anatomical abbreviations indicated in text. Scale bars are $2 \mathrm{~cm}$.

Sternum.-In contrast to K. gruelli n. sp., the sternum is completely known by three elements, though not from a single individual. Specimen MCZ 8829 preserves the manubrium, which is similar to that of MB.Ma. 52009, where the corpus is also present (Fig. 16.1). MNHM PW 1984/37-1 includes the corpus and the xiphisternum (Fig. 16.2). Overall morphology resembles that in K. gruelli n. sp. Manubrium of MCZ 8829 is flat to slightly concave dorsally and convex ventrally with a ventromedial knob on its anterior half, whereas MB.Ma. 52009 is double-curved in lateral views with the dorsal surface being concave anteriorly and flat to slightly convex posteriorly. Otherwise, the surfaces are smooth. Manubrium reaches its greatest mediolateral width at about half its length, whence the large and deep rugosities for articulation with the first ribs extend laterodistad. A smaller and less concave pair of facets lies at the junction of the manubrium and the corpus, as indicated by chamfered posterolateral edges of the former. Corpus is compact and roughly octagonal, and is a small element intermediate between the much larger manubrium and xiphisternum. Its dorsal and ventral surfaces are smooth and flat. All edges are rounded and chamfered for the appropriate rib articulation that it forms together with the adjacent sternal elements. Xiphisternum has a paired articulation only at its anterolateral corner, indicating that, in total, three pairs of the anteriormost ribs articulated with the whole sternum, which is consistent with the rugose distal texture of R1-3. Anterior part of the xiphisternum resembles the corpus in shape and size, but it tapers distad to form a long posterior process. Although its distal end is broken in MNHM PW 1984/37-1, this process is clearly divided, and asymmetrical.

Scapula.-Does not significantly differ from that in $K$. gruelli n. sp. A tuber spinae is minor (MB.Ma. 52009; Fig. 16.3, 16.4) or not (MCZ 8829) developed. Distal end of the acromion is broken in all specimens, but its position at the collum scapulae is clearly determinable.

Humerus.-Left humerus is preserved in the partial skeleton MAz GP 1000 (Fig. 16.5). As in K. gruelli n. sp., it is a compact bone. However, the suture between the proximal epiphysis and humeral shaft is not obliterated, indicating that this animal was not very old. Deltoid crest is separated from the greater tubercle by this suture and overhangs only slightly laterally. 
1

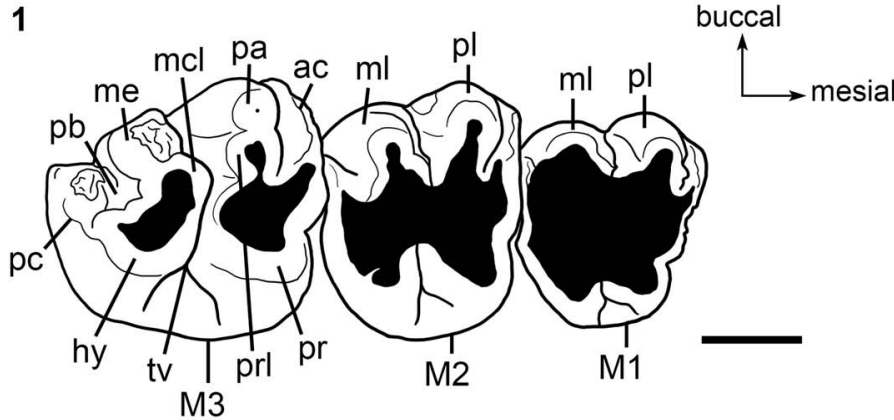

2

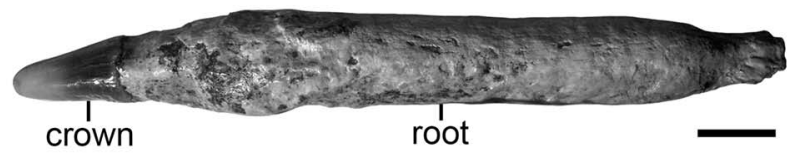

3
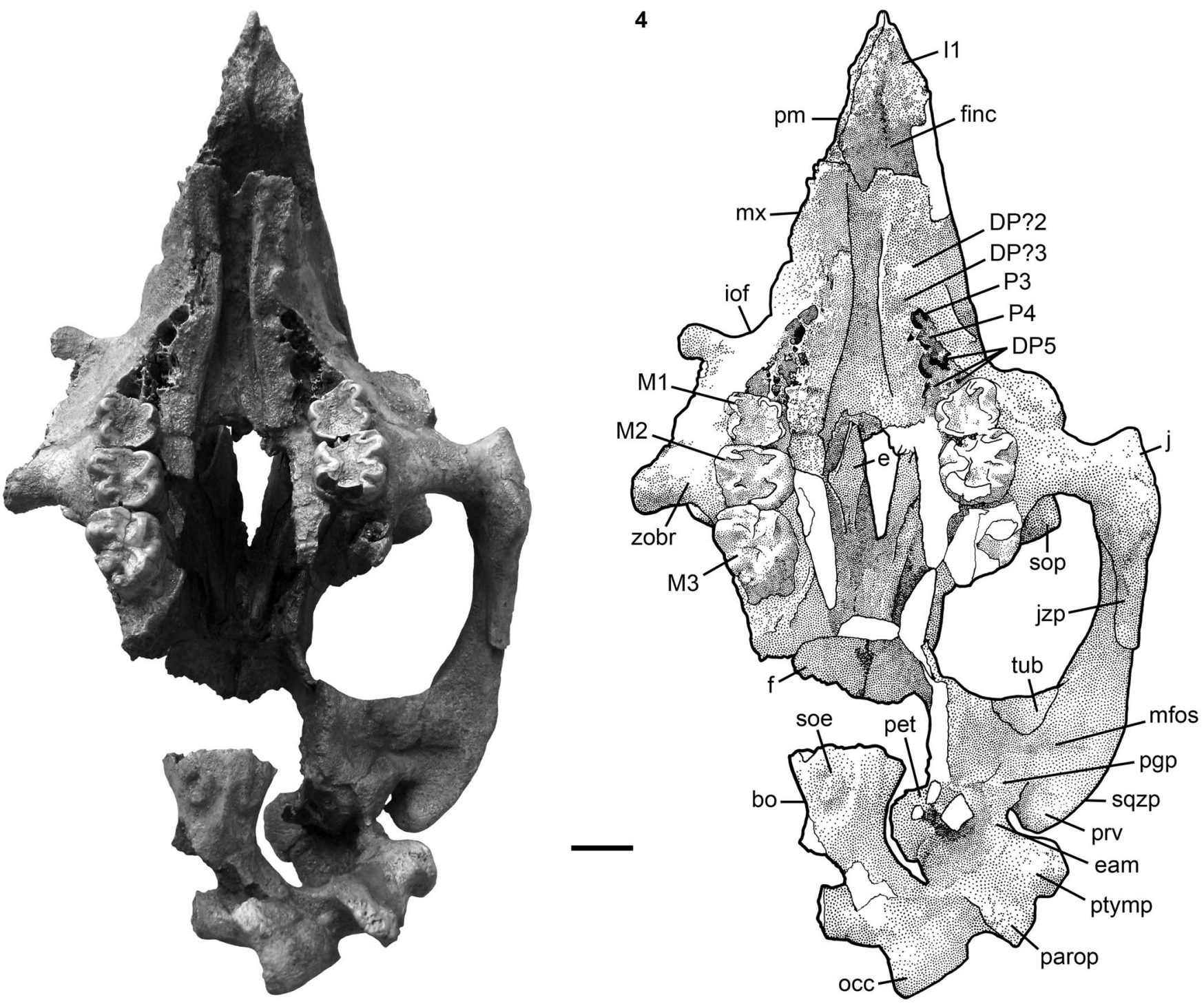

Figure 14. Dentition of Kaupitherium bronni: (1) right M1-3 of MWNH-TER-1 in occlusal view; (2) I1 of MCZ 8829, supposedly from the right side and in mesial view; $(\mathbf{3}, \mathbf{4})$ tooth arcades of MWNH-TER-1 in ventral view $(\mathbf{3}=$ photograph; $\mathbf{4}=$ drawing; white areas indicate broken parts). Anatomical abbreviations indicated in text. Scale bars are $1 \mathrm{~cm}(\mathbf{1}, \mathbf{2})$ or $2 \mathrm{~cm}(\mathbf{3}, \mathbf{4})$.

Radius and ulna.- Right articulated radius-ulna complex is known from MNHM PW 1945/233 (Fig. 16.6) and similar to K. gruelli n. sp. Both lack their distal epiphyses, but are otherwise completely preserved. Ulnar shaft is $\sim 10 \mathrm{~mm}$ shorter than that of the radius. Articulation surface for the humerus has a semilunar shape on the ulna, but is flat on the radius. Anterior margin of the olecranon is tilted back and forms an angle of $\sim 50^{\circ}$ with the axis of the ulnar shaft. Proximally, the olecranon is thickened and bears a tuberosity.

Manus.-Autopodium elements unquestionably referable to $K$. bronni are known by two middle phalanges (QB-4/12.721$\mathrm{PH}$ ), which were already described by Voss (2012). Further, a 


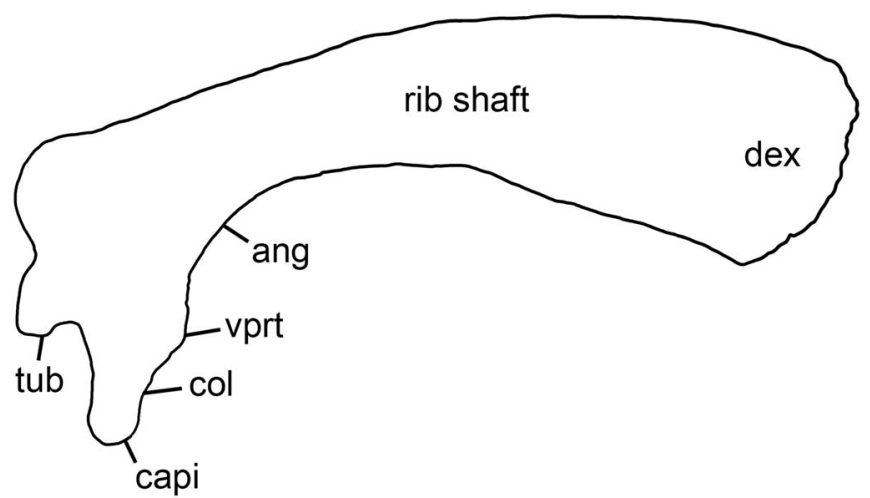

Figure 15. Outline drawing of the left R1 of Kaupitherium bronni (MB Ma. 49618 ) in anterior view. Anatomical abbreviations indicated in text. Exact scale was not determinable, because the skeleton is on display.

single distally broken metacarpal, measuring $62 \mathrm{~mm}$ in preserved length, is known from IRSNB Reg. 4006. It most likely represents the left metacarpal III, according to its congruent morphology with that in $K$. gruelli n. sp.

Innominate.-Pelvic remains associated with partial skeletons of K. bronni are known from QB-4/12.721 (Voss, 2012) and MB.Ma. 52009, the latter of which preserves the complete pelvis of the right side (Fig. 16.7-16.10). Posterior end of the ischium is neither markedly thickened nor flaring laterad. According to Domning (1991), this animal could therefore be interpreted as a female. A rugose protuberance is present on the dorsal edge of the ischium directly across from the ventralmost pubic extension. Another protuberance occurs on the ventromedial edge of the acetabular region $\sim 20 \mathrm{~mm}$ from the ventral tip of the pubis. A foramen obturatum is missing.

Femur.-Specimen IRSNB Reg. 4006 includes the left femur lacking its distal end and measuring $88 \mathrm{~mm}$ in preserved length. Femur is an overall gracile element, with its proximal end distinctly thickened. Femur head is rounded and flanked laterally by the greater trochanter, which forms an oval tuberosity well below the top of the head. Femur neck is indistinct. A slight prominence is present anteroventral to the neck, which corresponds to the lesser trochanter. Femoral shaft is slender, transversally rounded and tapering distad.

Materials.-For detailed listing of the referred specimens and their preserved skeletal parts, see Supplementary data set 3; Supplementary data set 4 provides measurements.

Remarks.-Kaupitherium bronni (Krauss, 1858) differs from K. gruelli n. sp. in the combination of the following characters: infraorbital foramen round, about as wide as high; frontal processes of parietal long, exceeding half the length of frontal; cranial roof slightly shortened relative to supraoccipital width; no contact between lacrimal and premaxilla; nuchal crest notched in the median plane; external occipital protuberance indistinct, neither rising above the parietal plane nor bulging caudally; P2/p2 absent.

\section{Discussion}

Taxonomy and morphological distinctions: present state of the art.-The taxonomy of early Oligocene Sirenia from Central
Europe traditionally referred to "Halitherium schinzii" Kaup, 1838 has been controversial (e.g., Hartlaub, 1886). One of the first attempts to discern morphological distinctions on the species level was undertaken by Krauss (1858), who established the species "H." bronni on the basis of his specimen "Nro. I" (Krauss, 1858, p. 523), a skullcap (SMNS 1539) from Flonheim (Mainz Basin) and the holotype of $K$. bronni in this study. Although Krauss' (1858) recognition of this new species is based on a morphological misinterpretation of the frontonasal area, he also recognized a specific morphology of the supraoccipital that was again observed by Voss (2012). In contrast to the very prominent external occipital protuberance of specimens now assigned to $K$. gruelli $\mathrm{n}$. sp., the supraoccipital of $K$. bronni shows an anteriorly concave nuchal crest in the median plane and a weak external occipital protuberance. Both are remarkably developed in MCZ 8829 (Fig. 11.6, 11.8), which most likely also Bronn (1853-1856, pl. 48, fig. 9a) illustrated, and reflect a completely opposite anatomical structure from that seen in $K$. gruelli $\mathrm{n}$. sp. The supraoccipital is one of the most frequently preserved elements, and therefore its specific morphology is classified as one of the main and most useful distinguishing characters on the species level.

There are also a number of dental arcades from both species known, which provide another reliable source for the species distinction, especially in addition to the supraoccipital. The dental formula is highly informative, as shown in the most recent phylogenetic approach on Sirenia (Springer et al., 2015, fig. 5), where the loss of canines, incisors, and permanent premolars is plotted on a tree. However, in previous studies, the quantitative assessment of the dental formula yielded different results for the absence or presence of the second permanent upper and lower premolars. In his monograph on " $H$. schinzii," Lepsius (1882) distinguished specimens with two sequential, single alveoli for $\mathrm{P} 3 / \mathrm{p} 3$ and $\mathrm{P} 4 / \mathrm{p} 4$ from those with an additional alveolus for a single-rooted P2/p2. This was taken up by Barthel (1962), who postulated that the loss of the right $\mathrm{P} 2$ in the very old specimen, BSPG 1956 I 540 (Fig. 3.1 and 3.2), now assigned to K. gruelli n. sp., has to be expected during the animal's lifetime. However, during lifetime, the subsequent loss of a tooth or its position belonging to the secondary dentition is documented neither for fossil nor extant sirenians nor, to the authors' best knowledge, for any other mammal. Instead, the re-investigation of specimens formerly assigned to " $H$. schinzil" supports the distinction of two species by the absence or presence of $\mathrm{P} 2 / \mathrm{p} 2$. This is best observable by comparing the upper dentitions of BSPG 1956 I 540 (K. gruelli n. sp.; Fig. 3.1, 3.2) and MB.Ma. 52009 (K. bronni; Fig. 10.3, 10.4), which represent similar growth stages. Both specimens have an obliterated basioccipitalbasisphenoid suture indicating adulthood (Pocock, 1940; Mitchell, 1973), and a fully erupted M3, showing a similarly high degree of wear, which indicates that these individuals died in old age. While the right P2 is preserved in situ in BSPG 1956 I 540, as well as the alveolus of its left counterpart, the tooth arcades in MB.Ma. 52009 exhibit no further alveoli or remains of P2. This difference is also observable in subadults like MWNH-TER-1 (K. bronni; Fig. 14.3, 14.4) and FIS M2597 (K. gruelli n. sp.; Fig. 4.1, 4.2). Both specimens show an unfused basioccipitalbasisphenoid suture associated with a M3 that is either fully erupted and slightly to moderately worn (MWNH-TER-1) or 
1

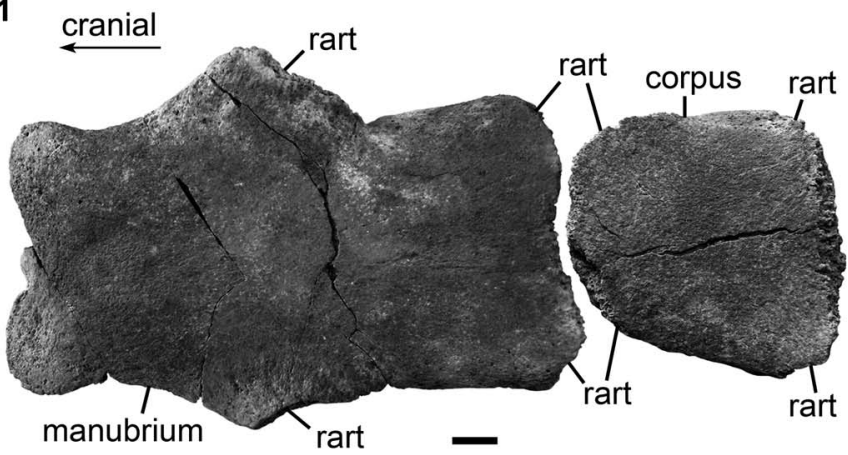

3

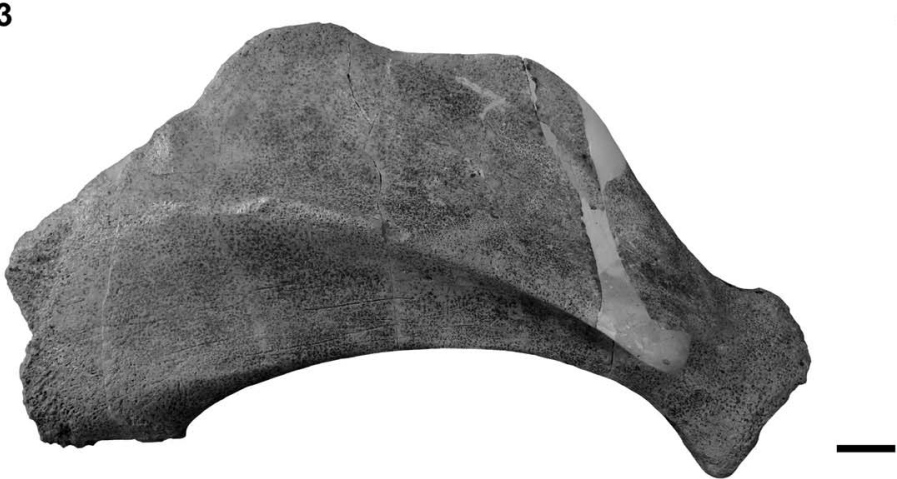

5

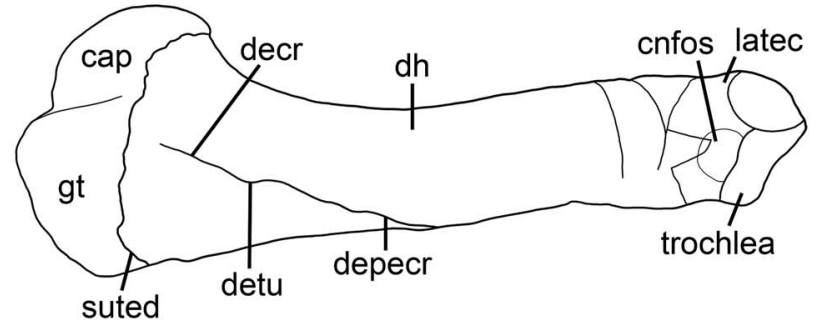

7

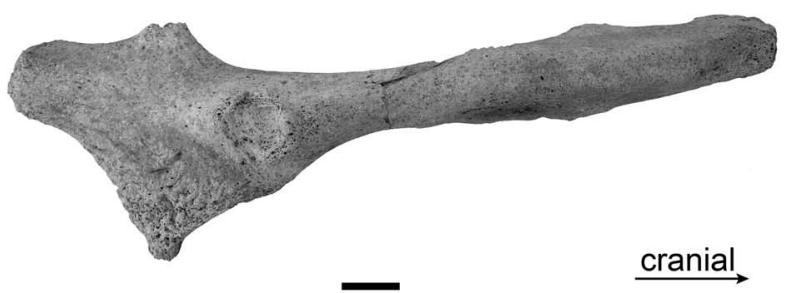

9

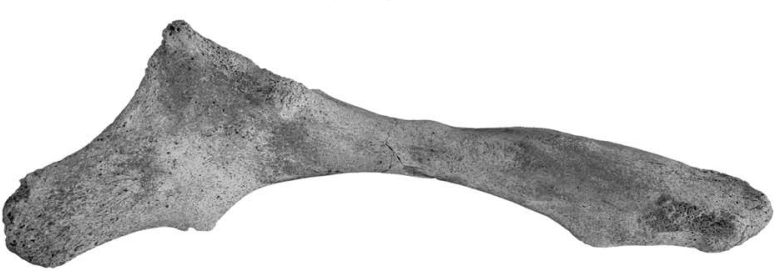

2

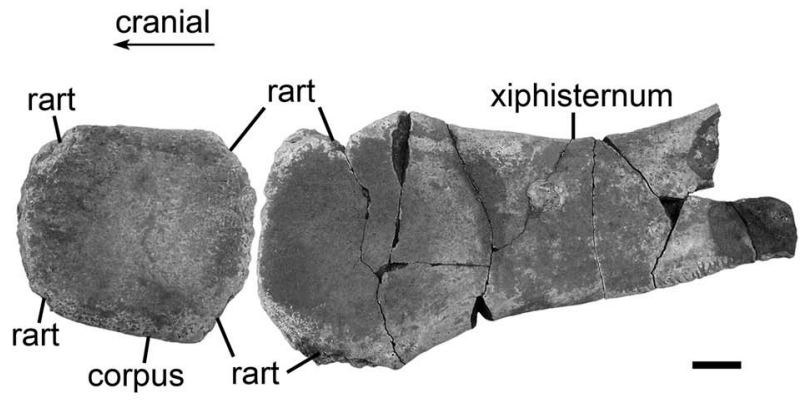

4

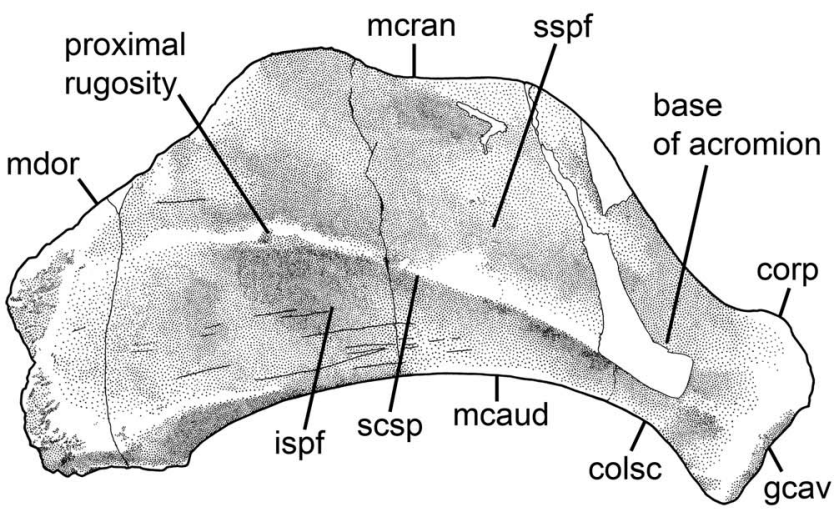

6

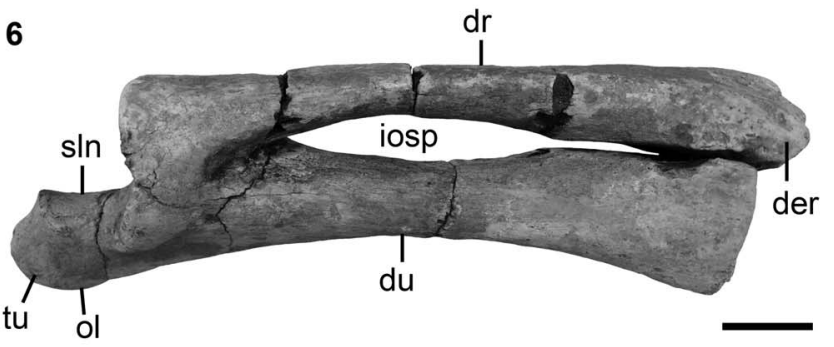

Figure 16. Postcrania of Kaupitherium bronni: (1) manubrium and corpus of MB.Ma. 52009 in ventral view; (2) corpus and xiphisternum of MNHM PW 1984/37-1 in ventral view; $(\mathbf{3}, \mathbf{4})$ right scapula of MB.Ma. 52009 in lateral view (3 = photograph; $\mathbf{4}=$ drawing; white areas indicate either missing or reconstructed parts); 5 , outline drawing of left humerus (MAz GP 1000) in anterolateral view (exact scale was not determinable, because the skeleton is on display); (6) left radius and ulna of MNHM PW 1945/233 in lateral views; (7-10) right innominate of MB.Ma. 52009 (photograph and corresponding drawing in $(\mathbf{7}, \mathbf{8})$ lateral and $(\mathbf{9 , 1 0})$ medial views). Anatomical abbreviations indicated in text. Scale bars are $1 \mathrm{~cm}(\mathbf{1 , 2})$ or $2 \mathrm{~cm}(\mathbf{3}, \mathbf{4 ,} \mathbf{6 - 1 0})$. 
nearly fully erupted and almost unworn, and hence dentally somewhat younger (FIS M2597). FIS M2597 preserves three isolated and deep alveoli in front of DP5 in each half of the upper jaw, which housed single-rooted P2-4 in the animal's lifetime. In contrast, a permanent P2 was certainly not developed in MWNH-TER-1, though it still retains a single alveolus $\sim 10 \mathrm{~mm}$ in front of P3 on the left and probably also on the right maxillary side. This alveolus is small, shallow, and not sharply defined, and therefore considered to be in a state of resorption. Lepsius (1882) already observed resorption at the DP2/dp2 position for some "H. schinzii" specimens, but drew no conclusions for their taxonomic treatment. Following Luckett's (1993) observations of rudimentary deciduous teeth lacking successors in mammals, the indication of an extra premolar position in front of P3 in MWNH-TER-1 is interpreted here to represent a remnant of the first premolar generation at the DP2 locus that was not replaced. Whether DP2 was vestigial diminutive or still functional can be only tentatively concluded, because even in extant taxa the decision on whether or not to consider a tooth as vestigial is sometimes difficult and not entirely objective (Van Nievelt and Smith, 2005). These authors consider a tooth as vestigial if it did not consistently pierce the gingiva or was shed after a short period. At least the latter can be hypothesized for the DP2 in MWNH-TER-1 because it was lost in a subadult stage. Additionally, it should be emphasized that the extant Dugong dugon is characterized by a highly derived dentition, which includes only premolars of the first ("milk") generation that are resorbed or progressively fall out, and molars, which by definition are never replaced (Heuvelmans, 1941; Lanyon and Sanson, 2006). Hence, a deciduous tooth does not necessarily need to be vestigial (i.e., non-functional) to remain unreplaced.

The issue of suppression of tooth replacement is a complex matter and not yet well investigated within living and fossil sirenians. Van Nievelt and Smith (2005) documented a wide range of tooth replacement patterns in therians and pointed out that the loss of deciduous teeth at various loci is fairly common in diverse eutherian groups. Likewise, they argued that no single hypothesis is adequate to explain the full range of observed tooth replacement patterns. The present paper does not attempt to resolve this issue, but the hypothesis that dental replacement may be lost in the process of full elimination of a tooth or locus could well match with the observations in $K$. bronni. This find especially supports the successive reduction of the antemolar dentition during the evolution of Sirenia (Springer et al., 2015). Besides both extant genera, Trichechus (e.g., Domning, 1982) and Dugong (e.g., Lanyon and Sanson, 2006), fossil taxa such as Metaxytherium krahuletzi (Domning and Pervesler, 2001), M. floridanum (Domning, 1988), and M. albifontanum (Velez-Juarbe and Domning, 2014), all of which are more derived than Kaupitherium n. gen., lack permanent premolars. While adults show the cheek dentition to be reduced to M1-3, young individuals (e.g., M. floridanum [Domning 1988, p. 411]) still preserve alveoli of deciduous premolars, as is the case at the DP2 locus in K. bronni (MWNH-TER-1).

Further criteria for the establishment of $K$. bronni and its distinction from $K$. gruelli $\mathrm{n}$. sp. are given by morphological differences involving the missing lacrimal-premaxilla contact, the shape of the infraorbital foramen, the length of the frontal processes of the parietal relative to the mid-frontal length, and the dimensions of the cranial roof relative to the supraoccipital width.
Aspects of intraspecific variations.-In addition to the identification of species, intraspecific variation in " $H$. schinzii" was debated in the past (e.g., Sickenberg, 1934). Observations in extant taxa argue against a significant presence of sexual dimorphism and ontogenetic variations. According to Domning and Hayek (1986), sexual dimorphism is not present in skulls of the three living Trichechus species (manatees). On the contrary, the monospecific Dugong does vary in the development of the snout region, which is related to the expansion of the male tusks (Spain and Heinsohn, 1974; Spain et al., 1976). According to Marsh (1980) the significance of this sexual difference is limited in that the male tusks only erupt and wear in the postpubertal phase and that females also possess tusks, which can erupt and show wear in old individuals. Hence, it is difficult to distinguish the sexes in prepubertal and very old specimens without additional data beyond the skeletal morphology. Another account of intraspecific variation was provided by Domning (1991) on the innominate bones of Dugong, which show sexual dimorphism along with ontogenetic variations. As such, the ischia of adults and males are often more expanded dorsoventrally and show processes on the ventral side, in contrast to younger individuals and females. Although Domning (1991) evaluated this variation as considerable, he likewise confirmed a broad overlap between the sexes and different ontogenetic stages making unambiguous distinctions difficult.

The results of previous approaches to intraspecific variations in manatees and dugongs were also personally verified and can be confirmed. In fossil sirenians, including Kaupitherium, and some Metaxytherium representatives (e.g., M. krahuletzi and M. floridanum), differences of the ischium are observable as described by Domning (1991; compare also Figs. 9, 16.7-16.10). Besides variable dimensions of bones, particularly noticeable are the height and course of the temporal crests, which change and produce different frontoparietal widths in different growth stages. This is clearly observable in $K$. gruelli $\mathrm{n}$. sp. by comparing the juvenile FMD SRK Eck 124 (Fig. 4.3) with the adult BSPG 1956 I 540 (Fig. 2.1, 2.2). While the temporal crests are low and distant in the juvenile, enclosing a wide frontoparietal area, the adult shows a relatively narrow skull roof delimited by high and converging crests. These observations were already recognized in the Dugong by Spain and Heinsohn (1974), who documented that the temporal crests are especially variable, but do not have any obvious association with sex or other factors. Above all, it was personally observed that skeletal structures relevant for the distinction of $K$. gruelli $\mathrm{n}$. sp. and $K$. bronni qualitatively vary neither in extant nor in fossil sirenian taxa. With regard to the supraoccipital, it was already pointed out that juveniles of K. gruelli n. sp. (FMD SRK Eck 124; Fig. 4.3, 4.4) do not significantly differ from adults (Figs. 2.1, 2.2, 3.3, 4.5-4.7) as to the course of the nuchal crest and the development of the external occipital protuberance. This can be also corroborated by observations in the Dugong, indicating that these features for the insertion of the neck muscles are morphologically similar in juveniles (e.g., JCU MM019, 181), subadults (e.g., MNHN 176079, 1883-241), and adults (e.g., MNHN 1907-303). The Dugong specimens mentioned above also support that intraspecific variation is absent as to distinguishing features that are not frequently preserved in both Kaupitherium taxa. This refers to 
the lacrimal-premaxilla contact, which is always present in dugongs of different age, and to the shape of the infraorbital foramen, which is constantly wider than high, although the absolute dimensions indeed differ between juveniles and adults. Morphometric characters referring to the length of the frontal processes of the parietal relative to the mid-frontal length, and to the dimensions of the cranial roof relative to the supraoccipital width are likely to underlie ontogenetic changes. However, the representative sets of specimens for K. bronni and K. gruelli $\mathrm{n}$. sp., which comprise mainly adults and some subadults, show no polymorphisms. Even in the juvenile FMD SRK Eck 124, the frontal processes do not extend half of the mid-frontal length, and the ratio $1_{\mathrm{FP}} / \mathrm{w}_{\mathrm{SO}}$ is $\sim 2.24$, hence falling within the specific range of $K$. gruelli $\mathrm{n}$. sp.

Ecomorphological considerations.-As outlined above, $K$. gruelli $\mathrm{n}$. sp. and $K$. bronni can be clearly distinguished amongst other features on the basis of the supraoccipital morphology and the occurrence of $\mathrm{P} 2 / \mathrm{p} 2$. The functional importance of these features may be tied to different feeding strategies, as was suggested by Domning and Hayek (1986) with respect to some interspecific morphological differences within manatees, and hence provide the best basis to explain sympatry. The hypothesis of niche partitioning in sympatric fossil sirenians is also supported by the perspective of marine plant evolution (e.g., Domning, 2001b). Ancient seagrasses and other macrophytes are supposed to have been more diverse and differed ecologically in energy flow patterns compared to present aquatic floras (Domning, 1982; Velez-Juarbe et al., 2012). Considering sirenians as having an obligate herbivorous lifestyle, it is suggested that feeding-niche partitioning had structuring effects on multispecies sirenian communities (Domning and Beatty, 2007).

With this background, the specific development of the supraoccipital insertion areas for the neck muscles and ligaments suggests differences in the use of these muscles in K. gruelli n. sp. and $K$. bronni. On the intraspecific level, Domning and Hayek (1986) point out that processes and protuberances tend to become more pronounced with age, which apparently correlates with the increased development and use of the muscles attached to these structures. Judging from this, the prominent external occipital protuberance in K. gruelli n. sp. (Fig. 4.5-4.7) and the reduction of it in addition to the presence of a nuchal fossa in $K$. bronni (Fig. 11.6, 11.8) indicate that the extension of the atlantooccipital joint was different. It is not exactly clear by now how these different structures affect the direction of movement of the head, and the present study does not attempt any functional morphology and/or myology. However, previous suggestions may provide proper explanations. For example, Trichechus inunguis predominantly shows a surface-feeding habit, which is explained, among other factors, by the strong development of its supraoccipital that allows the skull to stand upright (Domning and Hayek, 1986). Hence, it may be conceivable that $K$. gruelli n. sp. was more specialized for feeding at higher levels in the water column or even at the water surface, according to the prominent rear surface of its supraoccipital, indicating strongly developed neck muscles. By contrast, K. bronni may have been confined to feeding at the bottom or deeper levels in the water column. This hypothesis would imply that the relevant food plants were distributed throughout the water column, as in the case of niche partitioning in extant manatees and extinct hydrodamalines such as Steller's sea cow, whose food resources are and have been heterogeneous (e.g., Domning, 1978, 1982). In his approach on the food of Anomotherium langewieschei Siegfried, 1965, Diedrich (2008) provided indirect evidence for the presence not only of seagrass, but also of brown macroalgae in the Rupelian of Germany. This author hypothesized that Anomotherium and the species now assigned to Kaupitherium co-existed in the uppermost Rupelian of the Kassel Bay and Leipzig Bay. While seagrasses were the main food of Anomotherium, especially in the carbonate environment north of the Rhenish Massif and the Kassel Bay, the siliciclasticdominated Leipzig Bay produced seaweeds and possibly also other food sources that the Kaupitherium species could have shared. Brackish-marine conditions are at least postulated for the Bay of Leipzig (Böhme, 2001) and towards the Paris Basin (Meulenkamp and Sissingh, 2003), which may support Diedrich's (2008) hypothesis on the existence of other food sources besides seagrass.

In his first attempt to hypothesize on how fossil sirenians might have partitioned the available food resources in tropical marine waters, Domning (2001b) argued for the recognition of sirenians as being obligate seagrass consumers that are restricted to the bottom. Considering this, both species discussed herein might not have had fundamentally different diets, as suggested above, and hence alternative explanations for sympatry are required. In a comparative study of three different sympatric sirenian assemblages over the past $\sim 26 \mathrm{Ma}$, Velez-Juarbe et al. (2012) used features linked to sirenian dietary and foraging preferences such as tusk morphology, rostral deflection, and body size. Domning (2001b) and Domning and Beatty (2007) also outlined that the relative size and robustness of different seagrass species and their rhizomes provide another basis for partitioning food resources considering the size and morphology of sirenian tusks as indicators for different specialization degrees for excavating rhizomes. Both, $K$. gruelli n. sp. and $K$. bronni display mid-sized tusks, primarily used for feeding on the bottom (Domning, 2001b), and rather strongly downturned snouts with deflection angles of $50^{\circ}$ or more that Domning (1976) directly correlated with the degree of specialization for bottom-feeding. Additionally, neither species exhibits significantly different body sizes, which are presumed to have been 2.5-3 $\mathrm{m}$, and hence the possible strategy for partitioning seagrasses (e.g., by water depth; Domning, 2001b) is not applicable. Domning (2001b, p. 39) stated that, "when two or more sympatric species seem not to differ in regard to any of these morphological indicators of feeding niche, then (and only then) we must search for other ecological axes along which their separation and coexistence might have been maintained." Meeting this challenge, the present study aims at considering new ecomorphological criteria. As such, the differences in the supraoccipital morphology and permanent dentition in $K$. gruelli $\mathrm{n}$. sp. and $K$. bronni are postulated here to be related to niche partitioning. As outlined above, the supraoccipital morphology of $K$. gruelli n. sp. is associated with a greater strength of its neck muscles compared to $K$. bronni, and therefore this species probably could uproot larger rhizomes and chew these adequately with the range of its cheek dentition, including P2/p2, which evidently occluded (see Fig. 3.1, 3.2). On the contrary, K. bronni may have fed on smaller rhizomes 
and/or was specialized on seagrass leaves, which would also be consistent with the loss of the $\mathrm{P} 2 / \mathrm{p} 2$, indicating a reduced masticatory function. The hypothesis of species-related dietary preferences finds support by observations in the living Dugong. Although its diet consists of seagrasses of all available genera, and even of algae in small amounts, highly digestible (i.e., small and soft) pioneer taxa such as Halodule and Halophila are most frequently detected in the stomach contents (Marsh et al., 1982; De Iongh et al., 1996).

The conjecture about the role of the supraoccipital in feeding presented in this study still needs to be tested in the context of other hypotheses about sirenian niche-partitioning strategies. Pending substantiated studies on such ecomorphological parameters in pre-late Oligocene multispecies sirenian communities, which are still not available, the factor of niche partitioning is taken here as the best explanation for the postulated presence of two sympatric taxa in the lower Oligocene of Central Europe.

\section{Conclusions}

The present study provides evidence that Kaupitherium gruelli $\mathrm{n}$. gen. n. sp. and $K$. bronni (Krauss, 1858) represent sister taxa (Voss, 2013) and sympatric species according to their skeletal morphology and concordant geographic and stratigraphic occurrence. Both taxa are founded on a large sample of specimens that were originally referred to " $H$. schinzil" Kaup, 1838. Several features, such as reduced nasals that still meet in midline and the absence of canines and $\mathrm{P} 1 / \mathrm{p} 1$, support the monophyly of Kaupitherium n. gen., which includes two morphospecies that can be mainly distinguished by the specific supraoccipital morphology and the occurrence of $\mathrm{P} 2 / \mathrm{p} 2$. Both taxa are early Oligocene in age and, besides associated (post-) cranial elements, are well known by partial skeletons comprising nearly complete skulls and mandibles from their type locality, the Mainz Basin (western Germany). Kaupitherium gruelli n. gen. n. sp. is also known from the Antwerp and East Flanders Provinces in northern Belgium (e.g., IRSNB M.137; IRSNB Reg. 4005). The partial skeleton NMDU-Geo 0001 from the Ratingen Member of the Lower Rhine area in western Germany (Voss, 2008) is also now assigned to this taxon, as are sirenian finds from the Paris Basin (Bizzarini, 1995; Bizzarini and Reggiani, 2010), indicating the widespread distribution of this taxon. Kaupitherium bronni is also known from the upper Ratingen Member of the southern Münsterland in western Germany (Voss, 2012). Fischer and Krumbiegel (1982) described and illustrated a specimen ( $\mathrm{Ru} 26)$ from the Bay of Leipzig (eastern Germany), which now can be clearly assigned to $K$. bronni due to its distinctive supraoccipital morphology. The same applies to the specimens IRSNB Reg. 4006 and 4011 from the Boom Clay Formation of the Antwerp and East Flanders Provinces (northern Belgium). Skeletal material referred to Kaupitherium sp. is also reported from the Gironde region of France (Pilleri, 1987), Switzerland, and Hungary.

\section{Acknowledgments}

This work could not have been realized without the kind assistance of the following colleagues, curators, collection managers, and preparators, to whom we are much obliged for providing access to collections, collection datasets, and/or exhibitions.

Germany: E. Heller-Karneth (Alzey), I. Mann, F. Mayer, and D. Schwarz (Berlin), M. Walders (Bottrop), M. Strauss (Bünde), G. Gruber, N. Micklich, E. Milsom, and O. Sandrock (Darmstadt), M. Jäger and M. Raisch (Dotternhausen), R. Brocke and J. OelkersSchaefer (Frankfurt), D. Grüll (Gernsheim), J. Kontny (Heidelberg), F. Bach, R. Baudenbacher, and A. Müller (Leipzig), T. Engel and M. Wuttke (Mainz), M. Böhme (Tübingen), G. Rößner (Munich), H. Stapf (Nierstein), E. Heizmann and R. Ziegler (Stuttgart), M. Maisch (Tübingen), F. Geller-Grimm (Wiesbaden).

Europe: B. Engesser (Basel), A. Folie, O. Lambert, and E. Steurbaut (Brussels), M. Gasparik, L. Kordos, J. Palfy, and L. Peregovits (Budapest), J. Hooker and R. Sabin (London), C. Argot, C. Lefevre, and C. Sagne (Paris), U. Johansson and T. Moers (Stockholm).

Overseas: W. Amaral and J. Chupasko (Cambridge, MA), E. Fitzgerald, W. Longmore, R. O'Brian, and T. Rich (Melbourne), D. Bohaska, D.P. Domning, and C.W. Potter (Washington, D.C.).

J. Dunlop (Berlin) and S. Klug (Manchester) are acknowledged for checking the spelling and grammar of major parts of this paper. Both, the latter and M. Ohl (Berlin) are highly thanked for fruitful discussions on taxonomy and nomenclature. We thank J. Müller-Edzards for the preparation of some illustrations (Figures 4.2-4.4, 7.2, 9.1, 10.2, 10.4, 13.2, 13.4, 14.4, 16.4, 16.8, 16.10), T. Engel (Mainz) for his additional efforts in helping to clarify the skull morphology of a specimen displayed in MNHM, M. Schellenberger (Munich) for diligently making the photographs of the specimen BSPG 1956 I 540, and C. Radtke (Berlin) for photographing the hand skeleton of HLMD-WT 420. We appreciate the courtesy of K.I. Grimm (Mainz) for mailing essential and hardly available literature on the Geology of the Mainz Basin, and thank W. von Koenigswald (Bonn) for helpful information on mammalian tooth morphology. We also thank M. Uhen and D.P. Domning for providing helpful comments to improve the present paper. This research received support from the SYNTHESYS Project http://www.synthesys.info/, which is financed by European Community Research Infrastructure Action under the FP7 "Capacities" Program (GB-TAF-5171; HU-TAF-51589 both to MV), and from the Deutsche Forschungsgemeinschaft (DFG; HA 1776/11-1 to OH).

\section{Accessibility of supplemental data}

Data available from the Dryad Digital Repository: http://doi. org/10.5061/dryad.128jr

\section{References}

Bahlo, E., and Tobien, H., 1982, Bestandsaufnahme der Säugetiere im "präaquitanen" Tertiär des Mainzer Beckens: Mainzer geowissenschaftliche Mitteilungen, v. 10, p. 131-137.

Barthel, W., 1962, Über ein neues montiertes Skelett von Halitherium schinzi Kaup (Sirenia): Mitteilungen der Bayerischen Staatssammlung für Paläontologie und Historische Geologie, v. 2, p. 65-68.

Berger, J.-P., Reichenbacher, B., Becker, D., Grimm, M., Grimm, K., Picot, L., Storni, A., Pirkenseer, C., and Schaefer, A., 2005a, Paleogeography of the Upper Rhine Graben (URG) and the Swiss Molasse Basin (SMB) from Eocene to Pliocene: International Journal of Earth Sciences, v. 94, p. $697-710$. 
Berger, J.-P., Reichenbacher, B., Becker, D., Grimm, M., Grimm, K., Picot, L., Storni, A., Pirkenseer, C., and Schaefer, A., 2005b, Eocene-Pliocene time scale and stratigraphy of the Upper Rhine Graben (URG) and the Swiss Molasse Basin (SMB): International Journal of Earth Sciences, v. 94, p. 711-731.

Bizzarini, F., 1995, Osservazioni sull'Halitherium schinzi Kaup, 1838 (Sirenia, Mammalia) conservato presso il Museo Civico di Storia Naturale di Venezia: Bollettino del Museo Civico di Storia Naturale di Venezia, v. 44, p. $163-171$.

Bizzarini, F., and Reggiani, P., 2010, Halitherium schinzi nel nuovo allestimento del Museo di Storia Naturale di Venezia: Bollettino del Museo Civico di Storia Naturale di Venezia, v. 61, p. 131-137.

Böhme, M., 2001, Die Landsäugerfauna des Unteroligozäns der Leipziger Bucht - Stratigraphie, Genese und Ökologie: Neues Jahrbuch für Geologie und Paläontologie, Abhandlungen, v. 220, p. 63-82.

Bronn, H.G., 1853-1856, H. G. Bronn's Lethaea geognostica oder Abbildung und Beschreibung der für die Gebirgs-Formationen bezeichnendsten Versteinerungen, Band 3, 4. Caeno-Lethaea, 6. Theil, Molassen-Periode: Stuttgart, Schweizerbart'sche Verlagshandlung und Druckerei, $1130 \mathrm{p}$.

Carus, J.V., 1868, Handbuch der Zoologie. Erster Band. Wirbelthiere, Mollusken und Molluscoiden: Leipzig, Wilhelm Engelmann, 894 p.

De Iongh, H.H., Wenno, B.J., and Meelis, E., 1996, Seagrass distribution and seasonal biomass change in relation to dugong grazing in the Moluccas, East Indonesia: Aquatic Botany, v. 50,19 p.

De Man, E., Ivany, L., and Vandenberghe, N., 2004, Stable oxygen isotope record of the Eocene-Oligocene transition in the southern North Sea Basin positioning the Oi-1 event: Netherlands Journal of Geosciences/Geologie en Mijnbouw, v. 83, p. 193-197.

De Zigno, A., 1875, Sirenii fossil itrovati nel Veneto. Memorie del Reale Istituto Veneto di Scienze: Lettre ed Arti, v. 18, p. 427-456.

Diedrich, C.G., 2008, The food of the miosiren Anomotherium langenwieschei (Siegfried)-Indirect proof of seaweed or seagrass by xenomorphic oyster fixation structures in the Upper Oligocene (Neogene) of the Doberg, Bünde (NW Germany) and comparisons to modern Dugong dugon (Müller) feeding strategies: Senckenbergiana maritima, v. 38, p. 59-73.

Domning, D.P., 1976, An ecological model for late Tertiary sirenian evolution in the North Pacific Ocean: Systematic Zoology, v. 25, p. 352-362.

Domning, D.P., 1978, Sirenian evolution in the North Pacific Ocean: University of California Publications in Geological Sciences, v. 118, $177 \mathrm{p}$

Domning, D.P., 1980, Feeding position preference in manatees (Trichechus): Journal of Mammalogy, v. 61, p. 544-547.

Domning, D.P., 1981, Sea cows and sea grasses: Paleobiology, v. 7, p. 417-420.

Domning, D.P., 1982, Evolution of manatees: a speculative history: Journal of Paleontology, v. 56, p. 599-619.

Domning, D.P., 1988, Fossil Sirenia of the West Atlantic and Caribbean region. I. Metaxytherium floridanum Hay, 1922: Journal of Vertebrate Paleontology, v. 8, p. 395-426.

Domning, D.P., 1991, Sexual and ontogenetic variation in the pelvic bones of Dugong dugon (Sirenia): Marine Mammal Science, v. 7, p. 311-316.

Domning, D.P., 1994, A phylogenetic analysis of the Sirenia, in Berta, A., and Deméré, T., eds., Contributions in marine mammal paleontology honoring Frank C. Whitmore, Jr.: Proceedings of the San Diego Society of Natural History No. 29, p. 177-189.

Domning, D.P., 1996, Bibliography and Index of the Sirenia and Desmostylia: Smithsonian Contributions to Paleobiology, v. 80,611 p

Domning, D.P., 2001a, Evolution of the Sirenia and Desmostylia, in Mazin, J.M., and de Buffrénil, V., eds., Secondary adaptation of tetrapods to life in water: Proceedings of the international meeting Poitiers 1996: Munich, Verlag Dr. Friedrich Pfeil, p. 151-168.

Domning, D.P., 2001b, Sirenians, seagrasses, and Cenozoic ecological change in the Caribbean: Palaeogeography, Palaeoclimatology, Palaeoecology, v. 166, p. $27-50$.

Domning, D.P., and Beatty, B.L., 2007, Use of tusks in feeding by dugongid sirenians: observations and tests of hypotheses: The Anatomical Record, v. 290 , p. $523-538$.

Domning, D.P., and Hayek, L.A., 1986, Interspecific and intraspecific morphological variation in manatees (Sirenia: Trichechus): Marine Mammal Science, v. 2, p. 87-144.

Domning, D.P., and Pervesler, P., 2001, The osteology and relationships of Metaxytherium krahuletzi Depéret, 1895 (Mammalia: Sirenia): Abhandlungen der Senckenbergischen Naturforschenden Gesellschaft Frankfurt am Main, v. 553, p. 1-89.

Fischer, K., and Krumbiegel, G., 1982, Halitherium schinzi Kaup, 1838 (Sirenia, Mammalia) aus dem marinen Mitteloligozän des Weißelsterbeckens (Bezirk Leipzig, DDR): Hallesches Jahrbuch für Geowissenschaften, v. 7, p. 73-95.

Fitzinger, L.J., 1842, Bericht über die in den Sandlagern von Linz aufgefundenen fossilen Reste eines urweltlichen Säugers (Halitherium cristolii): Bericht über das Museum Francisco-Carolinum Linz, v. 6, p. 61-72.
Furusawa, H., 2004, A phylogeny of the North Pacific Sirenia (Dugongidae: Hydrodamalinae) based on a comparative study of endocranial casts: Paleontological Research, v. 8, p. 91-98.

Gray, J.E., 1821, On the natural arrangement of vertebrose animals: London Medical Repository, v. 15, p. 296-310.

Grimm, K.I., 1994, Paläoökologie, Paläogeographie und Stratigraphie im Mainzer Becken, im Oberrheingraben, in der Hessischen Senke und in der Leipziger Bucht während des Mittleren Rupeltons (Fischschiefer/ Rupelium/Unteroligozän): Mitteilungen der Pollichia, v. 81, p. 7-193.

Grimm, K.I., 1998, Correlation of Rupelian coastal and basin facies in the Mainz Basin (Oligocene, Germany): Neues Jahrbuch für Geologie und Paläontologie, v. 3, p. 146-156.

Grimm, K.I., 2002, Foraminiferal zonation of early Oligocene deposits (Selztal Group, Latdorfian, Rupelian) in the Mainz Basin, Germany: Journal of Micropalaeontology, v. 21, p. 67-74.

Grimm, K.I., 2005, Das Tertiär des Mainzer Beckens in der stratigraphischen Tabelle von Deutschland 2002: Newsletters on Stratigraphy, v. 41, p. 347-350.

Grimm, K.I., and Grimm, M.C., 2003, Geologischer Führer durch das Mainzer Tertiärbecken, in Grimm, K.I., Grimm, M.C., Neuffer, F.O., and Lutz, H., eds., Die fossilen Wirbellosen des Mainzer Tertiärbeckens. Teil 1-1: Mainzer Naturwissenschaftliches Archiv No. 26, p. 1-158.

Grimm, K.I., and Steurbaut, E., 2001, Foraminiferal biofacies analysis of the Boom Clay Formation in the Rupel area (Oligocene, Belgium), and correlation with the Mainz Basin (Germany): Aardkundige Mededelingen, v. 11, p. 9-20.

Grimm, K.I., Grimm, M.C., and Schindler, T., 2000, Lithostratigraphische Gliederung im Rupelium/Chattium des Mainzer Beckens, Deutschland: Neues Jahrbuch für Geologie und Paläontologie, v. 3, p. 343-397.

Grimm, K.I., Grimm, M.C., Köthe, A., and Schindler, T., 2002, Der "Rupelton" (Rupelium, Oligozän) der Tongrube Bott-Eder bei Rauenburg (Oberrheingraben, Deutschland): Courier Forschungsinstitut Senckenberg, v. 237 , p. $229-253$

Gürs, K., and Janssen, A.W., 2004, Sea-level related molluscan plankton events (Gastropoda, Euthecosomata) during the Rupelian (early Oligocene) of the North Sea Basin: Netherlands Journal of Geosciences/Geologie en Mijnbouw, v. 83, p. 199-208.

Hartlaub, C., 1886, Ueber Manatherium delheidi, eine Sirene aus dem Oligocän Belgiens: Zoologische Jahrbücher, v. 1, p. 369-378.

Heizmann, E.P.J., 1992, Das Tertiär in Südwestdeutschland: Stuttgarter Beiträge zur Naturkunde, Serie C, v. 33, p. 1-61.

Heuvelmans, B., 1941, Notes sur la dentition des Siréniens. III. La dentition du Dugong: Bulletin du Musée Royal d'Histoire Naturelle de Belgique, v. 17, p. $1-14$.

ICZN 1999, International Code of Zoological Nomenclature, 4th ed., London, The International Trust for Zoological Nomenclature, $306 \mathrm{p}$.

Illiger, C., 1811, Prodomus systematis mammalium et avium: additis terminis zoographicis utriusque classis eorumque versione Germanica: Berolini, Sumptibus C. Salfeld, $301 \mathrm{p}$.

Kaiser, H.E., 1974, Morphology of the Sirenia: a macroscopic and X-Ray atlas of the osteology of recent species: Basel, S. Karger AG, 75 p.

Kaup, J.J., 1838, Halytherium und Pugmeodon im Maynzer Becken: Neues Jahrbuch für Mineralogie, Geognosie, Geologie und Petrefaktenkunde, v. 1838 , p. $318-320$.

Kaup, J.J., 1855, Beitraege zur naeheren Kenntnis der urweltlichen Saeugethiere. Zweites Heft: Darmstadt, C.W. Leske, 23 p.

Krauss, C.F.F., 1858, Beiträge zur Kenntnis des Schädel-Baues von Halitherium: Neues Jahrbuch für Mineralogie, Geognosie, Geologie und Petrefaktenkunde, v. 1858, p. 519-531.

Krauss, C.F.F., 1862, Der Schädel des Halitherium schinzi Kaup: Neues Jahrbuch für Mineralogie, Geognosie, Geologie und Petrefaktenkunde, v. 1862 , p. $385-415$.

Lanyon, J.M., and Sanson, G.D., 2006, Degenerate dentition of the dugong (Dugong dugon) or why a grazer does not need teeth: morphology, occlusion and wear of mouthparts: Journal of Zoology, v. 268, p. 133-152.

Lepsius, G.R., 1882, Halitherium Schinzi, die fossile Sirene des Mainzer Beckens. I. Band: Darmstadt, Abhandlungen des Mittelrheinischen geologischen Vereins, $200 \mathrm{p}$.

Linnaeus, C., von, 1758, Systema naturae per regna tria naturae, secundum classes, ordines, genera, species, cum characteribus, differentiis, synonymis, locis: Holmiae, impensis direct: Laurentii Salvii, Editio 10 (reformata), v. 1, p. 6-823.

Luckett, W.P., 1993, An ontogenetic assessment of dental homologies in therian mammals, in Szalay, F.S., Novacek, M.J., and McKenna, M.C., eds., Mammal Phylogeny: Mesozoic Differentiation, Multituberculates, Monotremes, Early Therians, and Marsupials: New York, Springer, p. 182-204.

Marsh, H., 1980, Age determination of the dugong (Dugong dugon (Müller)) in northern Australia and its biological implications: Reports of the International Whaling Commission, Special Issue 3, p. 181-201. 
Marsh, H., Channells, P.W., Heinsohn, G.E., and Morrissey, J., 1982, Analysis of stomach contents of dugongs from Queensland: Australian Wildlife Research, v. 9, p. 55-67.

Martini, E., 1982, Bestandsaufnahme des Nannoplankton im "prä-aquitanen" Tertiär des Mainzer Beckens: Mainzer geowissenschaftliche Mitteilungen, v. 10 , p. $29-36$.

Martini, E., and Müller, C., 1971, Das marine Alttertiär in Deutschland und seine Einordnung in die Standard Nannoplankton Zonen: Erdöl und Kohle, v. 24, p. $381-384$.

Matthew, W.D., 1916, New sirenian from the Tertiary of Porto Rico, West Indies: Annales of New York Academy of Science, v. 27, p. 23-29.

McKenna, M.C., 1975, Toward a phylogenetic classification of the Mammalia, in Luckett, W.P., and Szalay, F.S., eds., Phylogeny of the Primates: A Multidisciplinary Approach: New York and London, Plenum, p. 21-46.

Meulenkamp, J.E., and Sissingh, W., 2003, Tertiary palaeogeography and tectonostratigraphic evolution of the northern and southern Peri-Tethys platforms and the intermediate domains of the African-Eurasian convergent plate boundary zone: Palaeogeography, Palaeoclimatology, Palaeoecology, v. 196 , p. $209-228$.

Mitchell, J., 1973, Determination of relative age in the dugong (Dugong dugon, Müller) from a study of skulls and teeth: Zoological Journal of the Linnean Society, v. 53, p. 1-23.

Neumann, D., 1936, Das Handskelett von Halitherium schinzi Kaup: Paläontologische Zeitschrift, v. 18, p. 257-291.

Petit, G., 1928, Sur la synostose de l'axis et de la troisième vertèbre cervicale chez les lamantins: Bulletin du Musèum national d'histoire naturelle, v. 34, p. $429-431$.

Phillips, R.C., and Meñez, E.G., 1988, Seagrasses: Smithonian Contributions to the Marine Sciences, no. 34, p. 1-104.

Pilleri, G., 1987, The Sirenia of the Swiss Molasse. With a descriptive catalogue of the fossil Sirenia preserved in Swiss collections: Ostermundigen (Bern), Brain Anatomy Institute, $114 \mathrm{p}$.

Pirkenseer, C., Spezzaferri, S., and Berger, J-P., 2010, Palaeoecology and biostratigraphy of the Paleogene Foraminifera from the southern Upper Rhine Graben and the influence of reworked planktonic Foraminifera: Palaeontographica, Abteilung A, v. 293, p. 1-93.

Pocock, R.I., 1940, Some notes on the dugong: The Annals and Magazine of Natural History, v. 11, Series 5, p. 329-345.

Robineau, D., 1969, Morphologie externe du complexe osseux temporal chez les siréniens: Mémoires du Muséum National d'Histoire Naturelle, Série A, Zoologie, v. 60, p. 1-32.

Rögl, F., 1999, Mediterranean and Paratethys. Facts and hypotheses of an Oligocene to Miocene paleogeography (short overview): Geologica Carpathica, v. 50, p. 339-349.

Rothausen, K., and Sonne, V., 1984, Sammlung geologischer Führer Band 79: Mainzer Becken: Berlin, Stuttgart, Gebrüder Bornträger, $167 \mathrm{p}$.

Rousse, S., Duringer, P., and Stapf, K.R.G., 2012, An exceptional rocky shore preserved during Oligocene (late Rupelian) transgression in the Upper Rhine Graben (Mainz Basin, Germany): Geological Journal, v. 47, p. 388-408.

Sagne, C., 2001, Halitherium taulannense, nouveau sirénian (Sirenia, Mammalia) de l'Éocene supérieur provenant du domaine Nord-Téthysien (Alpes-de-HauteProvence, France): Comptes rendus de l'Académie des Sciences de la Terre et des Planètes, v. 333, p. 471-476.

Schaarschmidt, F., 1982, Bestandsaufnahme der Makroflora im "prä-aquitanen" Tertiär des Mainzer Beckens: Mainzer geowissenschaftliche Mitteilungen, v. 10 , p. $19-28$.

Schmidtgen, O., 1912, Neue Beiträge zur Kenntnis der hinteren Extremität von Halitherium schinzi Kaup: Zoologisches Jahrbuch, v. 15, suppl., p. 457-498.

Sickenberg, O., 1934, Beiträge zur Kenntnis Tertiärer Sirenen. I. Die Eozänen Sirenen des Mittelmeergebietes. II. Die Sirenen des Belgischen Tertiärs: Mémoires du Musée Royal d'Histoire Naturelle de Belgique, v. 63, p. 1-352.

Siegfried, P., 1965, Anomotherium langewieschei n.g.n.sp. (Sirenia) aus dem Ober-Oligozän des Dobergs bei Bünde/Westfalen: Palaeontographica, Abteilung A, v. 124, p. 116-150.

Simpson, G.G., 1932, Fossil Sirenia of Florida and the evolution of the Sirenia: Bulletin of the American Museum of Natural History, v. 59, p. 419-503.

Sissingh, W., 1998, Comparative Tertiary stratigraphy of the Rhine Graben, Bresse Graben and Molasse Basin: correlation of Alpine foreland events: Tectonophysics, v. 300, p. 249-284.
Spain, A.V., and Heinsohn, G.E., 1974, A biometric analysis of measurement data from a collection of North Queensland dugong skulls, Dugong dugon (Müller): Australian Journal of Zoology, v. 22, p. 249-257.

Spain, A.V., Heinsohn, G.E., Marsh, H., and Correll, R.L., 1976, Sexual dimorphism and other sources of variation in a sample of dugong skulls from North Queensland: Australian Journal of Zoology, v. 24, p. 491-497.

Spiegel, C., Kuhlemann, J., and Frisch, W., 2007, Tracing sediment pathways by zircon fission track analysis. Oligocene marine connections in Central Europe: International Journal of Earth Sciences (Geologische Rundschau), v. 96, p. 363-374.

Springer, M.S., Signore, A.V., Paijmans, J.L.A., et al, 2015, Interordinal gene capture, the phylogenetic position of Steller's sea cow based on molecular and morphological data, and the macroevolutionary history of Sirenia: Molecular Phylogenetics and Evolution, v. 91, p. 178-193.

Stanhope, M.J., Waddell, V.G., Madsen, O., de Jong, W.W., Hedges, S.B., Cleven, G.C., Kao, D., and Springer, M.S., 1998, Molecular evidence for multiple origins of the Insectivora and for a new order of endemic African mammals: Proceedings of the National Academy of Sciences, v. 95, p. 9967-9972.

Vandenberghe, N., van Simaeys, S., Steurbaut, E., Jagt, J.W.M., and Felder, P.J., 2004, Stratigraphic architecture of the Upper Cretaceous and Cenozoic along the southern border of the North Sea Basin in Belgium: Netherlands Journal of Geosciences/Geologie en Mijnbouw, v. 83, p. $155-171$.

Van Nievelt, A.F.H., and Smith, K.K., 2005, To replace or not to replace: the significance of reduced functional tooth replacement in marsupial and placental mammals: Paleobiology, v. 31, p. 324-346.

Van Simaeys, S., de Man, E., Vandenberghe, N., Brinkhuis, H., and Steurbaut, E. 2004, Stratigraphic and palaeoenvironmental analysis of the Rupelian-Chattian transition in the type region: evidence from dinoflagellate cysts, foraminifera and calcareous nannofossils: Palaeogeography, Palaeoclimatology, Palaeoecology, v. 208 , p. $31-58$

Velez-Juarbe, J., and Domning, D.P., 2014, Fossil Sirenia of the West Atlantic and Caribbean region. IX. Metaxytherium albifontanum, sp. nov.: Journal of Vertebrate Paleontology, v. 34, p. 444-464.

Velez-Juarbe, J., and Domning, D.P., 2015, Fossil Sirenia of the West Atlantic and Caribbean region. XI. Callistosiren boriquensis, gen. et sp. nov.: Journal of Vertebrate Paleontology, v. 35, 1, e885034.

Velez-Juarbe, J., Domning, D.P., and Pyenson, N.D., 2012, Iterative evolution of sympatric seacow (Dugongidae, Sirenia) assemblages during the past 26 Million years: PLoS ONE, v. 7, p. 1-8.

Voss, M., 2008, New finds of Halitherium (Sirenia, Mammalia) from the lower Oligocene of the Rhine area (Germany): Neues Jahrbuch für Geologie und Paläontologie, Abhandlungen, v. 249, p. 257-269.

Voss, M., 2010, Character evolution, homoplasy and interrelationships of Sirenia: Zitteliana B, v. 29, p. 103.

Voss, M., 2012, A new sea cow record from the lower Oligocene of western Germany: new indications on the skeletal morphology of Halitherium schinzii (Mammalia: Sirenia): Paläontologische Zeitschrift, v. 86, p. $205-217$.

Voss, M., 2013, Revision of the Halitherium-species complex (Mammalia, Sirenia) from the late Eocene to early Miocene of Central Europe and North America [Ph.D. dissertation]: Berlin, Humboldt-Universität zu Berlin, Germany, 298 p.

Voss, M., 2014, On the invalidity of Halitherium schinzii Kaup, 1838 (Mammalia, Sirenia), with comments on systematic consequences: Zoosystematics and Evolution, v. 90, p. 87-93.

Voss, M., Berning, B., and Reiter, E., 2016, A taxonomic and morphological re-evaluation of "Halitherium" cristolii Fitzinger, 1842 (Mammalia, Sirenia) from the late Oligocene of Austria, with the description of a new genus: European Journal of Taxonomy, v. 256, p. 1-32.

Voss, M., Sorbi, S., and Domning, D.P., in press, Morphological and systematic re-assessment of the late Oligocene "Halitherium" bellunense De Zigno, 1875 reveals a new crown group genus of Sirenia (Mammalia, Tethytheria): Acta Palaeontologica Polonica.

Accepted 11 September 2016 